OPEN ACCESS

Edited by: Alex R. Gunderson,

Tulane University, United States

Reviewed by:

Manfred Roland Enstipp, UMR7178 Institut Pluridisciplinaire

Hubert Curien, France Emily Lam,

University of California, Berkeley,

United States

*Correspondence:

Arina B. Favilla

afavilla@ucsc.edu

Specialty section:

This article was submitted to Behavioral and Evolutionary Ecology, a section of the journal

Frontiers in Ecology and Evolution

Received: 25 April 2020

Accepted: 17 August 2020

Published: 11 September 2020

Citation:

Favilla $A B$ and Costa DP (2020) Thermoregulatory Strategies of Diving Air-Breathing Marine Vertebrates:

A Review.

Front. Ecol. Evol. 8:555509. doi: 10.3389/fevo.2020.555509

\section{Thermoregulatory Strategies of Diving Air-Breathing Marine Vertebrates: A Review}

\author{
Arina B. Favilla* and Daniel P. Costa \\ Department of Ecology and Evolutionary Biology, University of California, Santa Cruz, Santa Cruz, CA, United States
}

The aquatic habitat of marine "air-breathing" vertebrates provides a significant thermoregulatory challenge due to the high thermal conductivity of water. In addition to temperature changes across their range, air-breathing vertebrates experience temperature changes on the timescale of seconds to minutes as they perform dives to access two critical resources: air at the surface and food at depth. In response to these challenges, air-breathing vertebrates have developed morphological and physiological adaptations that align with their life histories and phylogenies and contribute to homeostasis. However, the physiological and behavioral mechanisms used to maintain thermal balance while diving is still poorly understood. The cardiovascular system is integral to the physiological responses associated with the dive response, exercise, digestion, and thermoregulation. The adjustments required to meet one physiological demand may not be compatible with another and can result in a potential conflict between the various physiological demands imposed on air-breathing divers. We reviewed the literature on thermoregulation while diving in an effort to synthesize our current understanding of the thermoregulatory strategies of diving air-breathing marine vertebrates. Studies have demonstrated that thermoregulatory strategies can involve the temporal separation of two conflicting responses, a compromise in the performance of one response over another, or coordination of synergistic responses. We hope that a review and synthesis of both laboratory and field studies will stimulate future research efforts at the intersection of thermoregulation and diving physiology. Expanding the use of physiological biologgers, particularly to understudied species, will enhance our understanding of how these animals coordinate various physiological demands to maintain homeostasis in a thermally challenging environment.

Keywords: thermoregulation, dive response, marine mammals, seabirds, sea turtles, field physiology, biologgers

\section{INTRODUCTION}

Marine vertebrates can be categorized as either "air-breathers" or "water-breathers". While they all share the same aquatic environment and its associated challenges, air-breathers are faced with an additional challenge: the spatial separation of two critical resources, air and food (Whittow, 1987; Boyd, 1997; Rosen et al., 2007). Moreover, the implications for aquatic vertebrate thermal physiology are significant as heat transfers about 25 times faster in water than in air. Thus, the avenues of heat exchange that animals can use to control their thermal balance are more limited in water. 


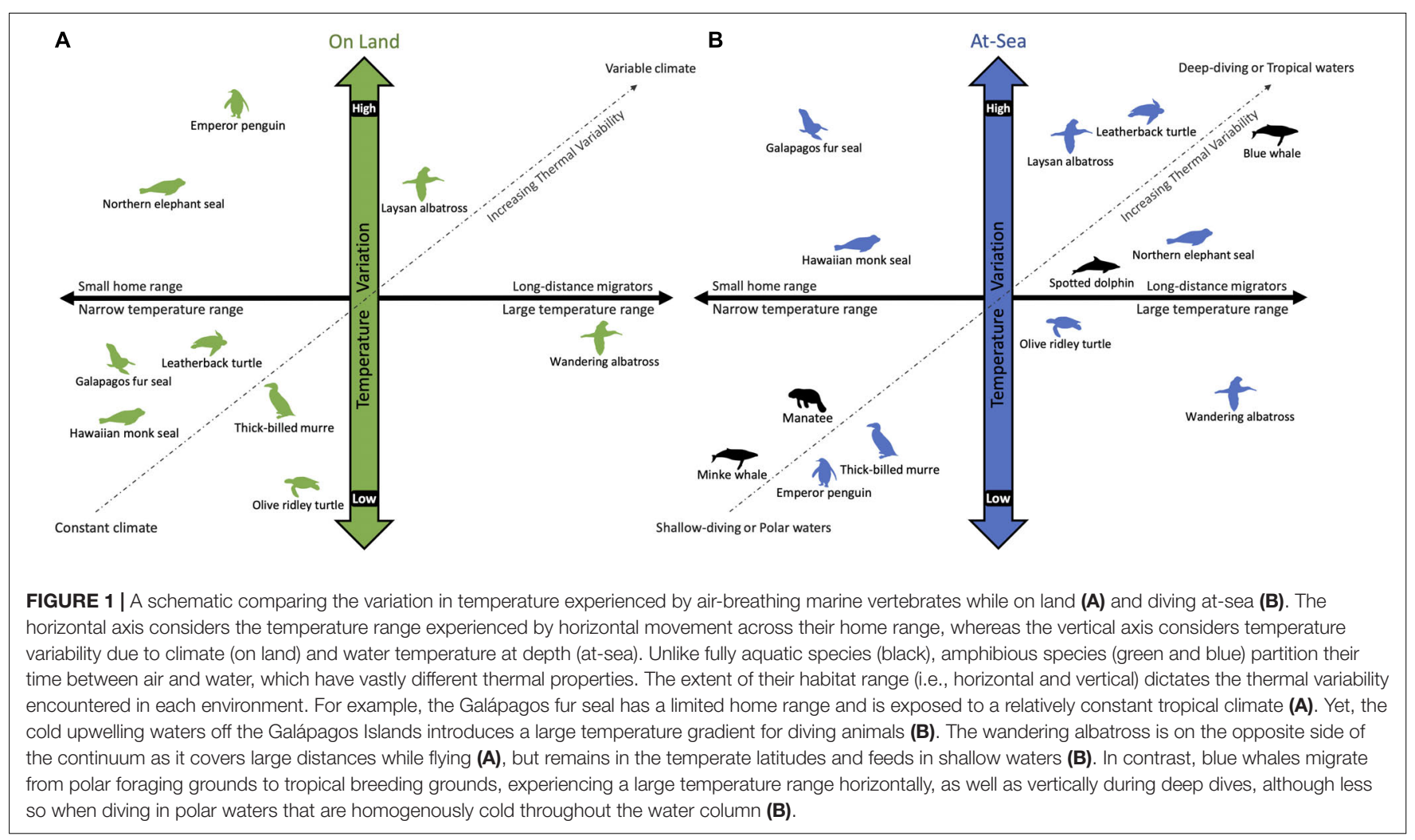

Multiple independent transitions from a terrestrial to marine life were made possible by developing a concomitant, often converging, suite of morphological, physiological, and behavioral adaptations that allow marine vertebrates to meet their thermoregulatory needs (Reidenberg, 2007; Pyenson et al., 2014; Kelley and Pyenson, 2015). In addition to spanning the endothermy-ectothermy spectrum, marine air-breathing vertebrates have different lifestyles that expose them to a wide range of thermal environments. While some have made the full transition to an aquatic lifestyle, others are tied to the land for reproduction and molting (Costa, 1991; Davenport, 1997; Schreiber and Burger, 2002), which exposes them to the contrasting thermal demands imposed by air and water. Some species, like the Galápagos fur seal, Arctocephalus galapagoensis, experience an extreme dichotomy in their thermal environments that requires different thermoregulatory strategies: dissipating excess heat while breeding on land in warm climates and conserving heat while foraging in cold waters (Costa and Maresh, 2017; Chilvers, 2018). Additionally, some migrate long distances from tropical breeding to polar foraging grounds where sea surface temperatures can vary from $30^{\circ} \mathrm{C}$ to $-2^{\circ} \mathrm{C}$ (Corkeron and Connor, 1999; Guerrero and Rogers, 2019). While this large shift in their thermal environment occurs over weeks to months, marine vertebrates also experience significant temperature changes on the timescale of seconds to minutes while diving. The exceptions are shallow divers that remain in the mixed layer or polar species that are exposed to cold temperatures throughout the water column. Thus, recognizing the temporal and spatial range of thermal challenges faced by marine air-breathers is essential when considering the suitability of their thermal adaptations for maintaining homeostasis (Figure 1).

This review synthesizes our current understanding of the thermoregulatory strategies of marine air-breathing vertebrates in light of the physiological challenges imposed by diving. We have selected lab and field studies that provide critical insights into the diving and thermal capabilities of marine air-breathers and how they operate in a physiologically challenging environment. To encourage field research to confirm the ecological relevance of lab-based findings in natural settings (Costa and Sinervo, 2004; Rosen et al., 2017), we summarize the approaches currently available to study the thermal physiology of free-ranging divers and evaluate their applicability to different taxa. Finally, we highlight gaps in our knowledge to direct future efforts at the intersection of diving physiology and thermoregulation, which will hopefully lead to a deeper understanding of how air-breathing marine vertebrates maintain homeostasis.

\section{DIVERSE DIVERS FACE A COMMON CHALLENGE}

Marine "air-breathing" vertebrates-referred to as air-breathers or divers in this review-span three classes of tetrapods (i.e., Mammalia, Aves, and Reptilia), all of which reinvaded the marine environment at different times and thus have adapted to marine living within the constraints of their different phylogenies (Pyenson et al., 2014; Kelley and Pyenson, 2015). Given the 


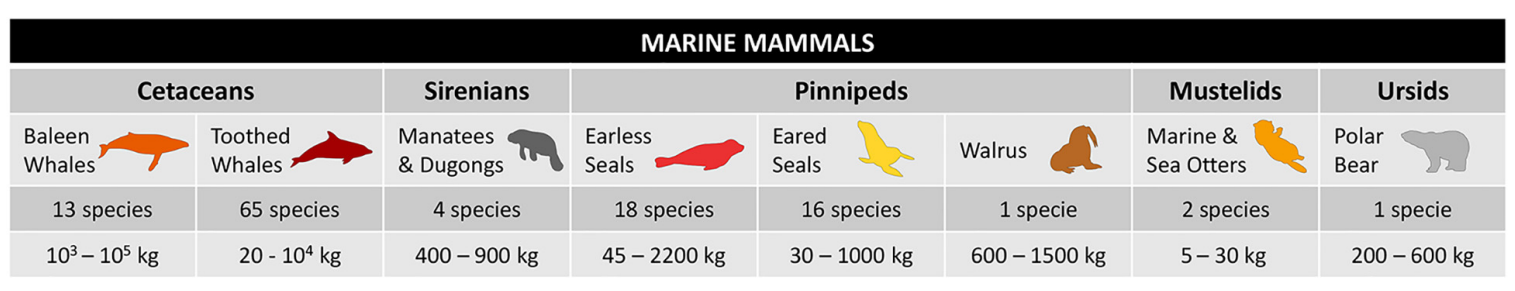

\begin{tabular}{|c|c|c|c|}
\hline \multicolumn{4}{|c|}{ DIVING SEABIRDS } \\
\hline Sphenisciformes & Procellariiformes & Pelecaniformes & Charadriformes \\
\hline Penguins & $\begin{array}{l}\text { e.g. Petrels, } \\
\text { Albatross }\end{array}$ & $\begin{array}{l}\text { e.g. Boobies, } \\
\text { Cormorants }\end{array}$ & e.g. Alcids \\
\hline 18 species & 52 species & 42 species & 24 species \\
\hline $1-45 \mathrm{~kg}$ & $0.2-12 \mathrm{~kg}$ & $1-5 \mathrm{~kg}$ & $0.08-1.5 \mathrm{~kg}$ \\
\hline
\end{tabular}

\begin{tabular}{|c|c|c|c|}
\hline \multicolumn{4}{|c|}{ MARINE REPTILES } \\
\hline \multicolumn{1}{|c|}{ Cheloniidae } & \multicolumn{1}{|c|}{ Dermochelyidae } & \multicolumn{1}{|c|}{ Iguanidae } & \multicolumn{1}{|c|}{ Elapidae* } \\
\hline $\begin{array}{l}\text { Hard-shelled } \\
\text { Turtles }\end{array}$ & $\begin{array}{l}\text { Leatherback } \\
\text { Turtle }\end{array}$ & $\begin{array}{l}\text { Marine } \\
\text { Iguana }\end{array}$ \\
\hline 6 species & 1 specie & 1 specie & 70 species \\
\hline $30-200 \mathrm{~kg}$ & $300-700 \mathrm{~kg}$ & $0.9-12 \mathrm{~kg}$ & $0.07-0.56 \mathrm{~kg}$ \\
\hline
\end{tabular}

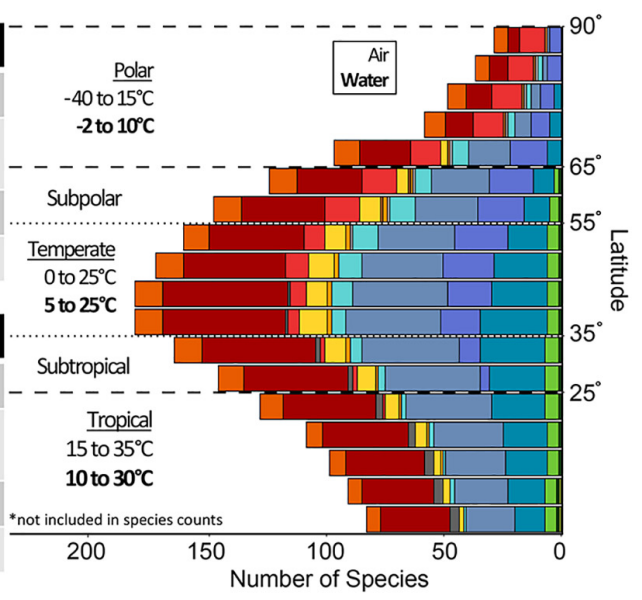

FIGURE 2 | Marine air-breathing vertebrates are comprised of the following groups: marine mammals, seabirds, and marine reptiles. The table includes the common name used in the remainder of the review for each taxonomic group (representative bolded species are used for seabird orders that do not have an all-encompassing common name). The number of species and mass range for each taxonomic group are provided and include species considered to be true air-breathing divers (full list of species and mass references in Supplementary Table S1), all of which are included in the bar graph, with the exception of Elapidae. Refer to the text in section "Diverse Divers Face a Common Challenge" for further explanation about which groups are discussed in the review. The bar graph in the lower right shows the distribution of species grouped by taxa across absolute latitude using $5^{\circ}$ bins (species counts provided in Supplementary Table S2). The habitat range classifications (Tropical, Subtropical, Temperate, Polar, and Subpolar) are defined based on the following absolute latitudes (0-25, $25-35^{\circ}, 35-55^{\circ}$, $55-65^{\circ}$, and $65-90^{\circ}$ ) and denoted by dashed lines. Air and water temperature ranges are provided for polar (including subpolar), temperate, and tropical (including subtropical) habitat ranges. The greatest number of diving air-breathers are found at mid-latitudes (i.e., temperate, subtropical, and subpolar), where temperatures are more moderate compared to equatorial and high latitudes. Monthly mean air and sea surface temperature data were obtained from ICOADS data products provided by the NOAA/OAR/ESRL Physical Sciences Laboratory (https://psl.noaa.gov/data/gridded/data.coads.1deg.html). Temperatures in the winter and summer months (e.g., summer months: January, February, March in the Northern Hemisphere and July, August, September in the Southern Hemisphere) were used to estimate minimum and maximum average temperatures in each region. Distribution maps for 264 species were used: 13 Mysticeti, 65 Odontoceti, 4 Sirenia, 18 Phocidae, 16 Otariidae, 1 Odobenidae, 2 Mustelidae, 1 Ursidae, 18 Sphenisciformes, 52 Procellariiformes, 42 Pelecaniformes, 24 Charadriiformes, 6 Cheloniidae, 1 Dermochelyidae, and 1 Iguanidae. Distribution maps obtained from https://www.iucnredlist.org.

perspective of this review, we chose a particular subset of marine air-breathers that are diving species and cover a broad range of thermal strategies and habitats (Figure 2). This group provides the opportunity to examine whether there is convergence in how the different ecologies and life histories shape physiology and behavior.

Within marine mammals, the most diverse and well-suited to marine life are the fully aquatic cetaceans. While both cetaceans and sirenians are fully aquatic, only cetaceans span tropical to polar waters, as sirenians are limited to tropical latitudes (Figure 2). Sirenians are the only herbivorous marine mammals, which has important implications for their thermoregulatory abilities. Their diet constrains them to low metabolism, which limits their capacity for thermogenesis and therefore increases their cold sensitivity (Gallivan and Best, 1980; Gallivan et al., 1983; Domning, 2018). Pinnipeds display a broad spectrum of morphologies for thermal adaptations that align with their amphibious lifestyle and different breeding strategies that dictate the frequency and duration of their foraging trips and the overall proportion of time they spend at sea (Berta, 2018; Chilvers, 2018; Hammill, 2018). Species of the other two extant taxonomic groups of marine mammals-mustelids and ursids-face some unique extreme challenges: sea otters, Enhydra lutris, are the smallest marine mammal and are found in cold temperate to subarctic waters (Kenyon, 1969) whereas polar bears, Ursus maritimus, spend most of their time on Arctic sea ice, a rapidly diminishing habitat (Rode and Stirling, 2018).

Seabirds are endothermic marine vertebrates that are all amphibious, a constraint likely associated with oviparity. Seabirds are defined as those species that feed in the marine environment and thus spend most of their lives above, on, or diving into the sea (Schreiber and Burger, 2002). However, in this review we only consider those species that dive, of which there are four avian orders: Sphenisciformes, Procellariiformes, Charadriiformes, and Pelecaniformes (Ponganis, 2015). Seabirds have diverse adaptations to the marine environment that suite their respective ecologies. They generally either use their wings or feet for propulsion and employ plunge or pursuit diving to 
feed (Ellis and Gabrielsen, 2002). Their relative efficiencies as flyers and divers are dictated by their anatomy and morphology, including body density, wing loading, as well as plumage wettability (Lovvorn and Jones, 1994). This trade-off in efficiency between the two modes of locomotion has thermal and ecological implications for their horizontal (i.e., distance from breeding colony) and vertical (i.e., diving depth) ranges (Figure 1). For example, the most efficient flyers, the albatrosses, soar long distances to reach productive waters to feed at the surface. In contrast, penguins have lost the ability to fly, but with paddle-like wings, some can dive down to $500 \mathrm{~m}$ but have much more limited horizontal movements (Prince et al., 1994; Ellis and Gabrielsen, 2002).

In contrast to marine mammals and seabirds, marine lizards, sea snakes and sea turtles are ectotherms and mainly rely on behavior and habitat selection to regulate their body temperature. There is only one species of totally marine iguana, Amblyrhunchus cristatus, and it is in the family Iguanidae (Dawson et al., 1977). There are 70 species of sea snakes that are entirely marine as they are mostly ovoviviparous and are able to give birth at sea (Murphy, 2012). Due to their ectothermy and small size, sea snakes are limited to narrow thermal habitats. Furthermore, they employ cutaneous respiration while diving, which curtails the physiological restriction faced by strictly air-breathing divers and thus will not be considered further (Heatwole et al., 2012; Udyawer et al., 2016). As such, sea turtles will serve as the representative group of marine reptiles for this review.

All sea turtles are in the family Cheloniidae, except the leatherback turtle, Dermochelys coriacea, the only extant species of the family Dermochelyidae, which has many unique characteristics that set it apart from the hard-shelled turtles. Sea turtles are amphibious as they must nest on land, but only female sea turtles come ashore after mating at sea to bury a clutch of eggs, which are left unattended to hatch into precocial young (Davenport, 1997). Egg-laying commonly occurs at night and allows sea turtles to minimize time spent on land where they are more vulnerable to heat stress (Spotila and Standora, 1985; Meek and Avery, 1988). As reptiles, they have temperaturedependent sex determination, which could result in skewed sex ratios as temperatures on beaches are affected by rising global temperatures (Hamann et al., 2013).

\section{Adaptations for Diving With a Finite Oxygen Supply}

All air-breathing divers face the dilemma of needing to forage underwater, where they do not have access to an exogenous source of oxygen. Thus, the key to being an efficient diver is optimizing the utilization of their 'on-board' oxygen supply. This is accomplished by a suite of cardiovascular adjustments that characterize the dive response, which includes apnea, bradycardia, and peripheral vasoconstriction (for reviews on diving physiology, see Hochachka, 2000; Costa, 2007; Ponganis, 2015; Kooyman and Ponganis, 2018). The intensity of these cardiovascular adjustments depends on the circumstances of the dive, supporting the concept of a plastic rather than an all-ornone response (Butler and Jones, 1997; Elmegaard et al., 2016).
Ultimately, differences in physiology and ecology dictate speciesspecific routine diving behavior and performance (Figure 3). Here, a brief overview of diving adaptations and energetics is presented with emphasis on key differences between marine mammals, seabirds, and sea turtles.

\section{Not All Oxygen Stores Are Equal}

Oxygen is stored in the lungs, blood, and muscle, as well as a small fraction in the brain (via neuroglobin; Williams et al., 2008). The diver's oxygen storage capacity is a function of the size of these principal compartments (i.e., lung volume, blood volume, and muscle mass) as well as the concentrations and characteristics of the oxygen-binding proteins in the blood and muscle (i.e., hemoglobin and myoglobin, respectively). The aerobic diving capacity is, therefore, dictated by the size of oxygen stores, which also scales with body mass, and its rate of utilization (Ponganis et al., 2011). The magnitude and distribution of these oxygen stores vary among species (Figure 4). For example, lung oxygen stores account for less than $30 \%$ of the total oxygen stores in marine mammals. In contrast, sea turtles rely heavily on their respiratory oxygen stores (Lutcavage and Lutz, 1991). Seabirds have lung oxygen stores roughly equal to their muscle and blood oxygen stores combined (Butler et al., 1984; Ponganis, 2015). Interesting outliers within their respective groups are: sea otters, with larger lung oxygen stores (45\% of total); leatherback turtles, with larger muscle and blood oxygen stores due to relatively small lung volumes (Lutcavage et al., 1992); and penguins, with a smaller relative respiratory oxygen store due to increased oxygen affinity of hemoglobin, which allows them to carry more oxygen in their blood at lower partial pressures (Ponganis, 2015).

Increased reliance on respiratory oxygen stores has important implications for diving, including buoyancy and pulmonary gas exchange. The air in the respiratory system-or any other part of the body-will increase the diver's buoyancy at the surface and contribute to the high initial cost of descent, which decreases as air is compressed with depth. Some species-usually those less reliant on lung oxygen stores-minimize buoyancy by diving after exhalation (e.g., phocids, Figure 4; and some ducks, which were not included in this review). Some species of penguins, cormorants, and otariids that dive upon inhalation regulate their lung air volumes to match the oxygen requirements of the dive, showing some anticipatory pre-dive adjustments (Sato et al., 2002; Wilson, 2003; Cook et al., 2010; McDonald and Ponganis, 2012). On the other hand, sea turtles adjust their diving depth to achieve neutral buoyancy with the given lung air volume (Minamikawa et al., 2000; Hochscheid et al., 2003; Hays et al., 2004).

Regardless of their pre-dive respiratory pattern, many species undergo lung collapse past a certain depth, which reduces their risk of pressure-related complications, such as decompression sickness and nitrogen narcosis (Kooyman et al., 1972; Falke et al., 1985; Bostrom et al., 2008; Fahlman et al., 2009; Hooker et al., 2012; McDonald and Ponganis, 2012). Sea turtles undergo lung collapse during forced submergence (Berkson, 1967), but under natural conditions, intermittent perfusion of the lungs allows access to their primary oxygen supply (Lutz and Bentley, 1985; Hochscheid et al., 2007b; García-Párraga et al., 2018a). Continuous gas exchange at depth would increase their 


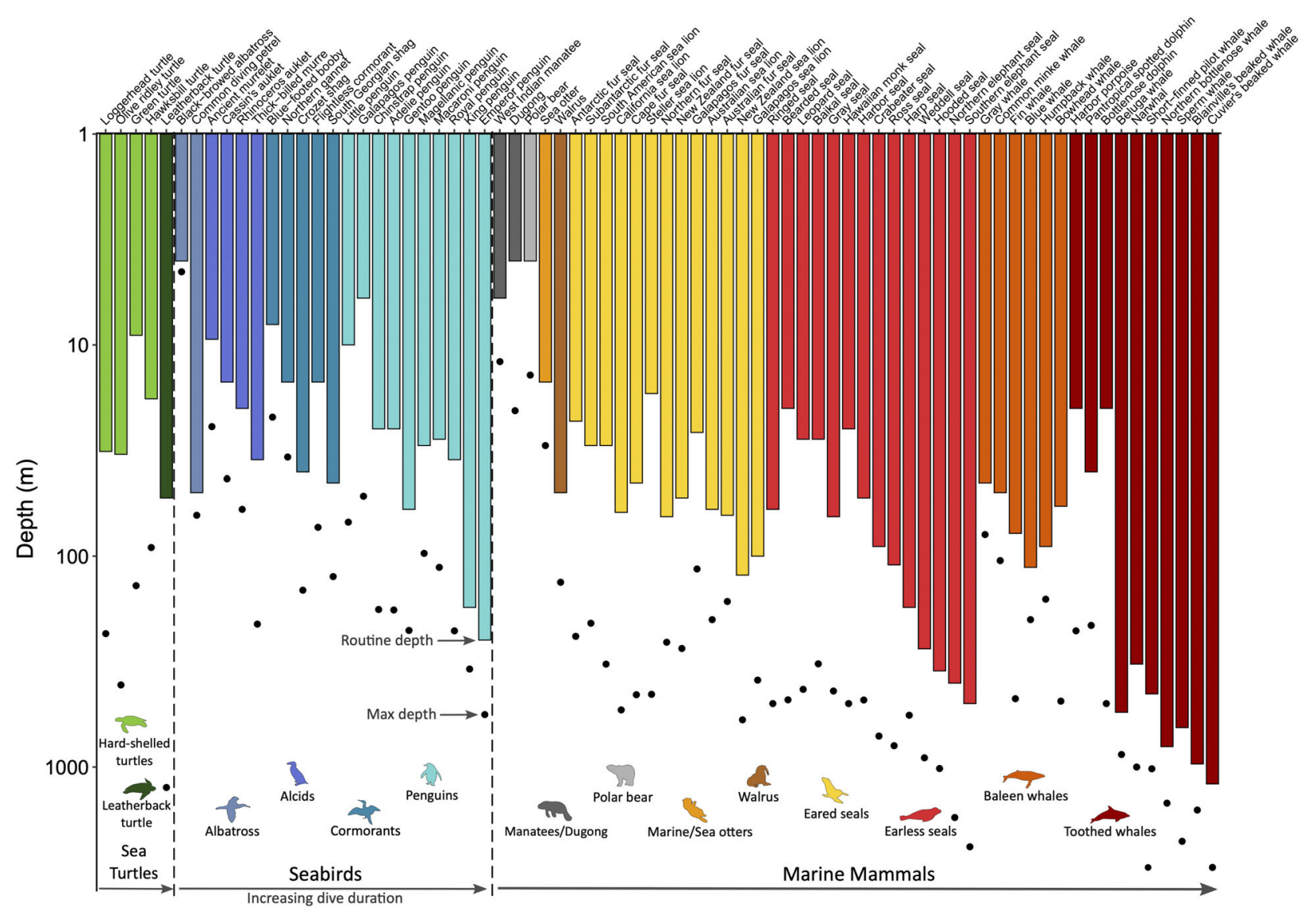

FIGURE 3 | Routine and maximum dive depths across marine air-breathers. Within the three taxonomic groups (sea turtles, seabirds, and marine mammals), species are grouped by order/family as indicated by the common names associated with the colored animal icons and then ordered by increasing routine dive duration. Species for which routine diving behavior data are available from time-depth recorders were included to demonstrate the physiological plasticity within a species (i.e., routine vs. maximum depth) and the range of diving abilities within each order/family and across taxonomic groups. Refer to Supplementary Table S3 for data sources.

susceptibility to decompression sickness by increasing nitrogen absorption in the blood, which would result in bubble formation on the ascent. However, body temperatures lower than those of endotherms by $\sim 10^{\circ} \mathrm{C}$ increase the solubility of nitrogen in the blood and reduces the risk of bubble formation, ultimately counteracting the effects of gas exchange at depth (Fossette et al., 2010). Moreover, their ability to control pulmonary ventilation-perfusion mismatch minimizes nitrogen uptake while preferentially exchanging oxygen and carbon dioxide. Thus, sea turtles should be more tolerant of decompression sickness during normal diving than endothermic divers (Fossette et al., 2010; García-Párraga et al., 2014, 2018a,b). Besides pressurerelated injuries, the primary role of blood to transport rather than store oxygen for sea turtles has direct implications for thermoregulation that will be discussed further below (section "Using Blood Flow to Control Heat Flow").

\section{Quantifying How Limited Oxygen Affects Diving Behavior}

Quantifying the magnitude, distribution, and utilization of oxygen stores is a prerequisite for understanding the physiological basis of diving ability. The aerobic dive limit (ADL) is the dive duration associated with the threshold where metabolism becomes predominately anaerobic. The physiological basis for this metric is the depletion of muscle oxygen stores and a subsequent rise in blood lactate, a byproduct of anaerobic metabolism (Kooyman et al., 1980; Butler, 2006; Ponganis et al., 2011). While ADLs have only been determined empirically in a few species for which post-dive blood samples were feasible (Kooyman et al., 1980; Ponganis et al., 1997a,b; Shaffer et al., 1997; Williams et al., 1999a), estimated ADLs are useful for ecological comparisons of diving abilities (Boyd and Croxall, 1996; Watanuki and Burger, 1999; Costa et al., 2004; Butler, 2006; Halsey et al., 2006). ADLs are generally calculated using lab measurements of oxygen stores and oxygen consumption rate. ADLs have also been determined behaviorally for wild animals equipped with time-depth recorders, where the majority (95-97\%) of dive durations or those that precede routine surface intervals are considered within the ADL (Ponganis, 2015).

A comparison of ADLs to observed dive durations provides a proxy for investigating how often divers operate near their physiological limits in nature (Figure 5; Boyd and Croxall, 1996; 


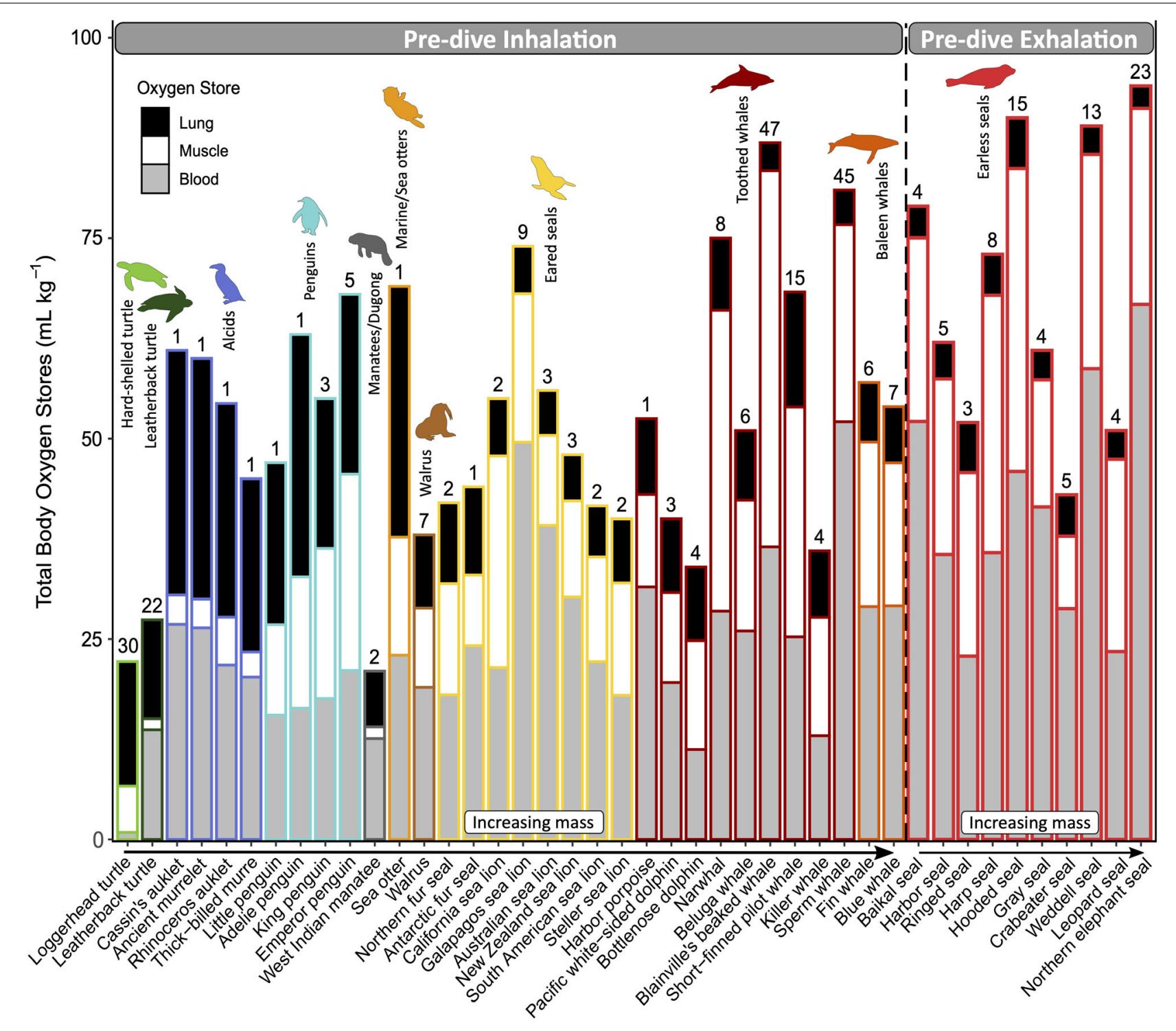

FIGURE 4 | Magnitude and distribution of mass-specific total body oxygen stores and the relative contributions of each oxygen-storing compartment: lung (black), muscle (white), and blood (gray). Divers are grouped by those that inhale or exhale upon descent and ordered within each common name group by increasing body mass. Routine dive duration (minutes) is indicated above the bar for each species. All species of sea turtles, seabirds, and marine mammals for which this data is available to the best of our knowledge were included. Refer to Supplementary Table S3 for data sources.

Costa et al., 2001, 2004; Green et al., 2005). Because metabolic rates dictate the rate of oxygen utilization, ADL inherently integrates the energetic costs of all physiological demands during a dive, including thermoregulatory costs. However, a better understanding of the extent to which thermoregulatory demands might limit their diving behavior requires disentangling the complex interactions between these physiological responses occurring in a diving animal.

\section{Adaptations for a Thermally Challenging Environment}

In addition to diving with a limited oxygen supply, air-breathers must maintain thermal homeostasis in their highly conductive aquatic environment. Even with the constraints of their different life-history strategies and phylogeny, marine vertebrates have converged upon similar thermoregulatory adaptations that include morphological, physiological, and behavioral traits (Reidenberg, 2007) with varying degrees of plasticity.

\section{Thermal Dynamics Across and Within an Immersed Body}

Animals are exposed to the environment through their body surface, and heat transfer across the body surface dictates their thermal state. For a homeothermic endotherm, thermal equilibrium is maintained when internal heat production balances heat loss (Scholander, 1955). Endogenous heat 


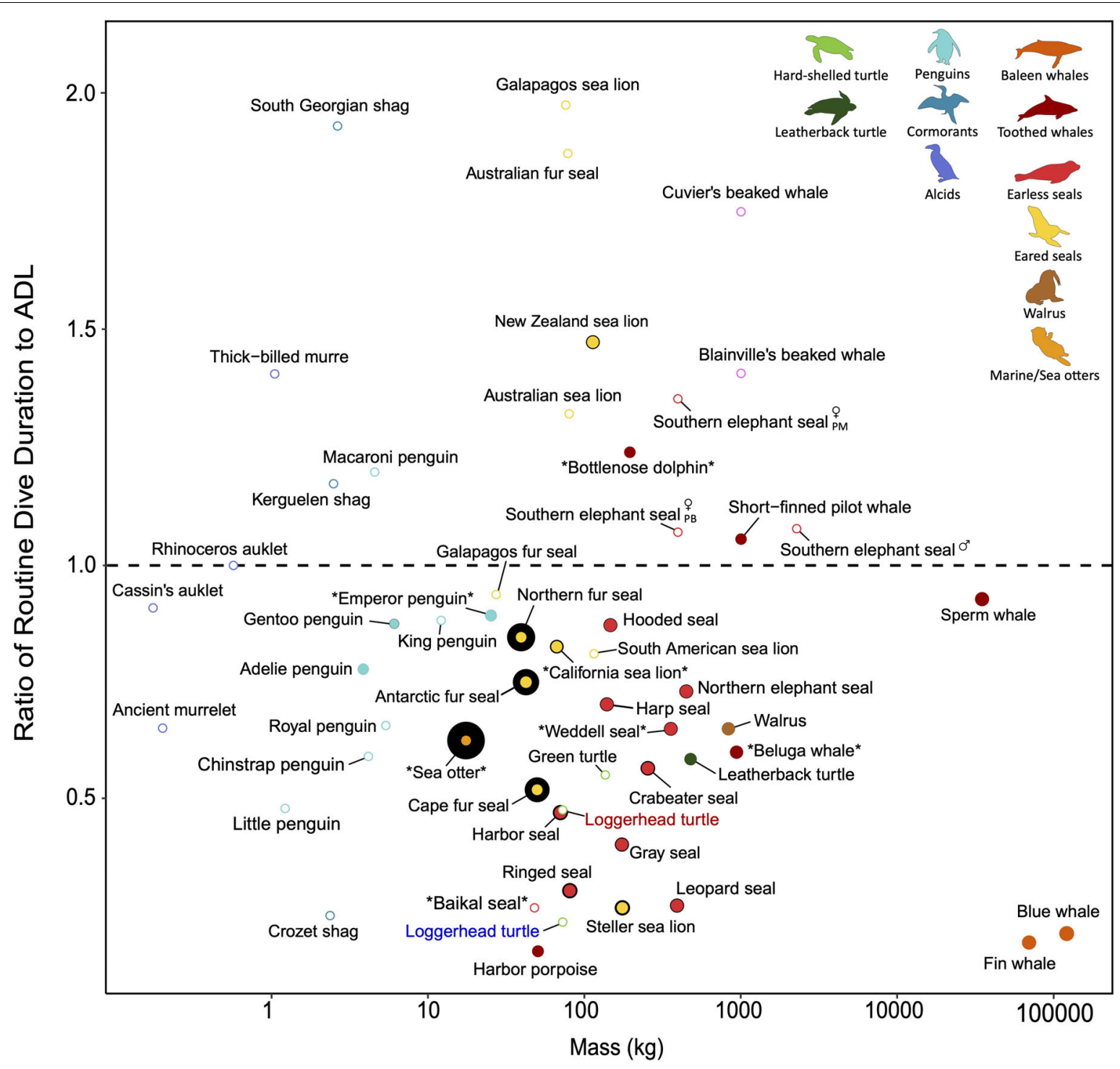

FIGURE 5 | The relative amount of insulation across divers with varying dive performance. Dive performance here is defined as the ratio of routine dive duration to aerobic dive limit (ADL). A ratio greater than 1 indicates diving behavior exceeds what is expected based on $A D L$ and diving performance may be close to physiological limits. Species denoted by asterisks have ADLs determined by lactate measurements; all other species' ADLs are estimated from oxygen stores and oxygen consumption rates (CADL) or behaviorally (bADL). Please refer to Supplementary Table $\mathbf{S} 3$ for the various methods used to estimate ADL when interpreting the figure. The relative size of the colored points indicates blubber thickness and the black border around the colored points represents fur/feather density. Open points are species for which blubber thickness and/or fur/feather density are not available to the best of our knowledge, but are included for interspecific comparison. In addition to variation introduced by how ADL is estimated (see method for each species in Supplementary Table S3), ADLs may vary across seasons and between sexes (especially for sexually dimorphic species, e.g., southern elephant seal; PM, post-molt foraging trip; PB, post-breeding foraging trip). The ADL of ectotherms will differ in cold vs. warm water (e.g., blue vs. red labeled loggerhead turtle) due to the temperature sensitivity of their metabolism. Generally, most species dive within their ADL, including earless seals and baleen whales, and reliance on blubber rather than fur is common among the larger divers. Other species, such as the Australian fur seal and South Georgian shag, routinely exceed their ADL. In addition to ecological factors (e.g., benthic foraging), increased thermoregulatory costs associated with a reduced air layer in the fur/feathers at depth may contribute to the need of performing near physiological limits for these relatively smaller divers. Refer to Supplementary Table S3 for data sources.

production is limited in ectotherms and their ability to store heat and dampen their response to environmental fluctuations will depend on their size (Willmer et al., 2005). Thus, the implications of the body's surface area to volume ratio (SA:V) is relevant for the thermal physiology of both endothermic and ectothermic air-breathing divers.
A common solution to reduce heat loss in the marine environment is to have a small SA:V, which favors large-bodied animals (Innes et al., 1990; Gearty et al., 2018). The largest animals exemplify this trait in each of the taxonomic groups, which all encounter near-freezing water temperatures: blue whales, Balaenoptera musculus, emperor penguins, Aptenodytes 
forsteri, and leatherback turtles. Some consider leatherback turtles to be endothermic (Mrosovsky and Pritchard, 1971; Goff and Stenson, 1988; Davenport et al., 1990) while others suggest they use gigantothermy. However, most agree that the endothermic-like state is due to their large size, insulation, muscular thermogenesis, along with careful regulation of peripheral perfusion (Davenport et al., 1990; Paladino et al., 1990; Bradshaw et al., 2007).

While diving, the primary modes of heat transfer are conduction and convection. Both radiation (which is quickly absorbed by water) and respiratory evaporative heat loss are generally limited to when divers are at the surface. Some marine mammals, such as dolphins, exhibit significant cutaneous water loss, which is associated with osmoregulation rather than heat balance (Hui, 1981; Andersen and Nielsen, 1983). As eared seals are amphibious, they have retained functional sweat glands and sweat to regulate heat loss while on land (Mauck et al., 2003; Rotherham et al., 2005; Khamas et al., 2012).

In addition to heat retention or dissipation mechanisms, activity-oriented strategies - the heat increment of feeding (HIF) and exercise-can contribute to thermoregulatory homeostasis by increasing heat production. A prerequisite for either form of thermal substitution is that the ambient temperature must be below the lower critical temperature of the animal, which is not uncommon in the marine environment (Hampton and Whittow, 1976; Croll and McLaren, 1993; Humphries and Careau, 2011). HIF, also known as specific dynamic action (SDA), is the rise in metabolism associated with processing a meal, including digestion, absorption, and conversion of food to useful macromolecules and excretory products. Since divers are generally active for at least some portion of their dive, the heat generated from their locomotory muscleswhere only $20 \%$ of energy is converted into useful power-can also contribute to thermal substitution. If the $80 \%$ of energy that becomes 'wasted' heat can be efficiently stored in the body, it can mitigate the need for increased metabolic heat production (Kaseloo and Lovvorn, 2006; Bostrom and Jones, 2007; Liwanag et al., 2009). Furthermore, these two forms of facultative thermogenesis could occur during dives, unlike shivering thermogenesis, which is inhibited by the dive response (Kvadsheim et al., 2005).

\section{Fat, Fur, Feathers: Trade-Offs Between Diving With Internal vs. External Insulation}

Increases in insulation reduces conductive heat transfer across the body surface by increasing the thermal resistance of the outer layer. Fur and feathers are located externally and are relatively static, whereas subcutaneous fat, or blubber, is internal and much more dynamic (Davis, 2019). These differences, as well as the quantity and quality of the insulation, have significant thermal consequences for divers.

Blubber is a subcutaneous layer of adipose tissue reinforced by connective tissue fibers (Parry, 1949). Its relatively low conductivity (1/10th that of water) limits heat transfer, which allows skin temperatures to drop close to water temperatures while the core body temperature remains elevated (Castellini, 2007). It also serves as an energy source, although more so for some species or age-classes than others (Worthy and Edwards, 1990; Kwan, 1994; Dunkin et al., 2005). This dual role inherently introduces a trade-off between energetics and thermoregulation (Bryden, 1968; Stewart and Lavigne, 1980; Ryg et al., 1988). The insulating quality of blubber varies with its thickness as well as its lipid content and composition and may provide some heat storage capacity similar to phase change materials (Davenport et al., 1990; Worthy and Edwards, 1990; Dunkin et al., 2005; Liwanag et al., 2012b; Pearson, 2015). Thermal habitat ranges and phylogenetic constraints across species results in differences in blubber quality and quantity (Figure 6). For example, some deep-diving toothed whales in tropical and temperate waters have a relatively thin blubber layer for their size. It is thought that the presence of wax estersan uncommon lipid in mammals-reduces blubber conductivity and excess heat loss in deep cold waters (e.g., pygmy sperm whale, Kogia breviceps, and short-finned pilot whale, Globicephala macrorhynchus; Bagge et al., 2012).

While the blubber conductivity of smaller shallow diving porpoises and dolphins are similar to that of the larger deepdiving cetaceans, their mass-specific blubber thicknesses vary between species. The much smaller harbor porpoise, Phocoena phocoena, occupies a narrower and colder thermal range than the spotted dolphin, Stenella attenuata, and bottlenose dolphin, Tursiops truncatus, and thus has significantly higher massspecific blubber thickness (Figure 6). Interestingly, brown adipose tissue is present in the inner blubber along the entire body of both the harbor porpoise and bottlenose dolphin, Pacific white-sided dolphin, Lagenorhynchus obliquidens, and Dall's porpoise, Phocoenoides dalli. Known for its thermogenic properties, brown adipose tissue may enhance the function of their blubber layer-from modulating heat transfer to also generating heat-and allow these species to maintain thermal balance while inactive (Hashimoto et al., 2015).

Both fur and feathers are better insulators per unit quantity than blubber. Their effectiveness is due to the air layer that is trapped within the insulative layer as air has a very low thermal conductivity $\left(0.025 \mathrm{~W} \mathrm{~m}^{-1}{ }^{\circ} \mathrm{C}^{-1}\right)$. A few marine endotherms have developed specialized features, such as interlocking hairs and feather barbs, to prevent water penetration and enhance air-trapping-a prerequisite for relying on external insulation while submerged (Lustick, 1984; Liwanag et al., 2012a). While fur and feathers do not introduce energetic tradeoffs in the same manner as blubber, they are energetically more costly to maintain as they require grooming/preening and periodic molting (Lustick, 1984; Murphy, 1996). To compensate for its large SA:V, the sea otter has the densest fur (Figure 7) and spends up to $12 \%$ of its time grooming to maintain the fur's integrity (Loughlin, 1977), which is crucial for its survival in temperate habitats. As molting reduces the animal's insulation and requires perfusion of the skin that also increases heat loss, several species have found ways to reduce the physiological burden of molting. Many amphibious species return to land to molt (Worthy et al., 1992; Boily, 1995; Enstipp et al., 2019; Walcott et al., 2020), while others molt gradually and sometimes migrate to warmer waters (Boily, 1995; Pitman et al., 2019). 


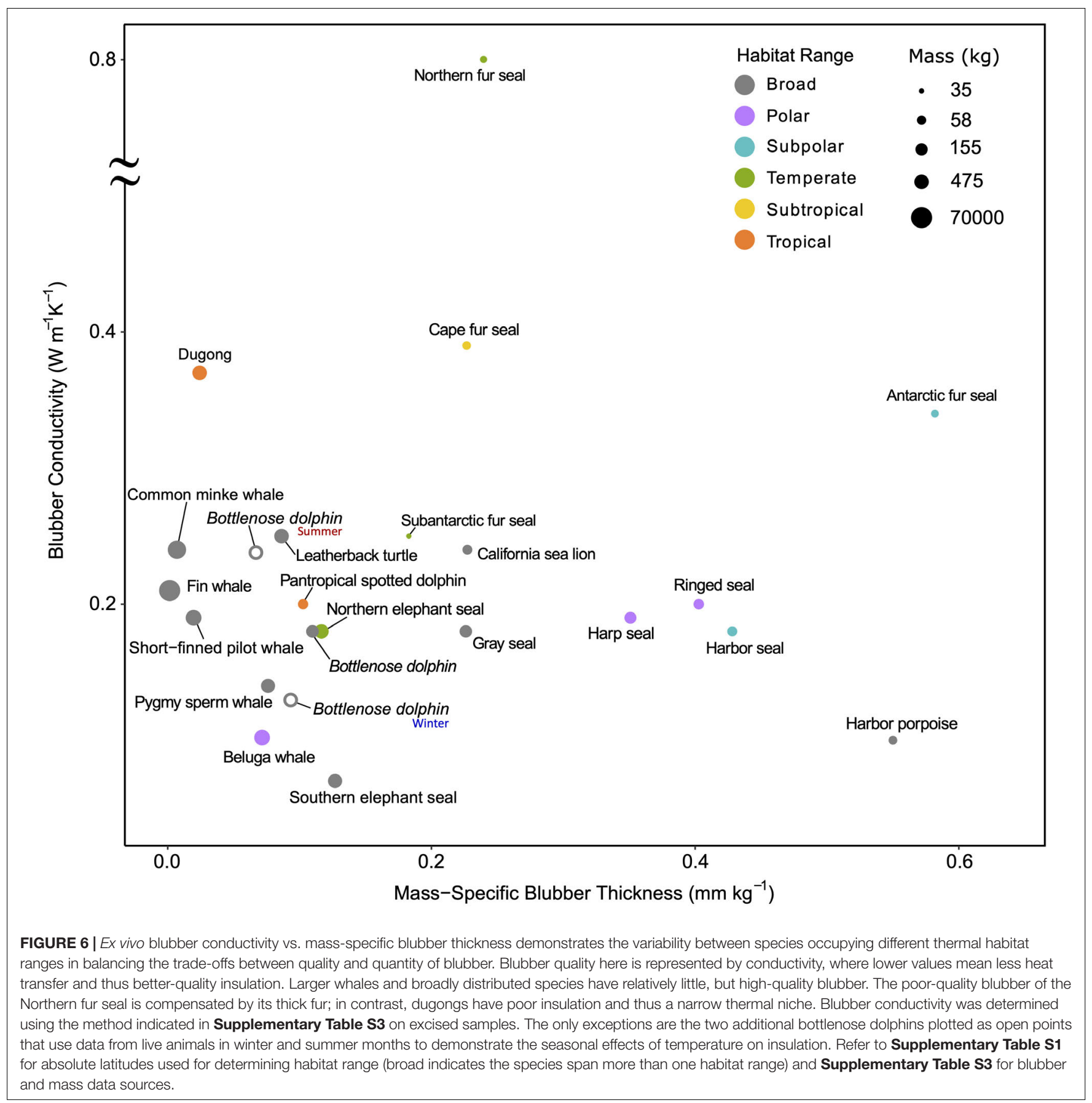

Blubber provides better insulation for deep divers despite its lower insulative capacity compared to fur or feathers (Figure 7), because the insulating layer of air compresses and may escape as the animal descends. The deeper the dive, the lower the insulative capacity of fur/feathers (until completely saturated), and the higher the thermoregulatory costs. Certain species can retain some air within their pelage or plumage at depth, but this entrapped air increases their buoyancy and adds to the energetic costs of diving (Fish et al., 2002). Some divers have sacrificed their insulation layer to reduce their buoyancy. For example, the deeper the diving seabird, the lower their mass-specific plumage air volume. Surface-feeders have the largest air volume, followed by plunge divers and, lastly, pursuit divers (Wilson et al., 1992b; Croll and McLaren, 1993; Lovvorn and Jones, 1994).

While incompressible, blubber may also affect buoyancy regulation (Webb et al., 1998; Miller et al., 2004), albeit on a longer timescale as the thickness of the blubber layer changes seasonally in response to energetic demands (Figure 6; Slip et al., 1992; Rosen and Renouf, 1997; Mellish et al., 2004; Meagher et al., 2008). Additionally, a body free from fur or 


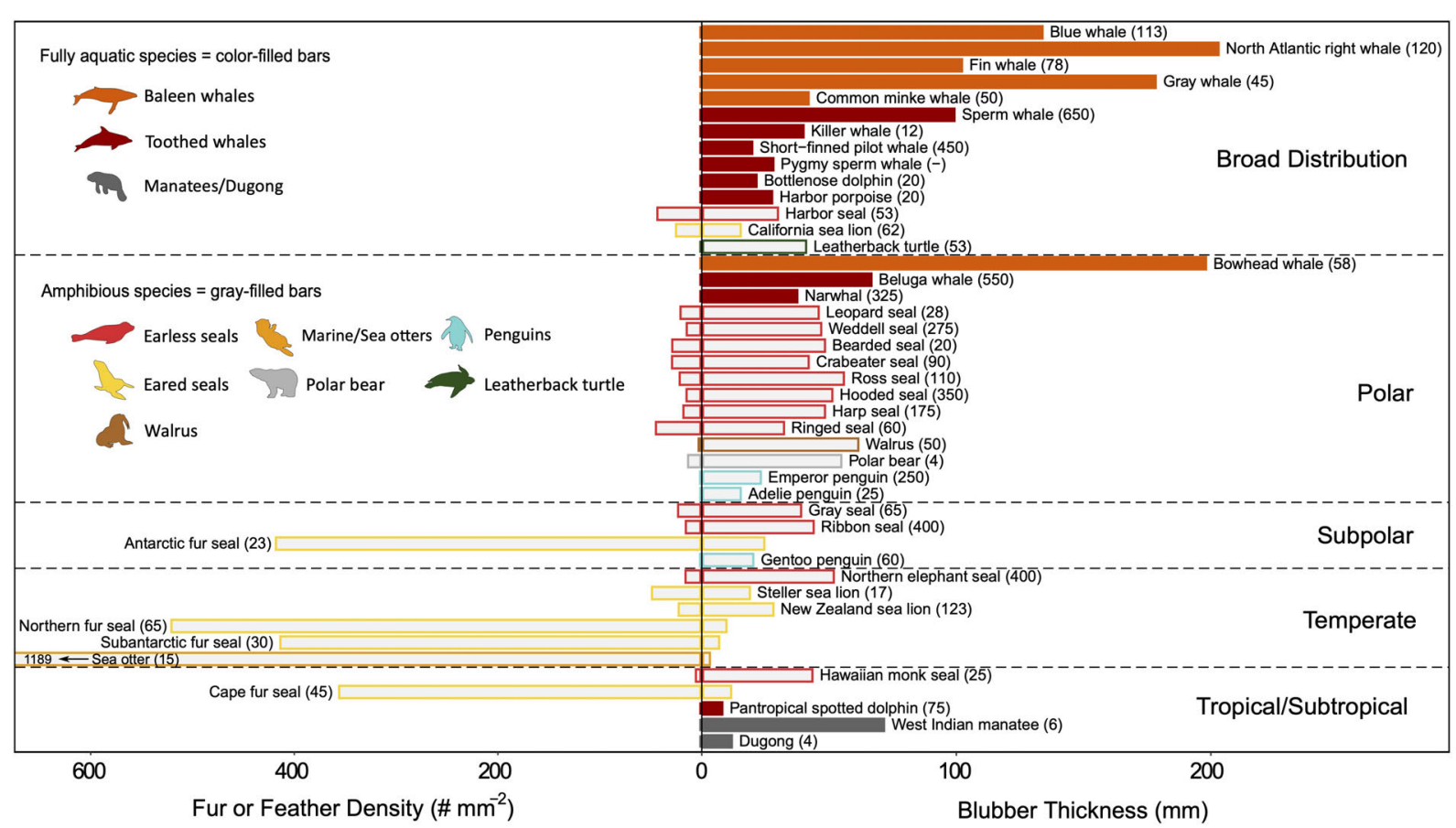

FIGURE 7 | A comparison of the quantity of external and internal insulation among marine divers that occupy different habitat ranges. Species were included for which both fur/feather density (number of hairs/feathers per $\mathrm{mm}^{2}$ ) and blubber thickness (mm) are known (values represent whole-body averages, i.e. not site-specific). It was assumed that cetaceans and sirenians have lost all insulating hair. Within each habitat range, species are grouped by family and ordered by increasing mass along the vertical axis. Routine dive depth (meters) is indicated in parentheses for each species. Fully aquatic species (color-filled bars) rely exclusively on blubber, whereas amphibious species (gray-filled bars) that retain both forms of insulation vary in which layer is most effective. The primary insulation layer for the species is indicated by whether the species common name is written on the fur/feather or blubber side of the graph. Amphibious species with broad distributions (i.e., species that span more than one habitat range) use blubber as their primary insulation layer. With the exception of the Antarctic and Cape fur seals, those that rely on fur as their primary insulation are found in temperate zones, but a gradient of morphological adaptations is seen in this region. Few data exist on feather densities, which are orders of magnitude smaller when compared to fur densities. Moreover, while contour feather density is generally reported, plumule feathers provide greater insulation and are present at higher densities. Refer to Supplementary Table S1 for absolute latitudes used for determining habitat range and Supplementary Table $\mathbf{S} 3$ for insulation layer properties data sources.

feathers is advantageous for moving through the water efficiently by reducing hydrodynamic drag (Fish, 2000). However, while streamlining is improved, a thicker layer of blubber is required to compensate for its poorer insulative capacity (Figure 8), which can, in turn, hinder maneuverability and flexibility. Therefore, small animals may be constrained to using fur or feathers, while large animals use blubber (Figure 7; Liwanag et al., 2012b).

In general, sea turtles are the only vertebrate group considered here that does not rely on substantial insulation. While the carapace and plastron are good insulators (Spotila and Standora, 1985), their fat reserves are primarily an energy store (Kwan, 1994). Leatherback turtles are the only sea turtle with a substantial fat layer containing both white and brown adipose tissue (Goff and Stenson, 1988; Davenport et al., 1990, 2009), which contributes to their homeothermic abilities. Interestingly, they are also the only sea turtle without a hard-shelled carapace.

The evolutionary transition from fur/feathers to blubber in highly adapted divers is exhibited in the most extreme divers of each taxonomic group, e.g., elephant seals, emperor penguins, and leatherback turtles (Figure 7). Marine mammals, in particular, demonstrate how their evolutionary history explains this convergence upon insulation strategies: the first groups to reinvade the oceans (Cetaceans and Sirenians) have lost nearly all their hair and are fully aquatic, the most recent groups (sea otters and polar bears) rely on a dense coat of fur, and the pinnipeds as the intermediate group exemplify a gradient of strategies that best suits their breeding strategies (i.e., income vs. capital breeding; Costa, 1991) and diving behavior (Fish, 2000; Uhen, 2007; Liwanag et al., 2012b). Similarly, with penguins, feathers are advantageous for their amphibious lifestyle, particularly those in polar climates, where it makes an effective barrier to freezing wind chills (Chappell et al., 1989). Moreover, the larger quantity of blubber required to provide an equal amount of insulation as fur or feathers would be too heavy in the case of a flying seabird or too cumbersome for species, like penguins or a sea otter, that are amongst the smaller air-breathing divers (Costa and Kooyman, 1982).

\section{Using Blood Flow to Control Heat Flow}

In addition to the role morphology (i.e., size and insulation) plays in modulating heat transfer to the animal's surroundings, key anatomical features present in the vasculature of air-breathers allow for more precise control of heat exchange by redistributing heat in the body. While heat conservation is a common challenge 


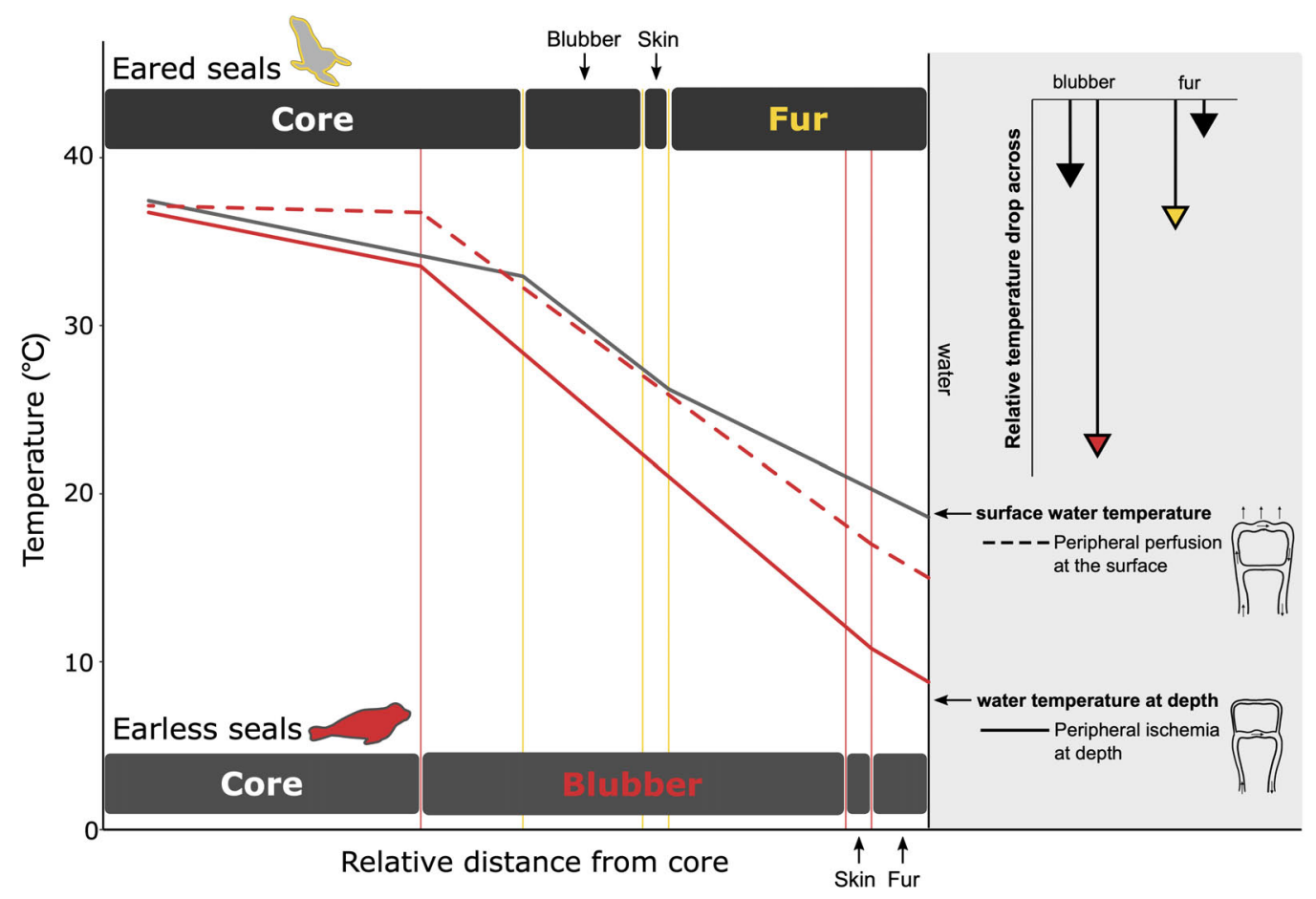

FIGURE 8 | A comparison of the temperature gradients within the fur and blubber layer for eared (gray line) and earless seals (red line) that primarily depend on fur and blubber, respectively, for insulation. The relative thicknesses of the insulation layers are scaled based on the thickness of the primary insulation needed to provide equal insulation for each species. While diving (solid lines), peripheral vasoconstriction reduces blood flow to the periphery. For earless seals, this mitigates heat loss by keeping the skin within a few degrees of water temperature. For eared seals, the air layer in the fur provides an insulative barrier and prevents such a drastic reduction in peripheral temperature. The lengths of the arrows in the upper right depict the extent to which temperature decreases in the primary (colored arrowhead) vs. secondary (black arrowhead) insulation layer when at depth. Larger temperature drops are observed in the primary insulative layer-fur for the eared seal and blubber for the earless seal-due to its lower conductivity when compared to that of the other species: pelt conductivity of the eared seal $\left(0.11 \mathrm{~W} \mathrm{~m}^{-1}\right.$ $\left.{ }^{\circ} \mathrm{C}^{-1}\right)<$ earless seal $\left(0.16 \mathrm{~W} \mathrm{~m}^{-1}{ }^{\circ} \mathrm{C}^{-1}\right)$ whereas blubber conductivity of the earless seal $\left(0.19 \mathrm{~W} \mathrm{~m}^{-1}{ }^{\circ} \mathrm{C}^{-1}\right)<$ eared seal $\left(0.28 \mathrm{~W} \mathrm{~m}^{-1}{ }^{\circ} \mathrm{C}^{-1}\right)$. At the surface, peripheral perfusion reduces the temperature gradient within the core and blubber layer (dashed line), resulting in warmer skin temperatures. Data sources: Northern fur seal, Callorhinus ursinus (Scheffer, 1961; Ohata et al., 1977; Liwanag, 2008; Sharma and Liwanag, 2017); Northern elephant seal, Mirounga angustirostris (Kuhn and Costa, 2006; Favilla, unpublished data).

in the marine environment, there are occasions where excess heat must be dissipated to prevent hyperthermia, especially during bouts of activity associated with the active pursuit of prey. Thus, a level of physiological plasticity is required in these adaptations.

Counter-current heat exchangers (CCHEs) are generally found in peripheral body parts and help retain heat in the core body by rewarming cold venous blood returning from the periphery as it passes in proximity to outgoing, warm arterial blood (Willmer et al., 2005). This mechanism makes regional heterothermy possible. The positive correlation between the number of humeral arteries within the plexus of penguin wings and the surface area of the wing shows the importance of this mechanism across species. Larger penguins have more of these heat-retaining structures to compensate for their large wings, and makes it possible to have up to a $25^{\circ} \mathrm{C}$ temperature difference between their shoulder and tip of the wing (Thomas and Fordyce, 2012).

Counter-current heat exchangers are present in the flippers and flukes of marine mammals (Elsner et al., 1974; Pabst et al., 1999; Rommel and Caplan, 2003), tongues of large cetaceans
(Heyning, 2001), legs, neck, and wings of seabirds (Frost et al., 1975; Midtgård, 1981; Thomas and Fordyce, 2012), and the limbs of leatherback turtles (Greer et al., 1973; Davenport et al., 2015). CCHEs also perform the opposite task of cooling temperaturesensitive organs, such as the brain (Scholander et al., 1942; Pettit et al., 1981; Odden et al., 1999; although see Porter and Witmer, 2016) and intra-abdominal testes (Rommel et al., 1994, 1995; Pabst et al., 1995). In these cases, cold blood from the periphery is directed towards a rete mirabile near the organ, providing a localized thermal gradient to cool the organ.

CCHEs require the circulation of blood to function and yet, peripheral vasoconstriction during the dive will limit the use of this mechanism. In short, shallow dives, CCHEs may still operate as the dive response is not as profound. However, in longer, deeper dives, the function of CCHEs is likely to be limited by the dive response. Sea turtles may be the exception as they maintain some circulation during dives to access oxygen stores in the lung. Although well-developed CCHEs are only present in the flippers of leatherback turtles (Davenport et al., 2015), evidence of the thermoregulatory role of flippers in green turtles, Chelonia mydas, and loggerhead turtles, Caretta caretta, suggests adjacent 
arteries and veins can serve a similar function (Mrosovsky, 1980; Hochscheid et al., 2002).

Arteriovenous anastomoses (AVAs) provide another thermoregulatory adaptation that relies on regulating peripheral blood flow through vasomotor control. AVAs are highly innervated vessels in the dermal layer and provide a conduit for blood to bypass capillaries, shunting directly from the arterial to the venous supply. These "shunt" vessels can be dilated or constricted to regulate blood flow to the skin, contributing to heat conservation or heat dissipation by shifting the location of the temperature gradient to either within the blubber layer or across the body surface, respectively (Figure 8). If, however, the skin is covered by dense fur, AVAs are not as effective because the temperature gradient within the fur serves as a barrier to heat transfer.

While present in all mammals, AVAs differ in density and distribution amongst taxonomic groups in part due to their relative fur densities. This is best demonstrated within the pinnipeds. Earless seals have equally high densities of AVAsup to eight times that of other mammals-across their entire body surface (Molyneux and Bryden, 1978) that contribute to heat dissipation. Unlike earless seals, eared seals have higher densities of AVAs in their flippers than their bodies, but sea lions have deeper AVAs in their furred flippers, whereas fur seals have superficial AVAs in their bare-skinned flippers (Bryden and Molyneux, 1978). These anatomical differences allow fur seals to use their flippers as heat dissipators on land or at the water's surface (e.g., jughandling behavior; Liwanag, 2010), Meanwhile, AVAs within sea lion flippers are likely to be more effective when immersed due to the negligible amount of insulation their fur provides in water.

Seabirds also have AVAs located in their eyelids, feet webbing, and brood patch (Frost et al., 1975; Midtgård, 1981; Thomas and Fordyce, 2012). These vascular structures are essential for thermoregulation during flight and incubation, but it is unclear whether they contribute to thermoregulation in water. Seabirds also have a sizeable marginal vein in their wings that provides an alternate path to $\mathrm{CCHE}$ and allows the axilla to serve as a thermal window, i.e., a peripheral site that is readily perfused to dump excess heat (Frost et al., 1975).

\section{Thermoregulatory Effects of Regulating Metabolism}

Central to the concept of heat balance is the regulation of metabolism. While endogenous heat production is limited in ectothermic divers, its regulation during diving is unclear in marine endotherms. Measurements of basal metabolic rates (BMR) of marine mammals suggest that they have higher BMRs than terrestrial mammals, but this is somewhat controversial due to inconsistencies in how BMR was measured (Castellini and Mellish, 2015). While measuring and comparing BMR is valuable for understanding maintenance costs, a more ecologically relevant measure is field metabolic rate. Still, the higher metabolic rate of marine endotherms appears to be associated with the thermoregulatory costs related to the marine environment (Irving, 1973; Lustick, 1984; Williams, 1998; Costa and Williams, 1999; Ellis and Gabrielsen, 2002; Costa and Maresh, 2017; but see Lavigne et al., 1986; Innes and Lavigne, 1991;
Williams et al., 2001). Interestingly, the field metabolic rate of Galápagos fur seals and sea lions are lower than congeners in colder habitats, which has been suggested to be an adaptation to reduce the thermal load in the equatorial climate (Costa and Trillmich, 1988; Trillmich and Kooyman, 2001; VillegasAmtmann et al., 2017). However, comparing energetic costs of marine and terrestrial vertebrates is confounded by the effects of temperature and diving on the metabolic rate of ectotherms and marine vertebrates, respectively (Hansen and Ricklefs, 2004; Davis, 2014; Costa and Maresh, 2017). The extent to which the dive response regulates metabolism will determine the rate of endogenous heat production (Hurley and Costa, 2001; Rosen et al., 2017), and ultimately thermal balance while diving. Thus, the interaction between the dive response and thermoregulation is context-dependent and expanded upon in the next section.

\section{PHYSIOLOGICAL INTERACTIONS DURING THE DIVE: SYNERGISTIC OR ANTAGONISTIC?}

Many authors have pointed out the paradoxical interactions between the physiological demands imposed on air-breathing divers (Castellini et al., 1985; Whittow, 1987; Noren et al., 1999; Williams et al., 1999a,b; Mauck et al., 2003; Green et al., 2006; Rosen et al., 2007; Sparling et al., 2007; Lewden et al., 2017b). There is potential for conflict between the dive response, exercise response, digestion, and thermoregulation because cardiovascular adjustments are integral to these responses, and those required for one activity may not be compatible with another. Therefore, divers face the dilemma of either compromising performance or prioritizing one response over another. These conflicting demands are managed in different ways by different species due to the diversity of thermoregulatory adaptations and habitats (Figure 1).

\section{The Potential for Thermal Conflict Is Context-Dependent}

Thermoregulation is energetically demanding, which is exacerbated in the thermally challenging marine environment. The ability of marine divers to meet this challenge and maintain thermal homeostasis will depend on their energetic balance. For example, if they are in an energy-deficient state, those that rely on blubber will begin to deplete this layer as an energy source. Whereas when those that depend on fur or feathers become energy deficient, they may not be able to maintain the integrity of their insulation through preening, grooming, or molting (Loughlin, 1977; Croll and McLaren, 1993; Walcott et al., 2020). Reducing the effectiveness of the insulation will, in turn, increase thermoregulatory costs and create a feedback cycle that leads to deteriorating body conditions where the body is unable to maintain thermal balance or meet energetic requirements (Costa and Kooyman, 1982; Worthy and Lavigne, 1987; Rosen et al., 2007).

The following discussion about the interplay between the dive response, exercise response, digestion, and thermoregulation, 
illustrated in Figure 9, assumes that the diver can acquire sufficient energy while foraging. Placing these interacting physiological requirements into context will serve to demonstrate situations where thermal conflicts may arise, and others where responses are synergistic.

\section{Consequences of the Dive Response on Thermoregulation}

The cardiovascular adjustments of the dive response, i.e., bradycardia and peripheral vasoconstriction (Figure 9, Box D), are generally associated with a reduced metabolism during diving, which is advantageous for increasing aerobic diving capacity due to decreased oxygen consumption. However, hypometabolism as a diving strategy also has implications for thermal physiology as a reduced metabolism results in less internal heat production. Diving into colder waters generally exacerbates the issue of heat conservation (Figure 9, bottom side panel); however, reducing the temperature gradient between the skin and water minimizes heat loss (Figure 9, Box E). This "peripheral shell cooling" can be accomplished through active mechanisms (i.e., peripheral vasoconstriction) or passively as the high thermal conductivity of water and the temperature gradient experienced by divers will naturally promote heat loss and cooling of the skin.

Those species that rely on internal insulation allow their outer shell to cool while maintaining the temperature of the core. Whereas, divers with an air layer in their water-resistant pelage or plumage undergo less cooling of their periphery, allowing them to maintain higher skin temperature (Castellini and Mellish, 2015). For example, the skin temperatures of northern elephant seals, Mirounga angustirostris, can drop to within a few degrees of water temperature (Figure 8). In comparison, sea otters and penguins keep their peripheral temperatures $\sim 10-20^{\circ} \mathrm{C}$ above water temperature (Costa and Kooyman, 1982; Ponganis et al., 2003; Enstipp et al., 2017). Regardless, marine endotherms maintain impressive thermal gradients between their core (generally $\sim 37^{\circ} \mathrm{C}$ ) and water, and even sea turtles have been shown to maintain body temperatures a few degrees up to $18^{\circ} \mathrm{C}$ above water temperature in the leatherback turtle (Frair et al., 1972). This enables leatherback turtles to expand their thermal niche into subpolar and deeper waters (Figure 1; James et al., 2006; McMahon and Hays, 2006).

In addition to changes in their insulation, vasomotor adjustments allow redistribution of heat, contributing to large temperature gradients - these result in regional heterothermia, or more specifically peripheral hypothermia. The severity of the dive response will determine the extent to which peripheral hypothermia extends into the core and causes core temperature to fall below normothermia. Even a slightly reduced core temperature is beneficial for the diver as hypothermia will reduce oxygen demands through metabolic depression (Scholander et al., 1942; Blix et al., 2010). Hypothermia may also relieve some of the thermoregulatory costs of maintaining a stable high core body temperature while diving. At the same time, it would be beneficial for conserving energy at times of reduced activity (Figure 9, Box G). However, these energetic savings during the dive must be repaid through increased activity (i.e., swimming, but also flying for seabirds) during extended postdive surface intervals to reestablish homeostasis (Figure 9, Box A). Additionally, since the metabolic rate of ectotherms is intrinsically dependent on ambient temperatures, sea turtles may be more vulnerable to significant reductions in body temperature as it would hinder physiological functions. However, even muscles in endotherms have an optimal functioning temperature (Faulkner et al., 1990). Therefore divers, and particularly ectotherms, must find a balance between the degree of body cooling and maintenance of minimum temperature for digestion or locomotion.

\section{Exercise vs. Thermoregulation: Context-Dependent Interactions and Strategies}

A hypometabolic state seems paradoxical for animals that are actively diving, pursuing prey, or escaping predators. Generally, exercise will increase heart rate and thus cardiac output to supply exercising muscles with elevated levels of oxygen to meet metabolic demands. Increased cardiac output is accompanied by the dilation of vessels to maintain blood pressure as well as an increase in breathing frequency to increase oxygen uptake (Taylor et al., 1987). Breath-hold divers have a limited ability to make these adjustments as their oxygen stores are limited. Most divers seem to avoid the typical exercise response, and maintain low diving metabolic rates by swimming efficiently-through neutral buoyancy and stroke-and-glide patterns (Figure 9, Box G; Williams et al., 2000; Lovvorn, 2001; Hochscheid et al., 2003; Watanuki et al., 2003; Trassinelli, 2016)-and matching their workload with perfusion patterns (Fedak et al., 1988; Williams et al., 1991, 1999a, 2015; McDonald et al., 2018).

Moreover, divers routinely experiencing intense peripheral vasoconstriction compensate with greater myoglobin concentrations in their locomotory muscles. More myoglobin allows for continued muscle activity despite ischemia (Davis et al., 2004). Isolating the muscle from circulation could result in a rise of local temperatures as the exercising muscle produces heat. Excess heat could be lost to the environment, or, could be retained to offset thermoregulatory costs (Figure 9, Box C).

If, however, exercise results in excess heat production, the diver may need to dissipate heat to avoid hyperthermia. This need to dump heat during periods of activity can lead to a thermal conflict for animals that are well insulated for the cold. To prevent hyperthermia and counteract thermal inertia during exercise, they can dissipate heat by bypassing the blubber layer using AVAs to perfuse the skin. Still, peripheral vasoconstriction during the dive will generally prevent this mechanism (Figure 9, Box D) as overriding the dive response will decrease their diving ability. The alternative is to store the excess heat, allowing body temperature to potentially rise, until the end of the dive when the dive response is relaxed (Figure 9, Box A and B). In other words, the diver may employ either a graded or temporally delayed thermoregulatory strategy depending on the severity of the heat load and particular dive conditions. However, if surface waters are comparably warm, delaying thermoregulation may 


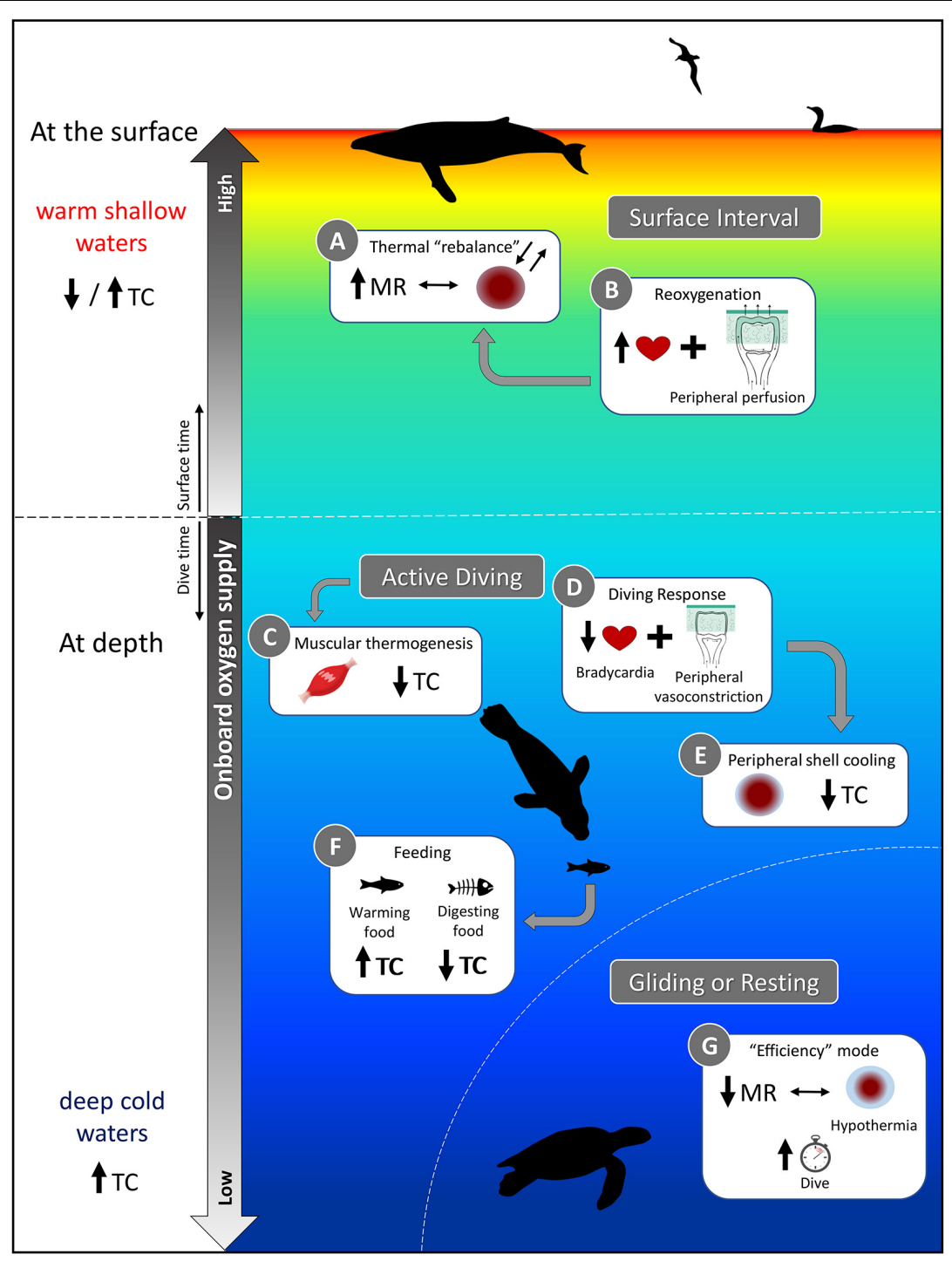

FIGURE 9 | A schematic representation of the various physiological demands faced by air-breathing divers and how thermoregulatory costs (TC) are affected. While some activities, such as digestion (Box F) and muscular heat production (Box C) may reduce TC through substitution, diving into cold waters will increase TC (bottom side panel), unless mechanisms to mitigate heat loss are used [Box E and G; e.g., long, resting dives of sea turtles in which metabolic rate (MR) is reduced]. A relaxation of the dive response at the surface (Box B vs. Box $D$ at depth) may facilitate regaining thermal balance (Box A), but the relative amount of time spent at the surface to achieve homeostasis may also be dictated by gas exchange in addition to thermoregulatory functions. If TC increases because surface waters are too warm to dump sufficient heat to compensate for increased activity, thermal inertia, etc. (top side panel), then diving activity may be altered to account for increased thermoregulatory needs. Refer to sections "Consequences of the Dive Response on Thermoregulation," "Exercise vs. Thermoregulation: Context-Dependent Interactions and Strategies," and "Ingestion and digestion of cold prey: A sink and source of heat" of the text for further explanation.

exacerbate the challenge of dissipating the excess heat that has been stored (Figure 9, top side panel). Since heat dissipation will be less efficient in warmer surface waters, this strategy may inevitably reduce diving efficiency by requiring longer surface intervals for thermoregulation.

\section{Ingestion and Digestion of Cold Prey: A Sink and Source of Heat}

Another physiological requirement that may be incompatible with the dive response is digestion. Foraging is one of the primary functions of diving for air-breathers; yet, digestion requires some blood flow to the splanchnic organs, which are generally hypoperfused during the dive (Zapol et al., 1979; Davis et al., 1983; Davis, 2014). Digestion could be delayed to when maximizing dive duration is not a priority, such as after foraging bouts or time on land to prevent this conflict. While delaying digestion may enhance foraging efficiency (up until satiation), there will also be thermal consequences of employing such a strategy.

An important thermoregulatory consideration associated with foraging is the ingestion of cold prey. In addition to the 
external temperature gradient experienced while diving, the ingestion of cold prey will introduce an internal temperature gradient. Warming ingested prey will exacerbate the challenge of maintaining thermal balance in cold water, particularly for endotherms feeding on cold ectothermic prey (Wilson et al., 1992a; Hedd et al., 1996). However, the energetic costs of digestion contribute to HIF, which can offset thermoregulatory costs. Therefore, the ingestion and digestion of cold prey can serve as a sink or source of heat, respectively (Figure 9, Box F; Croll and McLaren, 1993). Considering when these processes occur is essential for understanding how the diver's thermoregulatory strategy may affect its diving, and thus foraging behavior (Costa, 1988; Williams et al., 2004).

Mathematical models of how a breath-hold diver should optimize their energy intake have been developed and have made predictions that can be tested in the field (Charnov, 1976; Kramer, 1988; Houston and Carbone, 1992; Thompson and Fedak, 2001). However, the additional constraints imposed by digestion and thermoregulation have yet to be considered. Theoretical models that combine laboratory data on the thermoregulatory costs of foraging with field studies that identify when these processes occur in nature would provide insight into the intrinsic and extrinsic factors, besides oxygen stores and prey field, that may influence foraging efficiency.

\section{A THERMAL BALANCING ACT}

The management of concurrent, and potentially conflicting demands requires that a diver coordinates its response in a manner that aligns with diving conditions and physiological priorities. Such strategies could involve temporally separating two responses that are in direct conflict, using their response for one demand to minimize the cost of another, or attending to both requirements simultaneously but at a compromised capacity. A certain degree of flexibility is required to account for the complexity of potential interactions, differences between dive functions, and seasonal changes in their environment and body condition. In the following section, we review the literature for studies that examined thermoregulation in animals in the water and while diving in nature.

\section{Temporal Separation of Conflicting Demands \\ Checks and Balances of Thermal Budgets: Exercise and Water Temperature}

The conflicting demands of the dive response and thermoregulation were examined with trained bottlenose dolphins, Tursiops truncatus, swimming, and diving in warm tropical waters (Noren et al., 1999; Williams et al., 1999b). They found significant changes in heat flux (definition provided in section 'Heat Flux') across the body with diving, where diving attenuated heat flux even after an extended period of swimming at the surface. Heat flux only started to increase during the latter portion of the ascent-which coincides with the anticipatory tachycardia occurring at the end of the dive-and remained high during the post-dive surface interval. The authors concluded that dolphins delayed heat dissipation until after the dive instead of overriding the dive response to dissipate heat at depth. Interestingly, one of the dolphins that was vigorously active before diving showed elevated heat flux at the dorsal fin at depth, which suggests a momentary override of the dive response to dissipate heat through this thermal window. This scenario emphasizes the effects of exercise in determining the flexibility of their responses to account for their thermal demands, and also supports the claim that the dive response can be modulated by activity (Davis and Williams, 2012; Noren et al., 2012; Williams et al., 2015; McDonald et al., 2018).

Does a delay in heat dissipation compromise thermal balance, and if so, to what extent is thermal imbalance tolerated before the dive response is overridden to allow for some heat dissipation? An animal's heat tolerance will dictate the extent and time scale at which cellular consequences of hyperthermia, such as destabilization of proteins and changes in membrane fluidity, require prioritization of thermoregulation to regain homeostasis, or manifest as heat stress symptoms. Bottlenose dolphins exposed to increasingly warmer water temperatures were able to delay the onset of hyperthermia for an hour or longer. They did this by redistributing core body heat to their periphery, demonstrating their physiological ability to tolerate some heat stress (Heath and Ridgway, 1999). Although the physiological demands faced by the resting dolphins in this study are different than those for wild, active dolphins, such a short-term heat tolerance would explain how dolphins can manage the thermal challenge of moving from cold pelagic waters to warmer inshore waters. Therefore, in the case of smaller cetaceans, activity and water temperature are important factors for determining their thermal economy and the degree to which heat stress is tolerated during the dive. Furthermore, diving could increase their heat tolerance as hypometabolism, and colder waters at depth promote passive heat dissipation. How larger cetaceans face a similar challenge when migrating from the poles to the tropics, albeit on much longer timescales, is unknown.

Polar seals, such as the Antarctic Weddell seal, Leptonychotes weddelli, are unlikely to face the thermal conflict of dissipating heat while diving, even during intense activity. Yet, they also appear to regulate their thermal balance during the post-dive surface interval. Hill et al. (1987) measured aortic temperatures during the dive. They observed significant changes between dives rather than during dives, suggesting that this drop in aortic temperature (up to $2^{\circ} \mathrm{C}$ ) before bouts of diving serves as a "preparatory" thermoregulatory response to extend dive durations by reducing metabolism. Thus, dolphins and Weddell seals in drastically different thermal habitats resolved the conflicting demands of thermoregulation during diving by deferring active thermoregulation until surface intervals.

\section{Dive First, Digest Later}

A similar strategy of temporal separation has been observed in diving endotherms to mediate the thermal consequences of digestion. Amphibious species that haul out often have the option of completely separating digestion from diving. In contrast, those that perform long foraging trips or are fully aquatic must find an opportune time to digest while at sea when they are not 
concerned with maximizing their dive durations. For example, elephant seals appear to defer food processing to drift dives where the animal stops swimming and drifts thereby sparing oxygen that would otherwise be expended on locomotion for digestion (Crocker et al., 1997; Mitani et al., 2010). However, these 'foodprocessing' dives were occasionally associated with extended surface intervals (ESIs), suggesting oxygen stores may at times be insufficient to complete digestion at depth following extensive foraging bouts and may require additional time at the surface (Crocker et al., 1997). The thermoregulatory costs associated with warming, potentially large quantities of ingested prey, may also be a factor limiting their diving efficiency while foraging (Austin et al., 2006; Kuhn and Costa, 2006).

ESIs have also been observed in gray seals, Halichoerus grypus, and harbor seals, Phoca vitulina. By simulating natural foraging trips with gray seals in a laboratory setting, Sparling et al. (2007) demonstrated that gray seals delay digestion until ESIs, which may occur hours after the initial ingestion of prey. This strategy was flexible in that some digestion occurred during shallow dives, but not in deeper dives. A similar observation was made in Steller sea lions, Eumetopias jubatus (Hindle et al., 2010; Rosen et al., 2015). These ESIs were accompanied by significant peaks in metabolic rate, much higher than those reported for non-diving seals, likely as a result of HIF, as well as the added physiological demands of diving (Markussen et al., 1994; Rosen and Trites, 1997), and perhaps paying back the thermoregulatory costs of warming cold prey (Williams et al., 2004).

\section{Thermoregulating Smarter, Not Harder by Coordinating Synergistic Activities}

\section{HIF: Equivocal Evidence for Heat Substitution}

Whether HIF offsets thermoregulatory requirements has been investigated in several species with mixed results. Some studies have speculated the potential contribution of HIF towards maintaining thermal balance from lab experiments. For example, thick-billed murres, Uria lomvia, little penguins, Eudyptula minor, and double-crested cormorants, Phalacrocorax auritus, may benefit by deferring digestion until after dives while floating at the surface or flying to shore to dry their feathers where HIF can contribute to the post-dive recovery of body temperatures (Hawkins et al., 1997; Green et al., 2006; Enstipp et al., 2008).

On the other hand, studies on other seabirds and Steller sea lions have concluded that HIF does not significantly contribute to reduced thermoregulatory costs (Wilson and Culik, 1991; Rosen and Trites, 2003). Specifically, Wilson and Culik (1991) found that the increased postprandial metabolic rate of adult Adélie penguins, Pygoscelis adeliae, is due to the cost of warming cold prey, rather than HIF (for comparison with chicks, see Janes and Chappell, 1995). However, these studies were all performed in the lab where direct measurements of metabolic rate were possible. Still, the effects of varying activity levels associated with different foraging strategies are challenging to incorporate. Wilson and Culik (1991) suggest that the active foraging strategy of Adélie penguins may allow them to mobilize muscular heat to aid in warming ingested prey and would in turn dictate foraging rates to maximize food heating efficiency.
Unlike the majority of foragers limited by their non-prehensile limbs, sea otters can delay both prey ingestion and digestion until they are back at the surface. In doing so, they avoid the initial thermal costs required to warm ingested prey while at depth and reap the thermal benefits of HIF while inactive at the surface (Costa and Kooyman, 1984). Due to their overall high metabolic rates and unfavorable $\mathrm{SA}: \mathrm{V}$, sea otters rely on synergistically coordinating heat substitution strategies for maintaining thermal balance, as observed by a corresponding increase in activity as HIF decreased over time (Costa and Kooyman, 1984). Sea otters and seabirds suggest that perhaps the ability to float at the surface to reduce heat loss to the water may facilitate maximizing the thermal benefits of HIF, particularly during inactive periods that are increasingly costly with decreasing water temperatures (Richman and Lovvorn, 2011). These examples demonstrate the importance of disentangling the cost of warming ingested prey from those associated with digestion to assess the net thermoregulatory consequences of foraging.

\section{Muscular Thermogenesis: Using Muscular Inefficiency for Thermoregulation}

Another mechanism of thermal substitution is utilizing the 'wasted' heat produced by muscular activity. While this was mentioned in relation to foraging for sea otters and Adélie penguins, it also contributes to thermoregulation in the absence of foraging activity. Muscular thermogenesis as a thermoregulatory strategy is particularly useful for (1) species with a low heat-retaining capacity (i.e., large SA:V), (2) juveniles that may not have well-developed thermoregulatory capabilities in addition to having an unfavorable SA:V relative to adults, and (3) ectotherms that have a reduced capacity to increase their metabolic heat production.

Studies on captive animals have demonstrated how body size affects the relationship between activity and thermal homeostasis. For example, Hawaiian spinner dolphins, Stenella longirostris, a comparably small delphinid species, live in waters near their lower critical temperature, and their stenothermic body temperature is dependent on activity, demonstrating a synergistic interaction between exercise and thermoregulation (Hampton et al., 1971; Hampton and Whittow, 1976). In contrast, a larger delphinid species, the Pacific bottlenose dolphin, has been shown to experience a $2^{\circ} \mathrm{C}$ increase in body temperature after periods of vigorous activity (McGinnis et al., 1972). As juveniles are smaller, they have reduced thermal capabilities compared to adults. However, it is energetically cheaper for juvenile California sea lions, Zalophus californianus, to maintain moderate activity levels than to rest in water below their thermal neutral zone, and incur the increased cost of shivering (Liwanag et al., 2009).

The activity of ectothermic divers is primarily influenced by their thermal environment, often resulting in circadian patterns. In hawksbill turtles, Eretmochelys imbricata, Storch et al. (2005) found that the duration of night dives increased with decreasing water temperature below $28^{\circ} \mathrm{C}$. In contrast, there was no pattern in dive duration and water temperature during the day. They related this pattern to the different behaviors carried out during day and night. During the day, animals are actively foraging, while at night, they are resting, and their temperature and 
metabolism would be lower, allowing longer dives. Muscular thermogenesis associated with active swimming has also been demonstrated in green turtles in lab experiments (Jackson and Prange, 1979; Standora et al., 1982) and has been hypothesized to occur in free-ranging loggerhead turtles (Sakamoto et al., 1990). While heat generated in the muscles likely serves to primarily enhance muscle performance, some heat may be distributed to the rest of the body via circulation, increasing core body temperatures beyond their usual $1-2^{\circ} \mathrm{C}$ above ambient water temperatures (Standora et al., 1982; Sakamoto et al., 1990).

\section{Modifying Diving Behavior as a Thermoregulatory Strategy}

Vertical stratification of the water column allows divers to behaviorally thermoregulate by varying the time spent in warmer, surface waters vs. colder, deep waters. Although relatively rare, ESIs have been recorded in the diving behavior of loggerhead turtles in the Mediterranean Sea, with the majority of ESIs occurring during the day following dive bouts into deep waters up to $10^{\circ} \mathrm{C}$ colder than surface waters (Hochscheid et al., 2010). The positive correlation between body mass and ESI duration, along with extended surface time during sunlit hours, led the authors to hypothesize that ESIs serve a thermoregulatory function. In contrast, nocturnal ESIs occurred after dives that exceeded their calculated ADL where they were presumably foraging on patchy prey, indicating an alternative role of post-dive recovery for nocturnal ESIs. Core body temperature measurements would allow a test of the hypothesized functions for daytime and nocturnal ESIs.

Unlike loggerhead turtles in the Mediterranean Sea, leatherback turtles encounter a broader range in temperatures across their habitat-which spans both tropical to subpolar waters-and thus require greater flexibility in their thermoregulatory strategy. Wallace et al. (2005) suggested that leatherback turtles behaviorally regulate their body temperature by either increasing the time spent at colder depths while in tropical waters or performing shallower dives when in colder waters at the northern limits of their range. Additionally, in warm tropical waters leatherback turtles can use CCHEs in their hindlimbs to retain muscular heat locally to prevent core hyperthermia; whereas in colder waters they can transfer some of this heat to their core, where it is retained by their thermal inertia and insulation (Davenport et al., 2015).

Although behavioral thermoregulation is a more common strategy in ectotherms, adjusting diving behavior as a thermoregulatory strategy has also been documented in endothermic divers. Similar to the leatherback turtles, Magellanic penguins, Spheniscus magellanicus, occupy a relatively wide range of water temperatures on the Patagonian coast and adapt their diving behavior relative to water temperature and foraging activity. By comparing penguins from colonies at different latitudes and modeling the effects of environmental parameters on their thermal dynamics, Ciancio et al. (2016) found that penguins increased their swim speeds in colder waters while performing shallow transiting dives. Increased swim speeds will also increase convective heat loss. Still, they showed that the associated increase in heat production was disproportionately higher and compensated for convective heat loss, thus making this a suitable strategy to mitigate heat loss while diving shallowly in cold waters. However, when performing deep dives, heat loss is exacerbated by diving to depth. This may explain why penguins reduced, rather than increased, swim speeds during the ascent and descent of deeper foraging dives. By shifting their strategy and prioritizing oxygen conservation instead of thermoregulation, penguins could maximize bottom time and thus foraging efficiency. This exemplifies how diving behavior is modified to balance the physiological demands of thermoregulation and foraging.

Little is known about behavioral thermoregulation in marine mammals while in water despite a plethora of studies that describe behavioral strategies of amphibious species while on land (Whittow et al., 1972; Beentjes, 2006; Norris et al., 2010; Codde et al., 2016). One well described at-sea behavior is jughandling in Northern fur seals, Callorhinus ursinus, which is commonly associated with sleep (Donohue et al., 2000). By exposing their flippers while floating at the surface, fur seals enhance the efficiency of AVAs in their flippers for either heat conservation by reducing heat loss to the water or heat dissipation by increasing convective heat loss in air. Jughandling increased with water temperature in pups, and although shivering was observed, there was no relationship with water temperature. Despite an initial increase in metabolism associated with this body position (likely due to changes in perfusion), fur seals-particularly pups in water below their lower critical temperature-can reduce thermoregulatory costs compared to resting by remaining in this position for $\sim 30 \mathrm{~min}$ and thus extend their thermal neutral zone (Liwanag, 2010).

Manatees, Trichechus manatus, employ a longer-term behavioral strategy to avoid cold-stress. When Florida winter water temperatures reach below their lower critical temperature of $20^{\circ} \mathrm{C}$, manatees may migrate to warm-water thermal refuges in inland natural springs or near power plants (Laist et al., 2013). There have been up to 282 manatee deaths due to cold-stress in a single year, and those most vulnerable are juveniles and sub-adults due to their inexperience of finding thermal refuges and high SA:V relative to adults (Erdsack et al., 2018). Still, even those that use these thermal refuges may face energetic trade-offs with foraging as it requires traveling further distances to feeding grounds, resulting in reduced foraging time (Haase et al., 2019). Conversely, summer water temperatures can reach $32^{\circ} \mathrm{C}$, and during episodes of strenuous activity, albeit rare for this slow-moving mammal, heat may need to be dumped to prevent hyperthermia. Manatees do not possess AVAs, but a deep caudal vein has been proposed as a mechanism for bypassing the CCHE in their caudal fluke and contribute to heat dissipation (Rommel and Caplan, 2003). However, the deep location of this vein in comparison to AVAs in other species raises the question as to whether this strategy is efficient and sufficient to prevent hyperthermia.

\section{Regional Heterothermy vs. Hypothermy}

The dive response and thermoregulation are intricately connected through common underlying physiological 
mechanisms, namely metabolic rate and peripheral perfusion. In the diving physiology literature, regional heterothermia has been hypothesized as a mechanism to reduce diving metabolism and thus extend aerobic dive duration (Ponganis et al., 2001, 2003; Niizuma et al., 2007). However, the use of this strategy for diving or thermoregulation is not mutually exclusive. Similarly, hypothermia-induced metabolic depression is an alternative hypothesis, and this strategy of lowering the set-point in body temperature has often been proposed in the literature to explain the impressive diving behavior of marine vertebrates, particularly seabirds (Culik et al., 1996; Bevan et al., 1997). The costs and benefits of employing regional heterothermy vs. hypothermy will depend on concurrent physiological demands (e.g., foraging, digestion, migration, molting) and whether species-specific thermoregulatory adaptations allow the animal to withstand these departures from normothermia given the dive conditions (i.e., dive depth/duration and water temperatures).

Data from king penguins, Aptenodytes patagonicus, support a hypometabolic strategy as several studies have observed reductions of up to $\sim 25^{\circ} \mathrm{C}$ in abdominal and subcutaneous temperatures during dives with subsequent rewarming after foraging bouts returning to normothermic levels (Handrich et al., 1997; Schmidt et al., 2006; Enstipp et al., 2017). A reduction in metabolism afforded by lower body temperatures during the dive may explain their ability to routinely dive close to their ADL (Figure 5) and maximize foraging efficiency. Despite suffering increased heat loss, king penguins maintain peripheral perfusion while at the surface, particularly ESIs during the night, to either access or deposit fat into their subcutaneous layer depending on their foraging success and energy balance (Lewden et al., 2017a,b), thus demonstrating a trade-off between nutritional and thermoregulatory demands.

While a decline in the peripheral temperatures of emperor penguins and thick-billed murres have been observed, a marked reduction in core body temperature similar to the king penguins was absent (Ponganis et al., 2001, 2003; Niizuma et al., 2007). It is worth noting that Ponganis et al. $(2001,2003)$ observed a similar pattern to king penguins in the abdominal temperature of emperor penguins. Still, by comparing this site to several others in the body, they concluded that the abdominal temperature is not representative of the core body temperature for emperor penguins. Instead, deep venous temperatures that better represent core temperature did not drop below $37^{\circ} \mathrm{C}$ even during prolonged dives, while significant declines were observed in other peripheral sites. These findings do not support the concept of hypothermia or hypometabolism in emperor penguins but rather aligns with regional heterothermy.

Niizuma et al. (2007) reached a similar conclusion for thickbilled murres but also observed an overall decreasing trend in both core and peripheral temperatures throughout dive bouts. Superimposed on this trend is the opposing changes in core and peripheral temperatures during a dive. A progressive decline in peripheral temperatures across dive bouts was driven by reductions that occurred during the dive. Interestingly, a sharp drop in peripheral temperature upon submergence is reversed for a few seconds before a gradual reduction continues throughout the rest of the dive, indicating a brief relaxation of peripheral vasoconstriction during the dive. Conversely, core temperatures remained relatively high during the dive but then decreased at greater magnitudes during surface intervals. This pattern of within-dive changes in core temperature contrasts with those observed in king penguins and led the authors to hypothesize that larger seabirds use different thermoregulatory strategies than smaller seabirds. While body size may be important, other factors, such as dive or trip duration, may explain why emperor penguins diving from an isolated ice hole seem to be more similar to the smaller murre than the larger, more closely related king penguins.

There are species-specific differences in thermoregulatory strategies within the Phalacrocoracidae (i.e., cormorants and shags). For example, Great cormorants, Phalacrocorax carbo carbo, bank cormorants, Phalacrocorax neglectus, and European shags, Phalacrocorax aristotelis, maintain relatively stable core body temperatures $\left(\sim 41^{\circ} \mathrm{C}\right.$; measured via stomach temperature telemeters) while diving (Wilson and Grémillet, 1996; Grémillet et al., 1998, 2001; Enstipp et al., 2005). In contrast in South Georgian shags, significant declines $\left(\sim 10^{\circ} \mathrm{C}\right)$ in body temperatures occurred (measured in the abdomen, reaching as low as $\sim 31^{\circ} \mathrm{C}$ ) while diving (Bevan et al., 1997). These differences were partly attributed to the diving behavior and thermal environments encountered by these closely related species. While they are all exposed to cold waters, South Georgian shags perform more extreme dives to $\sim 100 \mathrm{~m}$ for 3-4 min (Croxall et al., 1991), which could be facilitated by a hypothermic strategy. On the other hand, temporal hypothermia may be costlier than maintaining normothermia for shallower diving cormorants (e.g., European shags and Great cormorants). Bank cormorants have the added advantage of absorbing the intense solar radiation from the South African sun to attain normothermia while in cold waters (Grémillet et al., 1998). Phalacrocoracidae (cormorants) living in polar climates reduce their time underwater by increasing their foraging efficiency, thus allowing them to ideally delay thermoregulatory responses until after short foraging bouts (Grémillet et al., 2001; although see Grémillet et al., 2005). However, European shags diving near Scottish Islands have long foraging bouts when compared to conspecifics at the more southernly located Chausey Islands ( $\sim 4$ h vs. $\sim 1$ h near Chausey Islands; Daunt et al., 2007; Lewis et al., 2015), which likely precludes delaying thermoregulation until after foraging, especially in these colder waters. Furthermore, Greenland Great cormorants maintain normothermia despite diving in waters often less than $0^{\circ} \mathrm{C}$ (Grémillet et al., 2005). Rather than delay thermoregulation, these arctic cormorants, likely employ intense thermogenesis to counteract heat loss to the water (Grémillet et al., 2001).

Compared to the seabird literature, there have been fewer studies on marine mammals that directly investigate hypometabolism and peripheral shell cooling. The ability to withstand hypothermia during forced submersion was demonstrated in some of the first sentinel studies of diving physiology on seals (Irving et al., 1941; Scholander et al., 1942; Elsner, 1969). However, it was not until reduced aortic temperatures were observed in Weddell seals diving voluntarily from an isolated ice-hole that hypothermia was suggested as a strategy employed by animals diving under natural conditions 
(Kooyman et al., 1980). While aortic temperatures were shown to decrease to $35^{\circ} \mathrm{C}$ during dives, the locomotory muscle temperature remained stable at $37^{\circ} \mathrm{C}$ instead of heating up as much as would be expected from the amount of work performed if it were completely ischemic (Kooyman et al., 1980; Hill et al., 1987; Ponganis et al., 1993). The lack of a temperature rise in the muscle likely indicates that either some perfusion is maintained or the muscle is hypometabolic while active. However, the muscle temperature could not be used to conclude the entire body's thermal conditions or metabolic rate (Ponganis et al., 1993). Andrews (1999) reached a similar conclusion about deep muscle temperature measurements in freely diving juvenile elephant seals. The muscle temperature dropped an average of only $1^{\circ} \mathrm{C}$ during dives, while peripheral temperatures (i.e., subcutaneous and blubber) decreased significantly supporting the strategy of peripheral hypothermia that may extend into the adjacent muscle tissue. In addition to these studies on phocids, regional heterothermy has also been observed in fur seals and dolphins (Ohata et al., 1977; Heath and Ridgway, 1999; Barbieri et al., 2010).

While confirming whether peripheral hypothermia is accomplished through active vasomotor control or passive mechanisms is more challenging, Boyd (2000) used a simple heat balance model in which peripheral circulation switched between complete and absent and demonstrated the model could predict the skin temperature changes observed in diving Antarctic fur seals, Arctocephalus gazella. However, he acknowledged that peripheral perfusion was modeled in an overly simplistic manner, and that it is likely to be more of a graded response. Nonetheless, the evidence of peripheral hypothermia in several endothermic divers emphasizes the importance of managing skin temperature for thermoregulation.

Unlike seabirds and most marine mammals, the majority of sea turtles do not have substantial insulation. Yet, their skin temperature is generally close to ambient water temperature while their core body temperature is maintained above water temperature. Their ability to maintain a high core body temperature is reduced when water temperatures reach $<10^{\circ} \mathrm{C}$ (Schwartz, 1978; Foley et al., 2007). Although only described in a few sea turtle species, hypometabolism can reduce their energetic costs but is associated with a decrease in performance. Dives where turtles remain quiescent on the seafloor or in the water column (at the depth where neutral buoyancy is achieved) longer than their average dive duration have been described in green turtles (Felger et al., 1976; Godley et al., 2002; Southwood et al., 2003), hawksbill turtles (Storch et al., 2005), and loggerhead turtles (Carr et al., 1980; Hochscheid et al., 2005, 2007a; Hawkes et al., 2007). These dives are typically shallow and nocturnal, and occur during winter when the water is colder, which facilitates a temperatureinduced depression of metabolism. By reducing their oxygen consumption, they can remain resting at depth for prolonged periods-as long as 10 hours was observed in a loggerhead turtle (Broderick et al., 2007). This behavioral thermoregulatory strategy has been referred to as hibernating, emphasizing the departure from homeostatic conditions that allows for minimal energy expenditure.
In addition to this behavioral strategy, there is evidence that sea turtles regulate their thermal balance. Laboratory studies have demonstrated that sea turtles have faster heating rates than cooling rates, suggesting physiological control over heat exchange (Heath and McGinnis, 1980; Smith et al., 1986). Although well-developed CCHEs, which provide an effective mechanism for controlling heat distribution, have only been identified in leatherback turtles (Mrosovsky, 1980; Davenport et al., 2015), Hochscheid et al. (2002) demonstrated changes in blood flow in response to changing ambient temperatures in the flippers of green and loggerhead turtles. Similarly, the relatively large size of green turtles, Chelonia mydas, and loggerhead turtles, Caretta caretta, facilitates the retention of heat and has led to the use of other terms, including homeothermy and regional endothermy, to describe their thermoregulatory capabilities (Standora et al., 1982; Sato et al., 1994). Therefore, despite their intrinsic differences in physiology, sea turtles and diving endotherms have converged upon a similar thermoregulatory strategy of regional heterothermy, which is made possible by regulating their circulation to control heat distribution within the body and heat dissipation to the environment. As Irving and Hart (1957) eloquently summarized it: "...the homoiothermism of their bodies is sustained by the heterothermism of superficial tissues."

\section{METHODS FOR STUDYING THE THERMAL PHYSIOLOGY OF FREE-RANGING DIVERS}

While laboratory investigations provide a fundamental understanding of thermoregulatory mechanisms, insight into conflicts between competing physiological processes associated during diving require field studies. Fortunately, technological advances have created new tools to study the movement patterns, behavioral and physiological ecology of air-breathing marine vertebrates. The incorporation of physiological sensors into biologging tags has made it possible to investigate how the physiological capabilities demonstrated in the lab are employed in the wild. The following section discusses the approaches that might be used to study the thermal physiology of free-ranging divers, with representative studies summarized in Table $\mathbf{1}$. These methods may not apply to all taxonomic groups, but a modification to procedures and approaches could expand our knowledge of understudied species.

\section{Temperature}

While handheld devices offer a snapshot of an animal's thermal state, continuous measurements at appropriate sampling rates can provide insight into the dynamic nature of an animal's physiological temperatures, which can vary drastically with activity and ambient conditions (Goldsmith and Sladen, 1961; Boyd and Sladen, 1971; Taylor et al., 2004). Thermistors and thermocouples have been used on many freely diving species, demonstrating the feasibility of using them for physiological studies. Given that continuous temperature measurements are likely to be taken at a few sites, these sites must be carefully chosen. Sensor placement can be guided by knowledge of the 
TABLE 1 | Summary of studies and their approaches used in field thermal physiological studies for (A) sea turtles, (B) seabirds, and (C) marine mammals.

\begin{tabular}{|c|c|c|c|c|c|c|}
\hline & Species & Study & Thermal Physiological Measurement(s) & Instrumentation & Other Measurement(s) & Derived Quantities \\
\hline \multirow[t]{8}{*}{ Sea turtles } & Green turtle & Heath and McGinnis, $1980^{x}$ & $\begin{array}{l}T_{\text {stomach }^{*}} \\
\mathrm{~T}_{\text {peripheral }} \text { - carapace and subcarapace } \\
\mathrm{HF} \mathrm{F}^{\mathrm{x}} \text { - carapace, plastron, neck, flippers }\end{array}$ & $\begin{array}{l}\text { External logger and } \\
\text { STT }\end{array}$ & $T_{\text {water }}$ - surface and benthic & $\begin{array}{l}\Delta T_{\text {core-water }} \text { from } \\
\text { heating and cooling } \\
\text { experiments }{ }^{x}, \text { Thermal } \\
\text { conductance }^{x}\end{array}$ \\
\hline & & Standora et al., 1982 & $\begin{array}{l}\mathrm{T}_{\text {deep }}{ }^{*} \text { - near liver/pectoral muscle } \\
\mathrm{T}_{\text {peripheral }} \text { - carapace, subcarapace, } \\
\text { plastron, subplastron }\end{array}$ & Sonic transmitter & & $\begin{array}{l}\text { Cooling-curve } \\
\text { experiments }{ }^{x}\end{array}$ \\
\hline & & Sato et al., $1998^{x}$ & $\mathrm{~T}_{\text {stomach }}{ }^{*}$ & STL & In situ $T_{\text {water }}$, diving depth & \\
\hline & Leatherback turtle & Southwood et al., 2005 & $\begin{array}{l}T_{\text {stomach }^{*}} \\
T_{\text {peripheral }} \text { - subcarapace }\end{array}$ & HTR/STT TDTR & $\begin{array}{l}\text { In situ } T_{\text {water }} \text {, diving depth, } \\
\text { swim speed }\end{array}$ & \\
\hline & & Casey et al., 2014 & $\mathrm{~T}_{\text {stomach }}{ }^{*}$ & STP & In situ $T_{\text {water }}$, diving depth & Metabolic rate $(\Delta T)$ \\
\hline & Loggerhead turtle & Sakamoto et al., 1990 & $\mathrm{~T}_{\text {stomach }}{ }^{*}$ & $T R$ & In situ $T_{\text {water }}$, diving depth & \\
\hline & & $\begin{array}{l}\text { Sato et al., 1994, } \\
\text { Sato et al., 1995, } 1998\end{array}$ & $\mathrm{~T}_{\text {stomach }}{ }^{*}$ & $T R$ & Diving depth & \\
\hline & & Sato, 2014 & $\mathrm{~T}_{\text {stomach }}{ }^{*}$ & TTR & In situ $T_{\text {water }}$, diving depth & Heat transfer model \\
\hline \multirow[t]{9}{*}{ Seabirds } & Cormorants and shags & $\begin{array}{l}\text { Wilson and Grémillet, } 1996 \\
\text { Bank cormorants }\end{array}$ & $\mathrm{T}_{\text {stomach }}{ }^{*}$ & STL & Diving depth & Heat balance model \\
\hline & & $\begin{array}{l}\text { Kato et al., } 1996^{M} \\
\text { King cormorants }\end{array}$ & $\mathrm{T}_{\text {stomach }}{ }^{*}$ & STL & Diving depth & \\
\hline & & $\begin{array}{l}\text { Bevan et al., } 1997^{X} \\
\text { South Georgian shags }\end{array}$ & $\mathrm{T}_{\text {peripheral }}{ }^{\star}$ - abdominal & HRDL & HR, diving depth & $\begin{array}{l}\mathrm{O}_{2} \text { consumption } \\
(\text { respirometry })^{x}\end{array}$ \\
\hline & & $\begin{array}{l}\text { Grémillet et al., } 1998 \\
\text { Great cormorants and } \\
\text { European shags }\end{array}$ & $\mathrm{T}_{\text {stomach }}{ }^{*}$ & STL & Diving depth & Heat loss model \\
\hline & & $\begin{array}{l}\text { Grémillet et al., } 2005 \\
\text { Great cormorants }\end{array}$ & $T_{\text {peripheral }}{ }^{\star}$ - abdominal & HRDL & $\begin{array}{l}\text { HR, diving depth Body } \\
\text { composition }^{X}\end{array}$ & $\begin{array}{l}\text { Thermal conductance } \\
\text { (based on Storch et al., } \\
1999^{X} \text { ), fasting } \\
\text { endurance, energetics } \\
\text { model, heat loss } \\
\text { calculations }\end{array}$ \\
\hline & Thick-billed murre & Niizuma et al., 2007 & $\begin{array}{l}\mathrm{T}_{\text {deep }}{ }^{*} \text { - under liver near heart/lung/pectoral muscle } \\
\mathrm{T}_{\text {peripheral }} \text { - muscle-skin interface }\end{array}$ & Implantable logger & Diving depth & \\
\hline & African penguin & Wilson and Grémillet, 1996 & $\mathrm{~T}_{\text {stomach }}{ }^{*}$ & STL & Diving depth, swim speed & Heat balance model \\
\hline & Emperor penguin & Ponganis et al., 2001 & $\begin{array}{l}\mathrm{T}_{\text {blood }}{ }^{*} \text { - inferior vena caval } \\
\mathrm{T}_{\text {peripheral }} \text { - abdominal }\end{array}$ & External logger & Diving depth & \\
\hline & & Ponganis et al., 2003 & $\begin{array}{l}\mathrm{T}_{\text {muscle }} \text { - pectoral } \\
\mathrm{T}_{\text {blood }} \text { - femoral, axillary, brachial, foot veins } \\
\mathrm{T}_{\text {peripheral }} \text { - subcutaneous and subfeather } \\
\mathrm{T}_{\text {stomach }}\end{array}$ & $\begin{array}{l}\text { External logger and } \\
\text { STP }\end{array}$ & $\begin{array}{l}\text { Diving depth, behavior via } \\
\text { video recording }\end{array}$ & \\
\hline
\end{tabular}


TABLE 1| Continued

\begin{tabular}{|c|c|c|c|c|c|c|}
\hline & Species & Study & Thermal Physiological Measurement(s) & Instrumentation & Other Measurement(s) & Derived Quantities \\
\hline & King penguin & Culik et al., 1996 & $\mathrm{~T}_{\text {deep }}-$ heart, liver, sternum & Implantable logger & Light levels & \\
\hline & & Handrich et al., 1997 & $\begin{array}{l}\mathrm{T}_{\text {stomach }} \\
\mathrm{T}_{\text {peripheral }} \text { - top and bottom abdominal }\end{array}$ & TTR & Diving depth & \\
\hline & & Schmidt et al., 2006 & $\begin{array}{l}\mathrm{T}_{\text {muscle }}-\text { pectoral } \\
\mathrm{T}_{\text {peripheral }} \text { - brood patch }\end{array}$ & External logger & In situ $T_{\text {water }}$, diving depth & \\
\hline & & Enstipp et al., 2017, 2019 & $T_{\text {peripheral }}-$ flank & Implantable logger & Diving depth & Heat loss model \\
\hline & Macaroni penguin & Green et al., 2003 & $\mathrm{~T}_{\text {peripheral }}$ - abdominal temperature & HRDL & $\mathrm{HR}$, diving depth & $\mathrm{O}_{2}$ consumption (HR) \\
\hline \multirow[t]{11}{*}{ Marine mammals } & Antarctic fur seal & Boyd, 2000 & $\begin{array}{l}\mathrm{T}_{\text {peripheral }}-\text { flank } \\
\mathrm{T}_{\text {skin }} \text { - flank }\end{array}$ & External logger & In situ $\mathrm{T}_{\text {water }}$ & Heat balance model \\
\hline & California sea lion & Villegas-Amtmann et al., 2012 & $\mathrm{~T}_{\text {stomach }}{ }^{*}$ & STT with HTR & & Total body $\mathrm{O}_{2}$ stores \\
\hline & Northern elephant seal & Andrews, $1999^{+}$ & $\begin{array}{l}T_{\text {peripheral }} \text { - subcutaneous blubber, blubber-muscle } \\
\text { interface } \\
T_{\text {muscle }}{ }^{*} \text { (see section "Regional Heterothermy vs. } \\
\text { Hypothermy") }\end{array}$ & External logger & $\begin{array}{l}\text { HR, diving depth, swim } \\
\text { speed }\end{array}$ & $\begin{array}{l}\text { Field metabolic rate } \\
\text { (DLW) }\end{array}$ \\
\hline & & Meir and Ponganis, 2010 & $\mathrm{~T}_{\text {blood }}{ }^{*}-$ arterial and venous & External logger & Blood $\mathrm{P}_{\mathrm{O} 2}$, diving depth & \\
\hline & Weddell seal & Hill et al., 1987 & $\mathrm{~T}_{\text {blood }}{ }^{*}$ - aortic & $\begin{array}{l}\text { Thermistor-tipped } \\
\text { catheter }\end{array}$ & HR, blood samples & \\
\hline & & Ponganis et al., 1993 & $\mathrm{~T}_{\text {muscle }}-$ muscle & external logger & Swim velocity & \\
\hline & & Willis and Horning, 2005 & $\begin{array}{l}\text { HF - hips, flank, shoulders, axilla } \\
T_{\text {skin }} \text { - hips, flank, shoulders, } \\
\text { IRT }^{\Delta}\end{array}$ & $\begin{array}{l}\text { External logger with } \\
\text { HF sensors, FLIR } \\
\text { ThermaCam PM } \\
695\end{array}$ & & Metabolic rate (HF) \\
\hline & & Hindle et al., 2015 & $\begin{array}{l}\text { HF - head, neck, axilla, flank } \\
T_{\text {skin }}-\text { head, neck, axilla, flank } \\
T_{\text {stomach }}{ }^{*} \text { (STP) } \\
\text { IRT' } \\
\text { IFLIR P25 or P640) }\end{array}$ & $\begin{array}{l}\text { External logger with } \\
\text { HF sensors }\end{array}$ & Diving depth, acceleration & $\begin{array}{l}\text { Total body heat } \\
\text { dissipation }\end{array}$ \\
\hline & Dolphins & $\begin{array}{l}\text { Pabst et al., } 2002 \\
\text { Spotted }^{a} \text { and Spinner }\end{array}$ & $\begin{array}{l}\mathrm{HF}^{\mathrm{a}}-\text { dorsal fin } \\
\mathrm{T}_{\text {deee }}{ }^{* \Delta}-\text { colonic }^{a} \\
\mathrm{IRT}^{\mathrm{T} \Delta}\end{array}$ & $\begin{array}{l}20 \mathrm{~cm} \text { deep, } \\
\text { thermocouple, FLIR } \\
\text { Agema } 570\end{array}$ & $\begin{array}{l}\text { Twater, diving depth, swim } \\
\text { velocity }\end{array}$ & \\
\hline & & $\begin{array}{l}\text { Barbieri et al., } 2010 \\
\text { Bottlenose }\end{array}$ & $\mathrm{IRT}^{\Delta}$ & FLIR Agema 570 & $T_{\text {water }}$ & $\Delta \mathrm{T}_{\text {fin-water }}$ \\
\hline & & $\begin{array}{l}\text { Westgate et al., 2007XM } \\
\text { Bottlenose and Spotted }\end{array}$ & $\begin{array}{l}\text { HF - dorsal fin } \\
T_{\text {skin }} \text { - dorsal fin }\end{array}$ & HF disks & $\begin{array}{l}\text { In situ } T_{\text {water }} \text {, diving depth, } \\
\text { swim velocity }\end{array}$ & Trial test - Bottlenose \\
\hline
\end{tabular}

We included studies that performed field measurements of a thermal physiological variable(s) on free-ranging, diving animals. Two forms of remote measurement are possible on free-ranging animals. For thermal physiological measurements, telemeters that transmit summarized data include STT/STP, Stomach temperature telemeter or transmitter/pill. Otherwise, data is stored onboard data loggers or recorders: STL, Stomach temperature logger; TTR, Time temperature recorder; TDTR, Time depth temperature recorder; HTR, Heart temperature recorder; HRDL, Heart rate data logger. Symbols are used to denote the following: *used as proxy for core body temperature; ${ }^{x}$ part of the study was performed in the lab; ${ }^{\Delta}$ measurement performed at the surface or while handling animal; ${ }^{\bar{M}}$ methodology paper; ${ }^{+}$dissertation research. 
animal's anatomy, coupled with the specific research question of interest. The following section focuses on temperature measurements in marine divers (for a thorough review of temperature measurements on free-ranging birds and mammals, see McCafferty et al., 2015).

Skin and subcutaneous temperatures have revealed the ability of several species of divers to cool their periphery and employ regional heterothermy (Irving et al., 1962; McGinnis, 1975; Ponganis et al., 2003; Schmidt et al., 2006). As blood flow measurements have only been done in laboratory setting (Zapol et al., 1979; Bevan and Butler, 1992; Hochscheid et al., 2002), fine-scale changes in peripheral temperatures can be used as a proxy for peripheral perfusion in free-ranging divers. On the other hand, changes in peripheral temperatures over long periods reflect changes in the insulation layer. For example, Enstipp et al. (2017) found minimum and maximum subcutaneous temperatures measured in juvenile king penguins occurred during diving and surface intervals, respectively, reflecting patterns of peripheral perfusion. They attributed a decline in the weekly average subcutaneous temperatures to increased insulation associated with a thicker fat layer accumulated over their year-long foraging trip during their dispersal phase. In contrast to pre-molt trips, periods of normothermic temperatures were longer and even occurred during some shallow dives during post-molt trips, underscoring the physiological need to restore their insulation layer after fasting for the duration of the molt on land (Enstipp et al., 2019). This example highlights the importance of considering how seasonal changes and varying energetic challenges across different life stages might influence thermoregulatory strategies.

While peripheral temperatures may provide insight into heterothermy and vasomotor control of heat dissipation, it is difficult to conclude whether an animal is effectively maintaining thermal balance without measuring their core body temperature. While rectal and cloacal temperatures are used to assess core body temperature, it is difficult to obtain long-term continuous measurements from this site. Probe placement is critical as unrepresentative cooler temperatures may be obtained that may lead to misinterpretations about true body temperature (e.g., too shallow or near the CCHE for animals with intra-abdominal testes; Mrosovsky and Pritchard, 1971; Stahel and Nicol, 1982; Rommel et al., 1994).

Therefore, field studies have relied on stomach temperature telemeters or thermistors inserted into the body to determine proxies for core body temperature. Stomach temperature telemeters are less-invasive but may not work as well for animals that regurgitate or pass the sensor quickly through their gut. Some studies have modified the sensor housing to increase retention time (Sato et al., 1994; Wilson et al., 1998; Austin et al., 2006; Kuhn and Costa, 2006). When used for identifying core body temperatures, the temperature data must be analyzed appropriately to account for the temperature drop associated with the ingestion of cold prey or water (Wilson et al., 1992a; Grémillet et al., 1998). While perhaps a nuisance for analyzing core body temperature, this temperature signal associated with ingestion has been useful for studying the thermal and metabolic effects of HIF in the lab as well as determining feeding events in the wild
(Wilson et al., 1995, 2002; Hedd et al., 1996; Kato et al., 1996; Kuhn et al., 2009; Simmons et al., 2010; Heide-Jørgensen et al., 2014; Vacquié-Garcia et al., 2015).

A combination of simultaneous measurements of the core body and peripheral temperatures in free-ranging animals will be necessary to unravel the conflicting demands of diving behavior and ambient temperature on the spatial and temporal distribution of heat throughout the body (McGinnis, 1975; Culik et al., 1996; Handrich et al., 1997; Andrews, 1999; Ponganis et al., 2003; Niizuma et al., 2007). Whenever possible simultaneous measurements at multiple sites should be taken and will identify which locations accurately reflect core body temperature.

\section{Heat Flux}

Most heat flux studies have been performed on captive animals using handheld devices, which measure the amount of heat transferred per unit area per unit time (Hampton et al., 1971; McGinnis et al., 1972; Hampton and Whittow, 1976; Heath and Ridgway, 1999; Noren et al., 1999; Williams et al., 1999b; Erdsack et al., 2018). Willis and Horning (2005) and Westgate et al. (2007) measured heat flux in free-ranging Weddell seals and dolphins using packages specifically designed for their study species. Similar attachment methods used with sea turtles in the lab also show promise for field applications (Heath and McGinnis, 1980; Bostrom et al., 2010). However, heat flux measurements on animals with dense fur or feathers will be compromised if the area is shaved/plucked to ensure good contact between the sensor and skin. To circumvent this issue, Boyd (2000) avoided this problem by using two thermistors to measure the temperature gradient across the fur and modeled heat transfer in Antarctic fur seals.

Heat flux measurements have improved our understanding of the spatial variability of heat transfer across the body surface and how it is affected by changes in insulation, peripheral perfusion, behavior, and water temperature. By comparing heat flux at multiple body sites in relation to water temperature and activity level in the lab, thermal windows have been identified in various species: dorsal fin and flippers in dolphins (Hampton et al., 1971; McGinnis et al., 1972; Heath and Ridgway, 1999; Noren et al., 1999; Williams et al., 1999b; Meagher et al., 2008), fluke and flippers in manatees (Erdsack et al., 2018), flippers in seals (Kvadsheim and Folkow, 1997), and soft white skin areas in turtles (Heath and McGinnis, 1980; Standora et al., 1982). Unlike the dorsal fin of dolphins, heat flux sensors have not been attached to the highly maneuverable flippers of sea lions or fur seals and the wings of penguins to confirm the role of these appendages as thermal windows (Goldsmith and Sladen, 1961; Hindle et al., 2015).

\section{Quantifying Dynamic Properties of Insulation}

Another important, but often overlooked, consideration is the dynamic changes that occur in insulation. Blubber varies in thickness and composition depending on nutritional requirements, whereas feathers and fur may vary in condition based on how recently they were molted or maintained. While these issues may only arise when collecting data over seasons, 


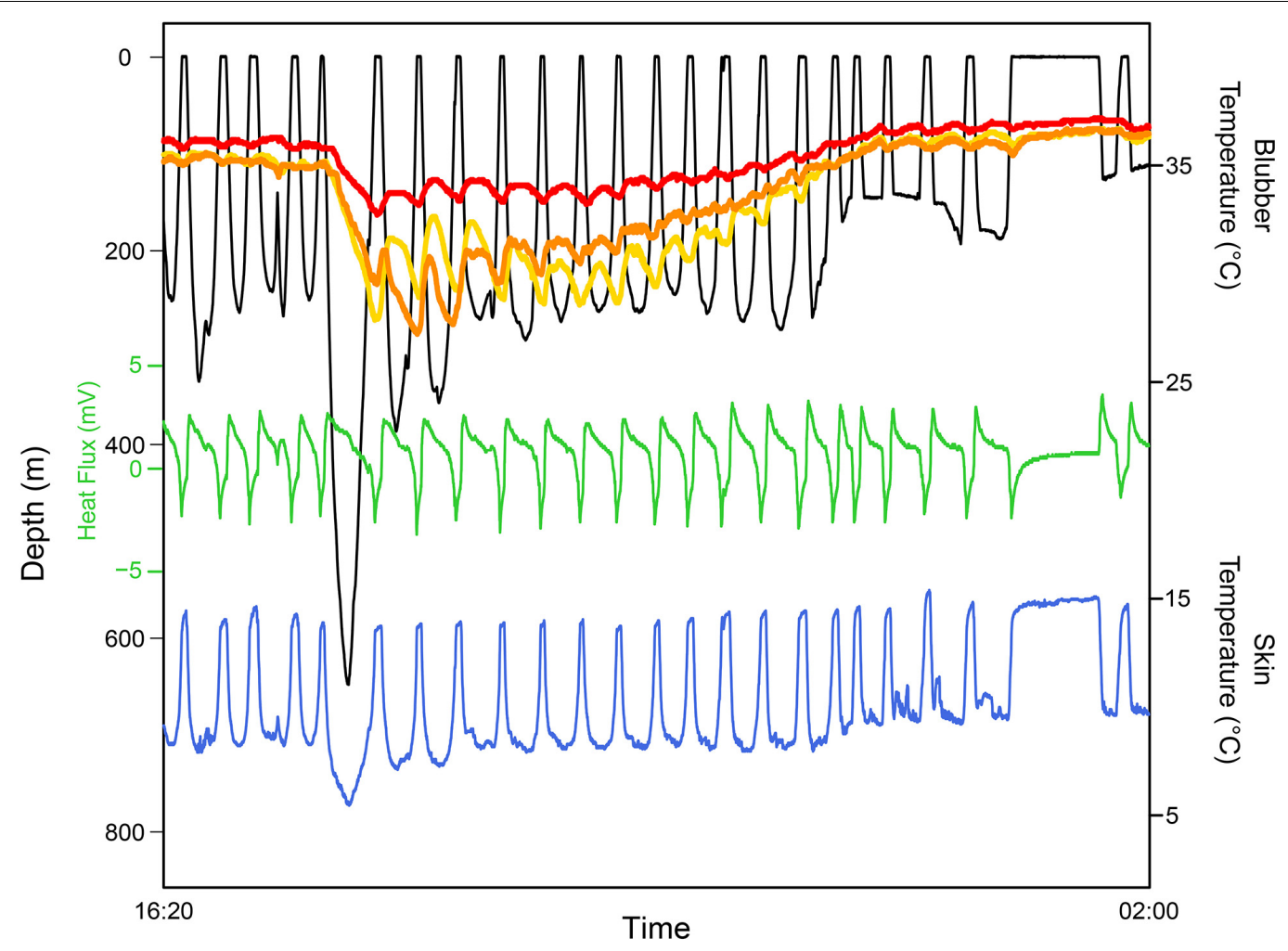

FIGURE 10 | An example of time series data from a freely diving juvenile Northern elephant seal, Mirounga angustirostris, over a short at-sea trip equipped with physiological biologgers that measure heat flux and body temperatures. The dive profile (black) shows a deep dive to $>600 \mathrm{~m}$ followed by an extended surface interval many hours later. The heat flux profile (green) - shown in raw voltage units-indicates whether the seal is gaining ( $<0 \mathrm{mV}$ ) or losing heat ( $>0 \mathrm{mV}$. Skin temperature (blue) measured by a thermistor imbedded in the heat flux sensor remained near water temperature (not shown; measured by a thermistor on the satellite tag mounted on the seal's head). Three thermistors inserted into the blubber layer (red, deep; orange, mid; yellow, shallow) show how the blubber temperature gradient changes with diving behavior, suggesting changes in peripheral perfusion (Favilla, unpublished).

insulation will change during a dive for animals that rely on fur or feathers.

A fundamental property of insulation is its thermal conductivity, which has been determined for blubber and fur from sculp samples of various species (Figure 6; Kvadsheim et al., 1994, 1996; Dunkin et al., 2005; Bagge et al., 2012; Liwanag et al., 2012a,b; Horgan et al., 2014). These studies provided a single, species-specific value for thermal conductivity, as is appropriate for ex vivo measurements. However, in vivo conductivity will vary during the dive due to changes in perfusion of the blubber layer or compression of fur/feathers at depth (Kvadsheim and Aarseth, 2002). Using ex vivo values in equations for modeling heat transfer of diving animals may result in inaccurate physiological conclusions (Kvadsheim et al., 1997).

The effects of hydrostatic pressure on the effectiveness of fur/feathers have been measured (Scholander et al., 1950; Kooyman et al., 1976; Blix et al., 1979a,b; Kvadsheim and Aarseth, 2002; Sharma and Liwanag, 2017). The results were used to estimate the retention of an air layer and the external insulation layer upon submersion (Grémillet et al., 1998; Fish et al., 2002). While marine mammals do not have arrector pili muscles, pilomotor adjustments in seabirds may need additional consideration (Kooyman et al., 1976; Lovvorn and Jones, 1991).
For example, penguins actively compress their feathers down to $5 \mathrm{~mm}$ thick upon submergence forming a thin, tight layer which helps prevent wetting of the skin (Kooyman et al., 1973). Despite compromising their insulation, deep divers in particular benefit from creating this water-tight barrier to minimize heat loss at depth where hydrostatic pressure will decrease their plumage air layer regardless (Kooyman et al., 1976).

On the other hand, the effects of peripheral perfusion on blubber conductivity have not been widely addressed, perhaps due to the difficulty of simulating conditions in the laboratory, as is possible with the compression of fur/feathers. The few instances where in vivo blubber conductivity was determined for an animal in the water revealed significantly higher values than excised blubber and varied with water temperature (Hart and Irving, 1959; Kanwisher and Sundnes, 1966). Similar approaches could be used to determine blubber conductivity in a free-ranging diver by obtaining three concurrent in vivo measurements: heat flux, subcutaneous temperature, and the temperature at the blubber-muscle interface (Figure 10). Measurements of in vivo blubber conductivity can serve as a proxy for peripheral perfusion as blubber conductivity will vary during the dive relative to the level of peripheral vasoconstriction. 


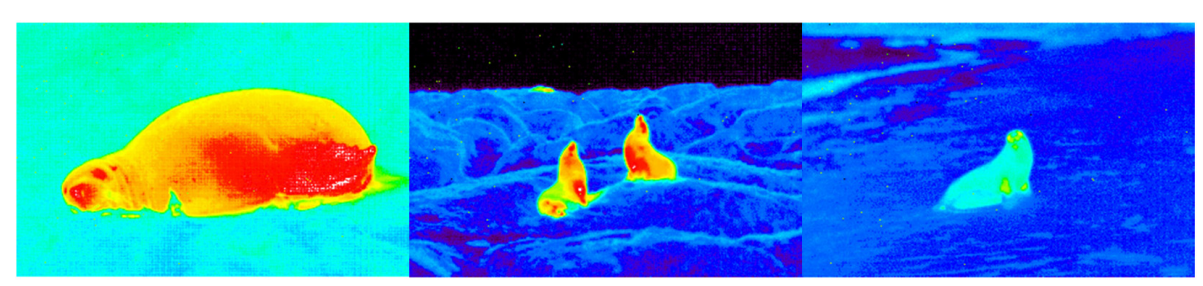

FIGURE 11 | Infrared thermographic images of Australian sea lions, Neophoca cinerea, on Kangaroo Island, South Australia where areas with warmer colors indicate higher temperatures and thus greater heat loss. Left image, a female sea lion hauled out on the beach. The greatest heat loss is through the eyes, nose and flippers. Middle image, two sea lions appear considerably warmer than the surrounding habitat. Notice that the flippers are significant thermal windows. Right image, a female sea lion is just coming out of the water. Although the animal has significantly lower heat loss than the previous two images where the animals had been out of the water for some time, the female is still losing some heat from the eyes and the base of the fore flippers. Photos by Heather Liwanag.

\section{Infrared Thermography: An Informative Tool}

There is a logistical and ethical limit to how many sensors are used and sites measured on an animal simultaneously. Infrared thermography (IRT) allows temperature across the entire body surface to be determined from an image, which makes it an extremely useful tool for studying the thermal physiology of animals on land (Speakman and Ward, 1998; McCafferty, 2007; McCafferty et al., 2011; Tattersall, 2016). Furthermore, IRT can be applied at the population level (e.g., aerial surveys, long-term monitoring and conservation efforts; Pabst et al., 2002; Udevitz et al., 2008; Horton et al., 2017) to study the thermal ecology and habitat range of a species, which is crucial particularly in light of recent studies that highlight the differential vulnerability of marine species to climate change (Hamann et al., 2013; Albouy et al., 2020). Unfortunately, water absorbs infrared radiation precluding its use underwater, but IRT has been used to study thermoregulation of amphibious marine vertebrates while on land (Figure 11; Willis et al., 2005; Nienaber et al., 2010; McCafferty et al., 2013; Mellish et al., 2015; Chaise et al., 2019), as well as some divers while at the surface (Cuyler et al., 1992; Perryman et al., 1999; Pabst et al., 2002; Barbieri et al., 2010).

While limited in its applicability to freely diving animals, this technology can serve to examine how anatomy influences heat transfer and better inform the placement of sensors. IRT images of seals after exiting the water (Mauck et al., 2003; Erdsack et al., 2012) or during moments of heat stress (Norris et al., 2010; Codde et al., 2016) have revealed the dynamics of thermal windows while on land, verifying the role of broadly distributed AVAs to control heat exchange. Hindle et al. (2015) used IRT on Weddell seals to determine the placement of heat flux sensors that best represented heat flux across the entire body and then extrapolated these measurements to estimate whole-body thermal dynamics. Similarly, IRT of dolphin dorsal fins revealed different surface temperatures that correspond to the underlying vasculature (Pabst et al., 2002). By comparing heat flux from sensors placed directly over or away from superficial veins, Meagher et al. (2002) found heat flux values were influenced by the underlying vasculature, particularly when taken underwater, demonstrating the importance of sensor location.

\section{Other Valuable Concurrent Measurements}

A suite of other measurements can contribute to an integrated understanding of physiology, energetics, and environmental factors. For example, a time-depth and temperature recorder can provide in situ water temperature measurements at the scale and resolution of the animal's behavior and are essential for contextualizing physiological responses relative to diving behavior and the thermal challenge imposed by the environment. Metabolic rate is an important factor for determining the rate of heat production, but because direct measurement through respirometry is challenging on free-ranging animals, field metabolic rate can be estimated using the doubly labeled water method and heart rate (for an assessment of the methods, see Costa, 1988; Butler et al., 2004; Sparling et al., 2008; Speakman and Hambly, 2016).

Heart rate is a useful measure of the dive response (Irving et al., 1941; Murdaugh et al., 1961; Thompson and Fedak, 1993; Hindle et al., 2010). While the onset and intensity of bradycardia only provide limited information on circulatory adjustments, measurements of blood flow have been made on captive animals using intravascular sensors as well as noninvasive Doppler flow sensors (Bevan and Butler, 1992; West et al., 1992; Jobsis et al., 2001; Hochscheid et al., 2002), and more recently, near-infrared spectroscopy (Williams et al., 2011; McKnight et al., 2019). Incorporating these noninvasive sensors into biologgers for deployment on freeranging animals to directly measure circulatory changes would provide key insights into how diving animals coordinate their responses to meet thermoregulatory demands. Finally, sensors that measure variables related to locomotion (e.g. swim speed sensor, accelerometer, gyroscope, magnetometer) can help link the contribution of swimming activity to thermal substitution (Davis et al., 2003; Mitani et al., 2010).

\section{Future Directions for Methodologies}

The disparity among the number of studies of different taxonomic groups, and even species, underscores the challenges of studying freely diving animals, particularly their physiology (Andrews and Enstipp, 2016). The development of novel attachment methods will be critical to apply new sensor technologies to measure physiological variables. Most currently 
available devices require the temporary restraint of animals to allow sensor and datalogger attachment. Unfortunately, this has limited their use on large cetaceans, but recent developments have enabled studies of their diving behavior and kinematics (Baird, 1998; Szesciorka et al., 2016; Goldbogen et al., 2017). Sensors are typically attached with suction cup tags or darts with little control over their placement. Despite these challenges, a recent study obtained the first heart rate measurements from a blue whale using a suction cup biologger, demonstrating the possibility of incorporating physiological sensors into existing tag designs (Goldbogen et al., 2019).

Nevertheless, it is still unknown how large cetaceans maintain thermal balance in their tropical breeding grounds while they are adapted to conserve heat in their polar foraging grounds (Brodie and Paasche, 1985; Kasting et al., 1988; Lavigne et al., 1990). The interplay between thermoregulation and the energetics of lunge feeding also provides an exciting area of research. Because so little is known about how they manage these thermal challenges given their large size, it would be valuable to develop tags that measure other physiological variables relevant to thermal physiology. For example, introducing thermistors into the tips of dart tags to measure blubber temperature, or integrating a heat flux sensor into large suction cups-similar to the integration of the ECG electrodes (Goldbogen et al., 2019) — could provide novel insight into their thermoregulatory strategies.

\section{CONCLUDING REMARKS}

The value of laboratory studies for studying physiology and aiding the interpretation of physiological data from field studies-where the natural environment introduces many confounding variables-cannot be understated. However, if we want to know how animals manage the thermal challenges of their environments, it is necessary to study their physiology in the wild (Costa and Sinervo, 2004).

The following questions highlight some important gaps in our understanding of the thermoregulation of marine air-breathers.

(1) To what extent is the dive response modulated by thermoregulation? Some laboratory studies have shown that under heat stress conditions-such as during intense exercise or heating of the hypothalamic region of the brain during a forced submersion-some degree of vasodilation is maintained, suggesting thermoregulatory responses are capable of overriding the dive response under extreme conditions (Hammel et al., 1977; Williams et al., 1999 b). Such a response would require a relaxation of peripheral vasoconstriction, resulting in increased oxygen consumption and thus decreased aerobic diving capacity. Field studies would provide the opportunity to address whether such situations occur in nature where overriding the dive response, and incurring the associated costs, to avoid thermal imbalance would be beneficial.

(2) When are thermal responses actively regulated, and when are they passive? Previous research studies have suggested that vascular changes are active thermoregulatory mechanisms (Hart and Irving, 1959; Hampton and Whittow, 1976; Heath and McGinnis, 1980; Schmidt et al., 2006). Passive responses are those that occur secondary to the dive response, ambient water temperatures, size or morphological adaptations (Sato, 2014). Although strategies fall along a continuum, Lovvorn (2007) suggested that the timescales at which the effects of active and passive mechanisms are observed differ and could therefore be used as a way to distinguish between the two, given appropriate sampling rates. Furthermore, understanding what factors dictate whether thermal responses are active or passive under natural conditions is critical for assessing thermoregulatory costs and the effects on overall energetic balance (Lovvorn, 2007).

(3) At what timescale is thermal balance maintained and how does it compare across taxonomic groups, age classes and sex? Since physiological time is dependent on metabolism which in turn depends on size (SchmidtNielsen, 1984), it is reasonable to predict that the timescale at which thermal balance is maintained will differ between divers and result in varying levels of thermal resilience. The smallest and largest animals in each taxonomic group exhibit the extremes in terms of thermal inertia and stability. Small animals and juveniles, who may also not have well-developed thermal capabilities, are likely to experience larger fluctuations in their temperature. In contrast, large animals have the advantage of relying on thermal inertia to conserve heat, which can be particularly beneficial for deep divers. However, their relatively small SA:V could also increase their vulnerability to heat stress when exposed to warmer environments. It would be interesting to know if they have control over the timescales at which they maintain thermal balance. Such a strategy would be similar in concept to animals that strategically deviate from homeostasis at times for either energetic savings (e.g., facultative hypometabolic states) or enhanced performance of certain activities at the cost of others (e.g., temporal separation of diving and/or foraging and thermoregulation; Costa and Kooyman, 1984; Wilson and Culik, 1991; Noren et al., 1999; Williams et al., 1999b). When physiological limits are reached, active regulatory mechanisms may serve to induce faster changes in their heat balance than would passive mechanisms and restore homeostasis. Assessing when deviations from thermal homeostasis occur requires first defining normothermia and understanding how diving activity might shift the body temperature set-point (Boyd and Sladen, 1971; Stahel and Nicol, 1982).

(4) How is thermoregulation affected by tagging, handling and disturbance? Because stress responses often lead to changes in physiological temperature, it is important to consider how our interactions with the animals affect their thermoregulation. The implications of such activities could range from obtaining data that is unrepresentative of the animal in its natural state to population level consequences of disturbance. Despite our incomplete understanding of how they manage potentially conflicting demands, it 
is clear that marine air-breathers are well-adapted for the physiological challenges presented in the marine environment. However, it is unclear whether additional anthropogenic stressors would exacerbate currently manageable thermal conflicts and lead to physiological imbalance. Various stress responses have been observed in diving animals, including an unanticipated prolongation of the dive (i.e., dive inversion) and an up-regulation of the dive response despite increased activity levels associated with an escape response (Fregosi et al., 2016; Williams et al., 2017). The effects of these responses on an animal's thermal balance has yet to be investigated. For example, several studies have found evidence for pressure-related injuries in whales from mass-strandings that coincided with military exercises using sonar (Bernaldo De Quirós et al., 2019). Yet, the observation that these strandings have occurred in warmwater regions warrants further investigation into whether thermal imbalance could have exacerbated an already precarious condition and contributed to the strandings (Filadelfo et al., 2009; Weise, 2009). A better understanding of the plasticity of their physiological adaptations under natural conditions would inform the analysis and mitigation of biologically significant responses to anthropogenic disturbances and changing environmental conditions.

This list is by no means exclusive and only serves to direct future research efforts towards topics that will ultimately advance our understanding of how marine air-breathers function and maintain homeostasis in a challenging environment. The current state and possible advances of physiological biologgers suggest a bright future for the study of thermal physiology of airbreathing marine divers.

\section{REFERENCES}

Albouy, C., Delattre, V., Donati, G., Frölicher, T. L., Albouy-boyer, S., Ru, M., et al. (2020). Global vulnerability of marine mammals to global warming. Nat. Sci. Rep. 10, 1-12. doi: 10.1038/s41598-019-57280-3

Andersen, S. H., and Nielsen, E. (1983). Exchange of water between the harbor porpoise, Phocoena phocoena, and the environment. Experientia 39, 52-53. doi: 10.1007/BF01960622

Andrews, R. D. (1999). The Cardiorespiratory, Metabolic, and Thermoregulatory Physiology of Juvenile Northern Elephant Seals (Mirounga angustirostris). PhD dissertation., University of British Columbia, Vancouver.

Andrews, R. D., and Enstipp, M. R. (2016). Diving physiology of seabirds and marine mammals: relevance, challenges and some solutions for field studies. Comp. Biochem. Physiol. Part A 202, 38-52. doi: 10.1016/j.cbpa.2016. 07.004

Austin, D., Bowen, W. D., McMillan, J. I., and Boness, D. J. (2006). Stomach temperature telemetry reveals temporal patterns of foraging success in a freeranging marine mammal. J. Anim. Ecol. 75, 408-420. doi: 10.1111/j.1365-2656. 2006.01057.x

Bagge, L. E., Koopman, H. N., Rommel, S. A., McLellan, W. A., and Pab, D. A. (2012). Lipid class and depth-specific thermal properties in the blubber of the short-finned pilot whale and the pygmy sperm whale. J. Exp. Biol. 215, 4330-4339. doi: 10.1242/jeb.071530

Baird, R. W. (1998). Studying diving behavior of whales and dolphins using suction-cup attached tags. Whalewatcher 32, 3-7.

\section{AUTHOR CONTRIBUTIONS}

$\mathrm{ABF}$ carried out the literature review and wrote the manuscript. DPC provided the input and edited the manuscript. All authors contributed to the article and approved the submitted version.

\section{FUNDING}

This review was supported by the National Science Foundation Graduate Research Fellowship to $\mathrm{ABF}$ and grants from the Office of Naval Research (N00014-18-1-2822) and NSF OPP (1644256) to DPC.

\section{ACKNOWLEDGMENTS}

We thank L. A. Hückstädt for bringing this special issue topic to our attention and providing feedback on the manuscript. We also thank S. K. Adamczak, R. S. Beltran, N. Frasson, T. R. Keates, K. A. Kelly, S. C. Kienle, and A. ValenzuelaToro for comments that greatly contributed to the manuscript. In the figures, all the animal images were downloaded from phylopic.org, including the dolphin and humpback whale which are from Chris Huh (https://creativecommons.org/licenses/by$\mathrm{sa} / 3.0 /)$.

\section{SUPPLEMENTARY MATERIAL}

The Supplementary Material for this article can be found online at: https://www.frontiersin.org/articles/10.3389/fevo.2020. 555509/full\#supplementary-material

Barbieri, M. M., McLellan, W. A., Wells, R. S., Blum, J. E., Hofmann, S., Gannon, J., et al. (2010). Using infrared thermography to assess seasonal trends in dorsal fin surface temperatures of free-swimming bottlenose dolphins (Tursiops truncatus) in Sarasota Bay, Florida. Mar. Mammal Sci. 26, 53-66. doi: 10.1111/ j.1748-7692.2009.00319.x

Beentjes, M. P. (2006). Behavioral thermoregulation of the New Zealand sea lion (Phocarctos hookeri). Mar. Mammal Sci. 22, 311-325. doi: 10.1111/j.1748-7692. 2006.00022.x

Berkson, H. (1967). Physiological adjustments to deep diving in the Pacific green turtle (Chelonia mydas agassizii). Comp. Biochem. Physiol. 21, 507-524. doi: 10.1016/0010-406x(67)90448-3

Bernaldo De Quirós, Y., Fernandez, A., Baird, R. W., Brownell, R. L., Aguilar De Soto, N., Allen, D., et al. (2019). Advances in research on the impacts of anti-submarine sonar on beaked whales. Proc. R. Soc. B 286:20182533. doi: 10.1098/rspb.2018.2533

Berta, A. (2018). "Pinnipeds," in Encyclopedia of Marine Mammals, eds B. Würsig, J. G. M. Thewissen, and K. M. Kovacs (San Diego, CA: Academic Press), 733-740. doi: 10.1016/B978-0-12-804327-1.00199-0

Bevan, R. M., Boyd, I. L., Butler, P. J., Reid, K., Woakes, A. J., and Croxall, J. P. (1997). Heart rates and abdominal temperatures of freeranging South Georgian shags, Phalacrocorax georgianus. J. Exp. Biol. 200, 661-675.

Bevan, R. M., and Butler, P. J. (1992). Cardiac output and blood flow distribution during swimming and voluntary diving of the tufted duck (AYthya FUligula). J. Exp. Biol. 168, 199-217. 
Blix, A. S., Grav, H. J., and Ronald, K. (1979a). Some aspects of temperature regulation in newborn harp seal pups. Am. J. Physiol. 236, R188-R197.

Blix, A. S., Miller, L. K., Keyes, M. C., Grav, H. J., and Elsner, R. (1979b). Newborn northern fur seals (Cullorhinus zlrsinus)-do they suffer from cold? Am. J. Physiol. 236, R322-R327.

Blix, A. S., Walløe, L., Messelt, E. B., and Folko, L. P. (2010). Selective brain cooling and its vascular basis in diving seals. J. Exp. Biol. 213, 2610-2616. doi: $10.1242 /$ jeb. 040345

Boily, P. (1995). Theoretical heat flux in water and habitat selection of phocid seals and beluga whales during the annual Molt. J. Theor. Biol. 172, 235-244. doi: 10.1006/jtbi.1995.0020

Bostrom, B. L., Fahlman, A., and Jones, D. R. (2008). Tracheal compression delays alveolar collapse during deep diving in marine mammals. Respir. Physiol. Neurobiol. 161, 298-305. doi: 10.1016/j.resp.2008.03.003

Bostrom, B. L., and Jones, D. R. (2007). Exercise warms adult leatherback turtles. Comp. Biochem. Physiol. Part A 147, 323-331. doi: 10.1016/j.cbpa.2006.10.032

Bostrom, B. L., Jones, T. T., Hastings, M., and Jones, D. R. (2010). Behaviour and physiology: the thermal strategy of leatherback turtles. PLoS ONE 5:e13925. doi: 10.1371/journal.pone. 0013925

Boyd, I. L. (1997). The behavioural and physiological ecology of diving. Trends Ecol. Evol. 12, 213-217. doi: 10.1016/s0169-5347(97)01054-9

Boyd, I. L. (2000). Skin temperatures during free-ranging swimming and diving in antarctic fur seals. J. Exp. Biol. 203, 1907-1914.

Boyd, I. L., and Croxall, J. P. (1996). Dive durations in pinnipeds and seabirds. Can. J. Zool. 74, 1696-1705. doi: 10.1139/z96-187

Boyd, J. C., and Sladen, W. J. L. (1971). Telemetry studies of the internal body temperatures of adélie and emperor penguins at cape crozier, ross island, antarctica. Auk 88, 366-380. doi: 10.2307/4083885

Bradshaw, C. J. A., McMahon, C. R., and Hays, G. C. (2007). Behavioral inference of diving metabolic rate in free-ranging leatherback turtles. Physiol. Biochem. Zool. 80, 209-219. doi: 10.1086/511142

Broderick, A. C., Coyne, M. S., Fuller, W. J., Glen, F., and Godley, B. J. (2007). Fidelity and over-wintering of sea turtles. Proc. R. Soc. B Biol. Sci. 274, 15331538. doi: $10.1098 / \mathrm{rspb} .2007 .0211$

Brodie, P., and Paasche, A. (1985). Thermoregulation and energetics of fin and sei whales based on postmortem, stratified temperature measurements. Can. J. Zool. 63, 2267-2269. doi: 10.1139/z85-336

Bryden, M. M. (1968). Growth and function of the subcutaneous fat of the elephant seal. Nature 220, 597-599. doi: 10.1038/220597a0

Bryden, M. M., and Molyneux, G. S. (1978). Arteriovenous anastomoses in the skin of seals: II. The california sea lion zalophus californianus and the northern fur seal callorhinus ursinus (Pinnipedia: Otariidae). Anat. Rec. 96, 285-300. doi: $10.1159 / 000144680$

Butler, P. J. (2006). Aerobic dive limit. What is it and is it always used appropriately? Comp. Biochem. Physiol. - A Mol. Integr. Physiol. 145, 1-6. doi: 10.1016/j.cbpa. 2006.06.006

Butler, P. J., Green, J. A., Boyd, I. L., and Speakman, J. R. (2004). Measuring meatabolic rate in the field: the pros and cons of the doubly labeled water and heart rate methods. Funct. Ecol. 18, 168-183. doi: 10.1111/j.0269-8463.2004. 00821.x

Butler, P. J., and Jones, D. R. (1997). Physiology of diving of birds and mammals. Annu. Rev. Physiol. 60, 19-32. doi: 10.1152/physrev.1997.77.3.837

Butler, P. J., Milsom, W. K., and Woakes, A. J. (1984). Respiratory, cardiovascular and metabolic adjustments during steady state swimming in the green turtle, Chelonia mydas. J. Comp. Physiol. B 154, 167-174. doi: 10.1007/BF00684141

Carr, A., Ogren, L., and McVea, C. (1980). Apparent hibernation by the Atlantic loggerhead turtle Caretta caretta off cape canaveral, Florida. Biol. Conserv. 19, 7-14. doi: 10.1016/0006-3207(80)90011-7

Casey, J. P., James, M. C., and Williard, A. S. (2014). Behavioral and metabolic contributions to thermoregulation in freely swimming leatherback turtles at high latitudes. J. Exp. Biol. 217, 2331-2337. doi: 10.1242/jeb.100347

Castellini, M. (2007). "Thermoregulation," in Encyclopedia of Marine Mammals, eds W. Perrin, B. Würsig, and J. G. M. Thewissen (San Diego, CA: Academic Press), 115-120. doi: 10.1016/B978-0-12-374144-8.00079-5

Castellini, M. A., and Mellish, J.-A. (2015). Marine Mammal Physiology: Requisites for Ocean Living. Boca Raton, FL: CRC Press.
Castellini, M. A., Murphy, B. J., Fedak, M., Ronald, K., Gofton, N., and Hochachka, P. W. (1985). Potentially conflicting metabolic demands of diving and exercise in seals. J. Appl. Physiol. 58, 392-399. doi: 10.1152/jappl.1985.58.2.392

Chaise, L. L., McCafferty, D. J., Krellenstein, A., Gallon, S. L., Paterson, W. D., Théry, M., et al. (2019). Environmental and physiological determinants of huddling behavior of molting female southern elephant seals (Mirounga leonina). Physiol. Behav. 199, 182-190. doi: 10.1016/j.physbeh.2018.10.016

Chappell, M. A., Morgan, K. R., Souza, S. L., and Bucher, T. L. (1989). Convection and thermoregulation in two Antarctic seabirds. J. Comp. Physiol. B 159, 313-322. doi: 10.1007/bf00691511

Charnov, E. L. (1976). Optimal foraging theory: the marginal value theorem. Theor. Popul. Biol. 9, 129-136. doi: 10.1016/0040-5809(76)90040-X

Chilvers, B. L. (2018). "Eared seals," in Encyclopedia of Marine Mammals, eds B. Würsig, J. G. M. Thewissen, and K. M. Kovacs (San Diego, CA: Academic Press), 281-284. doi: 10.1016/b978-0-12-804327-1.00005-4

Ciancio, J. E., Flavio Quintana, Sala, J. E., and Wilson, R. P. (2016). Cold birds under pressure: can thermal substitution ease heat loss in diving penguins? Mar. Biol. 163, 1-15. doi: 10.1007/s00227-016-2813-2

Codde, S. A., Allen, S. G., Houser, D. S., and Crocker, D. E. (2016). Effects of environmental variables on surface temperature of breeding adult female northern elephant seals, Mirounga angustirostris, and pups. J. Therm. Biol. 61, 98-105. doi: 10.1016/j.jtherbio.2016.09.001

Cook, T. R., Kato, A., Tanaka, H., Ropert-Coudert, Y., and Bost, C. A. (2010). Buoyancy under control: underwater locomotor performance in a deep diving seabird suggests respiratory strategies for reducing foraging effort. PLOS ONE 5:e9839. doi: 10.1371/journal.pone.0009839

Corkeron, P. J., and Connor, R. C. (1999). Why do baleen whales migrate? Mar. Mammal Sci. 15, 1228-1245. doi: 10.1111/j.1748-7692.1999.tb00887.x

Costa, D. P. (1988). Methods for studying the energetics of freely diving animals. Can. J. Zool. 66, 45-52. doi: 10.1139/z88-006

Costa, D. P. (1991). "Reproductive and foraging energetics of pinnipeds: implications for life history patterns," in The Behaviour of Pinnipeds, ed. D. Renouf (New York, NY: Chapman and Hall), 300-344. doi: 10.1007/978-94011-3100-1

Costa, D. P. (2007). Diving physiology of marine vertebrates. Encycl. Life Sci. 1-7. doi: 10.1002/9780470015902.a0004230

Costa, D. P., Gales, N. J., and Goebel, M. E. (2001). Aerobic dive limit: how often does it occur in nature? Comp. Biochem. Physiol. Part A 129, 771-783. doi: 10.1016/s1095-6433(01)00346-4

Costa, D. P., and Kooyman, G. L. (1982). Oxygen consumption, thermoregulation, and the effect of fur oiling and washing on the sea otter, Enhydra lutris. Can. J. Zool. 60, 2761-2767. doi: 10.1139/z82-354

Costa, D. P., and Kooyman, G. L. (1984). Contribution of specific dynamic action to heat balance and thermoregulation in the sea otter Enhydra lutris. Physiol. Zool. 57, 199-203. doi: 10.1086/physzool.57.2.30163705

Costa, D. P., Kuhn, C. E., Weise, M. J., Shaffer, S. A., and Arnould, J. P. Y. (2004). When does physiology limit the foraging behaviour of freely diving mammals? Int. Congr. Ser. 1275, 359-366. doi: 10.1016/j.ics.2004.08.058

Costa, D. P., and Maresh, J. L. (2017). "Energetics," in Encyclopedia of Marine Mammals, eds B. Würsig, J. G. M. Thewissen, and K. Kovacs (San Diego, CA: Academic Press), 329-335.*

Costa, D. P., and Sinervo, B. (2004). Field physiology: physiological insights from animals in nature. Annu. Rev. Physiol. 66, 209-238. doi: 10.1146/annurev. physiol.66.032102.114245

Costa, D. P., and Trillmich, F. (1988). Mass changes and metabolism during the perinatal fast: a comparison between antarctic (Arctocephalus gazella) and Galápagos Fur Seals (Arctocephalus galapoensis). Physiol. Zool. 61, 160-169. doi: 10.1086/physzool.61.2.30156147

Costa, D. P., and Williams, T. M. (1999). "Marine mammal energetics," in Biology of Marine Mammals, eds J. Reynolds III and J. R. Twiss (Washington, DC: Smithsonian Institution Press), 176-217.

Crocker, D. E., Le Boeuf, B. J., and Costa, D. P. (1997). Drift diving in female northern elephant seals: implications for food processing. Can. J. Zool. 75, 27-39. doi: 10.1139/z97-004

Croll, D. A., and McLaren, E. (1993). Diving metabolism and thermoregulation in common and thick-billed murres. J. Comp. Physiol. B 163, 160-166. 
Croxall, J. P., Naito, Y., Kato, A., Rothery, P., and Briggs, D. R. (1991). Diving patterns and performance in the Antarctic blue-eyed shag Phalacrocorax atriceps. J. Zool. 225, 177-199. doi: 10.1111/j.1469-7998.1991.tb03810.x

Culik, B. M., Pütz, K., Wilson, R. P., Bost, C. A., Le Maho, Y., and Verselin, J. L. (1996). Core temperature variability in diving king penguins (Aptenodytes patagonicus): a preliminary analysis. Polar Biol. 16, 371-378. doi: 10.1007/ BF02342186

Cuyler, L. C., Wiulsrod, R., and Oritsland, N. A. (1992). Thermal infrared radiation from free living whales. Mar. Mammal Sci. 8, 120-134. doi: 10.1111/j.17487692.1992.tb00371.x

Daunt, F., Afanasyev, V., Adam, A., Croxall, J. P., and Wanless, S. (2007). From cradle to early grave: juvenile mortality in European shags Phalacrocorax aristotelis results from inadequate development of foraging proficiency. Biol. Lett. 3, 371-374. doi: 10.1098/rsbl.2007.0157

Davenport, J. (1997). Temperature and the life-history strategies of sea turtles. J. Therm. Biol. 22, 479-483. doi: 10.1016/s0306-4565(97)00066-1

Davenport, J., Fraher, J., Fitzgerald, E., McLaughlin, P., Doyle, T., Harman, L., et al. (2009). Fat head: an analysis of head and neck insulation in the leatherback turtle (Dermochelys coriacea). J. Exp. Biol. 212, 2753-2759. doi: 10.1242/jeb. 026500

Davenport, J., Holland, D. L., and East, J. (1990). Thermal and biochemical characteristics of the lipids of the leatherback turtle Dermochelys coriacea: evidence of endothermy. J. Mar. Biol. 70, 33-41. doi: 10.1017/S0025315400034172

Davenport, J., Jones, T. T., Work, T. M., and Balazs, G. H. (2015). Topsy-turvy: turning the counter-current heat exchange of leatherback turtles upside down. Biol. Lett. 11, 1-5. doi: 10.1098/rsbl.2015.0592

Davis, R. W. (2014). A review of the multi-level adaptations for maximizing aerobic dive duration in marine mammals: from biochemistry to behavior. J. Comp. Physiol. B 184, 23-53. doi: 10.1007/s00360-013-0782-z

Davis, R. W. (2019). Marine Mammals. Cham: Springer.

Davis, R. W., Castellini, M. A., Kooyman, G. L., and Maue, R. (1983). Renal glomerular filtration rate and hepatic blood flow during voluntary diving in Weddell seals. Am. J. Physiol. 245, R743-R748. doi: 10.1152/ajpregu.1983.245. 5.r743

Davis, R. W., Fuiman, L. A., Madden, K. M., and Williams, T. M. (2003). Classification and behavior of free-ranging Weddell seal dives based on threedimensional movements and video-recorded observations. Deep Res. Part II Top. Stud. Oceanogr. 88-89, 65-77. doi: 10.1016/j.dsr2.2012.07.006

Davis, R. W., Polasek, L., Watson, R., Fuson, A., Williams, T. M., and Kanatous, S. B. (2004). The diving paradox: new insights into the role of the dive response in air-breathing vertebrates. Comp. Biochem. Physiol. Part A 138, 263-268. doi: $10.1016 /$ j.cbpb.2004.05.003

Davis, R. W., and Williams, T. M. (2012). The marine mammal dive response is exercise modulated to maximize aerobic dive duration. J. Comp. Physiol. A 198, 583-591. doi: 10.1007/s00359-012-0731-4

Dawson, W. R., Bartholomew, G. A., and Bennett, A. F. (1977). A Reappraisal of the aquatic specializations of the galapagos marine iguana (Amblyrhynchus cristatus). Evolution (N. Y) 31, 891-897. doi: 10.2307/2407452

Domning, D. P. (2018). "Sirenian evolution," in Encyclopedia of Marine Mammals, eds B. Würsig, J. G. M. Thewissen, and K. M. Kovacs (San Diego, CA: Academic Press), 856-859. doi: 10.1016/b978-0-12-804327-1.00229-6

Donohue, M. J., Costa, D. P., Goebel, M. E., and Baker, J. D. (2000). The ontogeny of metabolic rate and thermoregulatory capabilities of northern fur seal, Callorhinus ursinus, pups in air and water. J. Exp. Biol. 203, 10031016.

Dunkin, R. C., McLellan, W. A., Blum, J. E., and Pabst, D. A. (2005). The ontogenetic changes in the thermal properties of blubber from Atlantic bottlenose dolphin Tursiops truncatus. J. Exp. Biol. 208, 1469-1480. doi: 10. 1242/jeb.01559

Ellis, H. I., and Gabrielsen, G. W. (2002). "Energetics of free-ranging seabirds," in Biology of Marine Birds, eds B. A. Schreiber and J. Burger (Boca Raton, FL: CRC Press), 359-408. doi: 10.1201/9781420036305.ch11

Elmegaard, S. L., Johnson, M., Madsen, P. T., and McDonald, B. I. (2016). Cognitive control of heart rate in diving harbor porpoises. Curr. Biol. 26, R1175-R1176. doi: $10.1016 /$ j.cub.2016.10.020

Elsner, R. (1969). "Cardiovascular adjustments to diving," in The Biology of Marine Mammals, ed. H. T. Anderson (New York: Academic Press), 117-145.
Elsner, R., Pirie, J., Kenney, D. D., and Schemmer, S. (1974). "Functional circulatory anatomy of cetacean appendages," in Functional Anatomy of Marine Mammals, ed. R. J. Harrison (London: Academic Press), 143-159.

Enstipp, M. R., Bost, C.-A., Le Bohec, C., Bost, C., Laesser, R., Le Maho, Y., et al. (2019). The dive performance of immature king penguins following their annual molt suggests physiological constraints. J. Exp. Biol. 222, 1-14. doi: $10.1242 /$ jeb. 208900

Enstipp, M. R., Bost, C.-A., Le Bohec, C., Bost, C., Le Maho, Y., Weimerskirch, H., et al. (2017). Apparent changes in body insulation of juvenile king penguins suggest an energetic challenge during their early life at sea. J. Exp. Biol. 220, 2666-2678. doi: 10.1242/jeb.160143

Enstipp, M. R., Grémillet, D., and Jones, D. R. (2008). Heat increment of feeding in double-crested cormorants (Phalacrocorax auritus) and its potential for thermal substitution. J. Exp. Biol. 211, 49-57. doi: 10.1242/jeb.012229

Enstipp, M. R., Grémillet, D., and Lorentsen, S. H. (2005). Energetic costs of diving and thermal status in European shags (Phalacrocorax aristotelis). J. Exp. Biol. 208, 3451-3461. doi: 10.1242/jeb.01791

Erdsack, N., Hanke, F. D., Dehnhardt, G., and Hanke, W. (2012). Control and amount of heat dissipation through thermal windows in harbor seals (Phoca vitulina). J. Therm. Biol. 37, 537-544. doi: 10.1016/j.jtherbio.2012.06.002

Erdsack, N., McCully Phillips, S. R., Rommel, S. A., Pabst, D. A., McLellan, W. A., and Reynolds, J. E. (2018). Heat flux in manatees: an individual matter and a novel approach to assess and monitor the thermal state of Florida manatees (Trichechus manatus latirostris). J. Comp. Physiol. B 188, 717-727. doi: 10.1007/ s00360-018-1152-7

Fahlman, A., Hooker, S. K., Olszowka, A., Bostrom, B. L., and Jones, D. R. (2009). Estimating the effect of lung collapse and pulmonary shunt on gas exchange during breath-hold diving: the Scholander and Kooyman legacy. Respir. Physiol. Neurobiol. 165, 28-39. doi: 10.1016/j.resp.2008.09.013

Falke, K. J., Hill, R. D., Qvist, J., Schneider, R. C., Guppy, M., Liggins, G. C., et al. (1985). Seal lungs collapse during free diving: evidence from arterial nitrogen tensions. Science 229, 556-558. doi: 10.1126/science.4023700

Faulkner, J. A., Zerba, E., and Brooks, S. V. (1990). Muscle temperature of mammals: cooling impairs most functional properties. Am. J. Physiol. - Regul. Integr. Comp. Physiol. 259, R259-R265. doi: 10.1152/ajpregu.1990.259.2.r259

Fedak, M. A., Pullen, M. R., and Kanwisher, J. (1988). Circulatory responses of seals to periodic breathing: heart rate and breathing during exercise and diving in the laboratory and open sea. Can. J. Zool. 66, 53-60. doi: 10.1139/z88-007

Felger, R. S., Cliffton, K., and Regal, P. J. (1976). Winter dormancy in sea turtles: independent discovery and exploitation in the gulf of california by two local cultures. Science 191, 283-285. doi: 10.1126/science.191.4224.283

Filadelfo, R., Mintz, J., Michlovich, E., D’Amico, A., Tyack, P. L., and Ketten, D. R. (2009). Correlating military sonar use with beaked whale mass strandings: what do the historical data show? Aquat. Mamm. 35, 435-444. doi: 10.1578/AM.35. 4.2009 .435

Fish, F. E. (2000). Biomechanics and energetics in aquatic and semiaquatic mammals: platypus to whale. Physiol. Biochem. Zool. 73, 683-698. doi: 10.1086/ 318108

Fish, F. E., Smelstoys, J., Baudinette, R. V., and Reynolds, P. S. (2002). Fur does not fly, it floats: buoyancy of pelage in semi-aquatic mammals. Aquat. Mamm. 28, $103-112$.

Foley, A. M., Singel, K. E., Dutton, P. H., Summers, T. M., Redlow, A. E., and Lessman, J. (2007). Characteristics of a green turtle (Chelonia mydas) assemblage in northwestern Florida determined during a hypothermic stunning event. Gulf Mex. Sci. 25, 131-143. doi: 10.18785/goms.2502.04

Fossette, S., Gleiss, A. C., Myers, A. E., Garner, S., Liebsch, N., Whitney, N. M., et al. (2010). Behaviour and buoyancy regulation in the deepest-diving reptile: the leatherback turtle. J. Exp. Biol. 213, 4074-4083. doi: 10.1242/jeb.048207

Frair, W., Ackman, R. G., and Mrosovsky, N. (1972). Body temperature of Dermochelys coriacea: warm turtle from cold water. Science 177, 791-793. doi: 10.1126/science.177.4051.791

Fregosi, S., Klinck, H., Horning, M., Costa, D. P., Mann, D., Sexton, K., et al. (2016). An animal-borne active acoustic tag for minimally invasive behavioral response studies on marine mammals. Anim. Biotelemet. 4:9. doi: 10.1186/s40317-0160101-z

Frost, P. G. H., Siegfried, W. R., and Greenwood, P. J. (1975). Arterio-venous heat exchange systems in the Jackass penguin Spheniscus demersus. J. Zool. 175, 231-241. doi: 10.1111/j.1469-7998.1975.tb01398.x 
Gallivan, G. J., and Best, R. C. (1980). Metabolism and respiration of the amazonian manatee (Trichechus inunguis). Physiol. Zool. 53, 245-253. doi: 10. 1086/physzool.53.3.30155787

Gallivan, G. J., Best, R. C., and Kanwisher, J. W. (1983). Temperature regulation in the amazonian manatee Trichechus inunguis. Physiol. Zool. 56, 255-262. doi: 10.1086/physzool.56.2.30156057

García-Párraga, D., Crespo-Picazo, J. L., De Quirós, Y. B., Cervera, V., MartíBonmati, L., Díaz-Delgado, J., et al. (2014). Decompression sickness ('the bends') in sea turtles. Dis. Aquat. Organ. 111, 191-205. doi: 10.3354/dao 02790

García-Párraga, D., Lorenzo, T., Wang, T., Ortiz, J. L., Ortega, J., Crespo-Picazo, J. L., et al. (2018a). Deciphering function of the pulmonary arterial sphincters in loggerhead sea turtles (Caretta caretta). J. Exp. Biol. 221, jeb.179820. doi: $10.1242 /$ jeb. 179820

García-Párraga, D., Moore, M., and Fahlman, A. (2018b). Pulmonary ventilationperfusion mismatch: a novel hypothesis for how diving vertebrates may avoid the bends. Proc. R. Soc. B 285:20180482. doi: 10.1098/rspb.2018.0482

Gearty, W., McClain, C. R., and Payne, J. L. (2018). Energetic tradeoffs control the size distribution of aquatic mammals. Proc. Natl. Acad. Sci. U. S. A. 115, 4194-4199. doi: 10.1073/pnas.1712629115

Godley, B. J., Richardson, S., Broderick, A. C., Coyne, M. S., Glen, F., and Hays, G. C. (2002). Long-term satellite telemetry of the movements and habitat utilisation by green turtles in the Mediterranean. Ecography (Cop.) 25, 352-362. doi: 10.1034/j.1600-0587.2002.250312.x

Goff, G. P., and Stenson, G. B. (1988). Brown adipose tissue in leatherback sea turtles: a thermogenic organ in an endothermic reptile? Copeia 1988, 10711075. doi: $10.2307 / 1445737$

Goldbogen, J. A., Cade, D. E., Boersma, A. T., Calambokidis, J., Kahane-Rapport, S. R., Segre, P. S., et al. (2017). Using digital tags with integrated video and inertial sensors to study moving morphology and associated function in large aquatic vertebrates. Anat. Rec. 300, 1935-1941. doi: 10.1002/ar.23650

Goldbogen, J. A., Cade, D. E., Calambokidis, J., Czapanskiy, M. F., Fahlbusch, J., Friedlaender, A. S., et al. (2019). Extreme bradycardia and tachycardia in the world's largest animal. Proc. Natl. Acad. Sci. U. S. A. 116, 25329-25332. doi: $10.1073 /$ pnas. 1914273116

Goldsmith, R., and Sladen, W. J. L. (1961). Temperature regulation of some antarctic penguins. J. Physiol. 157, 251-262. doi: 10.1113/jphysiol.1961. sp006719

Green, J. A., Butler, P. J., Woakes, A. J., and Boyd, I. L. (2003). Energetics of diving in macaroni penguins. J. Exp. Biol. 206, 43-57. doi: 10.1242/jeb.00059

Green, J. A., Frappell, P. B., Clark, T. D., and Butler, P. J. (2006). Physiological response to feeding in little penguins. Physiol. Biochem. Zool. 79, 1088-1097. doi: $10.1086 / 507660$

Green, J. A., Halsey, L. G., and Butler, P. J. (2005). To what extent is the foraging behaviour of aquatic birds constrained by their physiology? Physiol. Biochem. Zool. 78, 766-781. doi: 10.1086/432423

Greer, A. E., James, J., Lazell, D., Richard, J., and Wright, M. (1973). Anatomical evidence for a counter-current heat exchanger in the leatherback turtle (Dermochelys coriacea). Nature 244:181. doi: 10.1038/244181a0

Grémillet, D., Kuntz, G., Woakes, A. J., Gilbert, C., Robin, J.-P., Le Maho, Y., et al. (2005). Year-round recordings of behavioural and physiological parameters reveal the survival strategy of a poorly insulated diving endotherm during the Arctic winter. J. Exp. Biol. 208, 4231-4241. doi: 10.1242/jeb.01884

Grémillet, D., Tuschy, I., and Kierspel, M. (1998). Body temperature and insulation in diving great cormorants and european shags. Funct. Ecol. 12, 386-394. doi: 10.1046/j.1365-2435.1998.00199.x

Grémillet, D., Wanless, S., Carss, D. N., Linton, D., Harris, M. P., Speakman, J. R., et al. (2001). Foraging energetics of arctic cormorants and the evolution of diving birds. Ecol. Lett. 4, 180-184. doi: 10.1046/j.1461-0248.2001.00 214.x

Guerrero, A. I., and Rogers, T. L. (2019). From low to high latitudes: changes in fatty acid desaturation in mammalian fat tissue suggest a thermoregulatory role. BMC Evol. Biol. 19:1-12. doi: 10.1186/s12862-019-1473-5

Haase, C. G., Fletcher, R. J., Slone, D. H., Reid, J. P., and Butler, S. M. (2019). Traveling to thermal refuges during stressful temperatures leads to foraging constraints in a central-place forager. J. Mammal. 101, 271-280. doi: 10.1093/ jmammal/gyz197
Halsey, L. G., Blackburn, T. M., and Butler, P. J. (2006). A comparative analysis of the diving behaviour of birds and mammals. Funct. Ecol. 20, 889-899. doi: 10.1111/j.1365-2435.2006.01170.x

Hamann, M., Fuentes, M. M. P. B., Ban, N. C., and Mocellin, V. J. L. (2013). Climate change and marine turtles. Biol. Sea Turtles 3, 353-378. doi: 10.1201/b13895

Hammel, H. T., Elsner, R. W., Heller, H. C., Maggert, J. A., and Bainton, C. R. (1977). Thermoregulatory responses to altering hypothalamic temperature in the harbor seal. Am. J. Physiol. Regul. Integr. Comp. Physiol. 232, R18-R26.

Hammill, M. O. (2018). "Earless seals," in Encyclopedia of Marine Mammals, eds B. Würsig, J. G. M. Thewissen, and K. M. Kovacs (San Diego, CA: Academic Press), 284-289. doi: 10.1016/b978-0-12-804327-1.00112-6

Hampton, I. F. G., and Whittow, G. C. (1976). Body temperature and heat exchange in the Hawaiian spinner dolphin, Stenella longirostris. Comp. Biochem. Physiol. 55A, 195-197. doi: 10.1016/0300-9629(76)90092-x

Hampton, I. F. G., Whittow, G. C., Szekerczes, J., and Rutherford, S. (1971). Heat transfer and body temperature in the Atlantic bottlenosed dolphin, Tursiops truncatus. Int. J. Biometerol. 15, 247-253. doi: 10.1007/bf01803907

Handrich, Y., Bevan, R. M., Charrassin, J.-B., Butler, P. J., Putz, K., Woakes, A. J., et al. (1997). Hypothermia in foraging king penguins. Nature 388, 64-67. doi: $10.1038 / 40392$

Hansen, E. S., and Ricklefs, R. E. (2004). Foraging by deep-diving birds is not constrained by an aerobic diving limit: a model of avian depth-dependent diving metabolic rate. Am. Nat. 163, 358-374. doi: 10.1086/381943

Hart, J. S., and Irving, L. (1959). The energetics of harbor seals in air and in water with special consideration of seasonal changes. Can. J. Zool. 37, 447-457. doi: $10.1139 / z 59-052$

Hashimoto, O., Ohtsuki, H., Kakizaki, T., Amou, K., Sato, R., Doi, S., et al. (2015). Brown adipose tissue in cetacean blubber. PLoS ONE 10:e0116734. doi: 10.1371/ journal.pone.0116734

Hawkes, L. A., Broderick, A. C., Coyne, M. S., Godfrey, M. H., and Godley, B. J. (2007). Only some like it hot - quantifying the environmental niche of the loggerhead sea turtle. Divers. Distrib. 13, 447-457. doi: 10.1111/j.1472-4642. 2007.00354.x

Hawkins, P. A. J., Butler, P. J., Woakes, A. J., and Gabrielsen, G. W. (1997). Heat increment of feeding in Brunnich's guillemot Uria lomvia. J. Exp. Biol. 200, 1757-1763.

Hays, G. C., Metcalfe, J. D., and Walne, A. W. (2004). The implications of lungregulated buoyancy control for dive depth and duration. Ecology 85, 1137-1145. doi: $10.1890 / 03-0251$

Heath, M. E., and McGinnis, S. M. (1980). Body temperature and heat transfer in the green sea turtle. Copeia 1980, 767-773. doi: 10.2307/1444455

Heath, M. E., and Ridgway, S. H. (1999). How dolphins use their blubber to avoid heat stress during encounters with warm water. Am. J. Physiol. 276, R1188-R1194.

Heatwole, H., Grech, A., Monahan, J., King, S., and Marsh, H. (2012). Thermal biology of sea snakes and sea kraits. Integr. Comp. Biol. 52, 257-273. doi: $10.1093 / \mathrm{icb} / \mathrm{ics} 080$

Hedd, A., Gales, R., and Renouf, D. (1996). Can stomach temperature telemetry be used to quantify prey consumption by seals? A re-examination. Polar Biol. 16, 261-270. doi: 10.1007/s003000050053

Heide-Jørgensen, M. P., Nielsen, N. H., Hansen, R. G., and Blackwell, S. B. (2014). Stomach temperature of narwhals (Monodon monoceros) during feeding events. Anim. Biotelem. 2, 1-9. doi: 10.1186/2050-3385-2-9

Heyning, J. E. (2001). Thermoregulation in feeding baleen whales: morphological and physiological evidence. Aquat. Mamm. 27, 284-288.

Hill, R. D., Schneider, R. C., Liggins, G. C., Schuette, A. H., Elliott, R. L., Guppy, M., et al. (1987). Heart rate and body temperature during free diving of Weddell seals. Am. Physiol. Soc. 253, R344-R351.

Hindle, A. G., Horning, M., and Mellish, J. A. E. (2015). Estimating total body heat dissipation in air and water from skin surface heat flux telemetry in Weddell seals. Anim. Biotelemet. 3, 1-11. doi: 10.1186/s40317-015-0081-4

Hindle, A. G., Young, B. L., Rosen, D. A. S., Haulena, M., and Trites, A. W. (2010). Dive response differs between shallow- and deep-diving steller sea lions (Eumetopias jubatus). J. Exp. Mar. Bio. Ecol. 394, 141-148. doi: 10.1016/j.jembe. 2010.08.006

Hochachka, P. W. (2000). Pinniped diving response mechanism and evolution: a window on the paradigm of comparative biochemistry and physiology. Comp. 
Biochem. Physiol. - A Mol. Integr. Physiol. 126, 435-458. doi: 10.1016/S10956433(00)00231-2

Hochscheid, S., Bentivegna, F., Bradai, M. N., and Hays, G. C. (2007a). Overwintering behaviour in sea turtles: dormancy is optional. Mar. Ecol. Prog. Ser. 340, 287-298. doi: 10.3354/meps340287

Hochscheid, S., McMahon, C. R., Bradshaw, C. J. A., Maffucci, F., Bentivegna, F., and Hays, G. C. (2007b). Allometric scaling of lung volume and its consequences for marine turtle diving performance. Comp. Biochem. Physiol. Part A 148, 360-367. doi: 10.1016/j.cbpa.2007.05.010

Hochscheid, S., Bentivegna, F., Hamza, A., and Hays, G. C. (2010). When surfacers do not dive: multiple significance of extended surface times in marine turtles. J. Exp. Biol. 213, 1328-1337. doi: 10.1242/jeb.037184

Hochscheid, S., Bentivegna, F., and Hays, G. C. (2005). First records of dive durations for a hibernating sea turtle. Biol. Lett. 1, 82-86. doi: 10.1098/rsbl.2004. 0250

Hochscheid, S., Bentivegna, F., and Speakman, J. R. (2002). Regional blood flow in sea turtles: implications for heat exchange in an aquatic ectotherm. Physiol. Biochem. Zool. 75, 66-76. doi: 10.1086/339050

Hochscheid, S., Bentivegna, F., and Speakman, J. R. (2003). The dual function of the lung in chelonian sea turtles: buoyancy control and oxygen storage. J. Exp. Mar. Bio. Ecol. 297, 123-140. doi: 10.1016/j.jembe.2003.07.004

Hooker, S. K., Fahlman, A., Moore, M. J., Aguilar, de Soto, N., Bernaldo, et al. (2012). Deadly diving? physiological and behavioural management of decompression stress in diving mammals. Proc. R. Soc. B Biol. Sci. 279, 10411050. doi: $10.1098 / \mathrm{rspb} .2011 .2088$

Horgan, P., Booth, D., Nichols, C., and Lanyon, J. M. (2014). Insulative capacity of the integument of the dugong (Dugong dugon): thermal conductivity, conductance and resistance measured by in vitro heat flux. Mar. Biol. 161, 1395-1407. doi: 10.1007/s00227-014-2428-4

Horton, T. W., Oline, A., Hauser, N., Khan, T. M., Laute, A., Stoller, A., et al. (2017). Thermal imaging and biometrical thermography of humpback whales. Front. Mar. Sci. 4:1-11. doi: 10.3389/fmars.2017.00424

Houston, A. I., and Carbone, C. (1992). The optimal allocation of time during the dive cycle. Behav. Ecol. 3, 255-265. doi: 10.1093/beheco/3.3.255

Hui, C. A. (1981). Seawater consumption and water flux in the common dolphin Delphinus delphis. Physiol. Zool. 54, 430-440. doi: 10.1086/physzool.54.4. 30155836

Humphries, M. M., and Careau, V. (2011). Heat for nothing or activity for free? Evidence and implications of activity-thermoregulatory heat substitution. Integr. Comp. Biol. 51, 419-431. doi: 10.1093/icb/icr059

Hurley, J. A., and Costa, D. P. (2001). Standard metabolic rate at the surface and during trained submersions in adult California sea lions (Zalophus californianus). J. Exp. Biol. 204, 3273-3281.

Innes, S., and Lavigne, D. M. (1991). Do cetaceans really have elevated metabolic rates? Physiol. Zool. 64, 1130-1134.

Innes, S., Worthy, G. A. J., Lavigne, D. M., and Ronald, K. (1990). Surface area of phocid seals. Can. J. Zool. 68, 2531-2538. doi: 10.1139/z90-354

Irving, L. (1973). "Aquatic mammals," in Comparative Physiology of Thermoregulation, ed. G. C. Whittow (New York, NY: Academic Press), 47-96.

Irving, L., and Hart, J. S. (1957). The metabolism and insulation of seals as bareskinned mammals in cold water. Can. J. Zool. 35, 497-511. doi: 10.1139/ z57-041

Irving, L., Peyton, L. J., Bahn, C. H., and Peterson, R. S. (1962). Regulation of temperature in fur seals. Physiol. Zool. 35, 275-284. doi: 10.1086/physzool.35. 4.30155424

Irving, L., Scholander, P. F., and Grinnell, S. W. (1941). Significance of the heart rate to the diving ability of seals. J. Cell. Comp. Physiol. 18, 283-197. doi: 10.1002/jcp.1030180302

Jackson, D. C., and Prange, H. D. (1979). Ventilation and gas exchange during rest and exercise in adult green sea turtles. J. Comp. Physiol. 134, 315-319. doi: 10.1007/BF00709998

James, M. C., Davenport, J., and Hays, G. C. (2006). Expanded thermal niche for a diving vertebrate: a leatherback turtle diving into near-freezing water. J. Exp. Biol. 335, 221-226. doi: 10.1016/j.jembe.2006.03.013

Janes, D. N., and Chappell, M. A. (1995). Comparative biology the effect of ration size and body size on specific dynamic action in adélie penguin. Physiol. Zool. 68, 1029-1044. doi: 10.1086/physzool.68.6.30163792
Jobsis, P. D., Ponganis, P. J., and Kooyman, G. L. (2001). Effects of training on forced submersion responses in harbor seals. J. Exp. Biol. 204, 3877-3885.

Kanwisher, J., and Sundnes, G. (1966). "Thermal regulation in cetaceans," in Whales Dolphins and Porpoises, ed. K. S. Norris (Los Angeles, CA: University of California Press), 397-407.

Kaseloo, P. A., and Lovvorn, A. J. R. (2006). Substitution of heat from exercise and digestion by ducks diving for mussels at varying depths and temperatures. J. Comp. Physiol. B 176, 265-275. doi: 10.1007/s00360-005-0047-6

Kasting, N. W., Adderley, S. A. L., Safford, T., and Gilbey, K. (1988). Thermoregulation in beluga (Delphinapterus leucas) and Killer (Orcinus orca) whales. Physiol. Zool. 62, 687-701. doi: 10.1086/physzool.62.3.30157921

Kato, A., Naito, Y., Watanuki, Y., and Shaughnessy, P. D. (1996). Diving pattern and stomach temperatures of foraging king cormorants at subantarctic. Condor 98, 844-848. doi: 10.2307/1369867

Kelley, N. P., and Pyenson, N. D. (2015). Evolutionary innovation and ecology in marine tetrapods from the triassic to the anthropocene. Science 348:aaa3716. doi: 10.1126/science.aaa3716

Kenyon, K. W. (1969). The Sea Otter in the Eastern Pacific Ocean. Washington, DC: U.S. Government Printing Office, doi: 10.1017/S003060530003948X

Khamas, W. A., Smodlaka, H., Leach-Robinson, J., and Palmer, L. (2012). Skin histology and its role in heat dissipation in three pinniped species. Acta Vet. Scand. 54:46. doi: 10.1186/1751-0147-54-46

Kooyman, G. L., Gentry, R. L., Bergman, W. P., and Hammel, H. T. (1976). Heat loss in penguins during immersion and compression. Comp. Biochem. Physiol. Part A Physiol. 54, 75-80. doi: 10.1016/S0300-9629(76)80074-6

Kooyman, G. L., and Ponganis, P. J. (2018). "Diving Physiology," in Encyclopedia of Marine Mammals, eds B. Würsig, J. G. M. Thewissen, and K. M. Kovacs (San Diego, CA: Academic Press), 267-271. doi: 10.1016/B978-0-12-8043271.00108-4

Kooyman, G. L., Schroeder, J. P., Denison, D. M., Hammond, D. D., Wright, J. J., and Bergman, W. P. (1972). Blood nitrogen tensions of seals during simulated deep dives. Am. J. Physiol. 223, 1016-1020. doi: 10.1152/ajplegacy.1972.223.5. 1016

Kooyman, G. L., Schroeder, J. P., Greene, D. G., and Smith, V. A. (1973). Gas exchange in penguins during simulated dives to 30 and $68 \mathrm{~m}$. Am. J. Physiol. 225, 1467-1471. doi: 10.1152/ajplegacy.1973.225.6.1467

Kooyman, G. L., Wahrenbrock, E. A., Castellini, M. A., Davis, R. W., and Sinnett, E. E. (1980). Aerobic and anaerobic metabolism during voluntary diving in Weddell seals: evidence of preferred pathways from blood chemsitry and behavior. J. Comp. Physiol. B 138, 335-346. doi: 10.1007/BF006 91568

Kramer, D. L. (1988). The behavioral ecology of air breathing by aquatic animals. Can. J. Zool. 66, 89-94. doi: 10.1139/z88-012

Kuhn, C. E., and Costa, D. P. (2006). Identifying and quantifying prey consumption using stomach temperature change in pinnipeds. J. Exp. Biol. 209, 4524-4532. doi: $10.1242 /$ jeb.02530

Kuhn, C. E., Crocker, D. E., Tremblay, Y., and Costa, D. P. (2009). Time to Eat: measurements of Feeding Behaviour in a Large Marine Predator, the northern elephant seal Mirounga angustirostris. Source J. Anim. Ecol. 78, 513-523. doi: 10.1111/J.1365-2656.2008.01509.X

Kvadsheim, P. H., and Aarseth, J. J. (2002). Thermal function of phocid seal fur. Mar. Mammal Sci. 18, 952-962. doi: 10.1111/j.1748-7692.2002.tb01084.x

Kvadsheim, P. H., and Folkow, L. P. (1997). Blubber and flipper heat transfer in harp seals. Acta Physiol. Scand. 161, 385-395. doi: 10.1046/j.1365-201X.1997. 00235.x

Kvadsheim, P. H., Folkow, L. P., and Blix, A. S. (1994). A new device for measurement of the thermal conductivity of fur and blubber. J. Therm. Biol. 19, 431-435. doi: 10.1016/0306-4565(94)90043-4

Kvadsheim, P. H., Folkow, L. P., and Blix, A. S. (1996). Thermal conductivity of minke whale blubber. J. Therm. Biol. 21, 123-128. doi: 10.1016/0306-4565(95) 00034-8

Kvadsheim, P. H., Folkow, L. P., and Blix, A. S. (2005). Inhibition of shivering in hypothermic seals during diving. Am. J. Physiol. Regul. Integr. Comp. Physiol. 289, 326-331. doi: 10.1152/ajpregu.00708.2004

Kvadsheim, P. H., Gotaas, A. R. L., Folkow, L. P., and Blix, A. S. (1997). An experimental validation of heat loss models for marine mammals. J. Theor. Biol. 184, 15-23. doi: 10.1006/jtbi.1996.0256 
Kwan, D. (1994). Fat reserves and reproduction in the green turtle, Chelonia mydas. Wildl. Res. 21, 257-265. doi: 10.1071/wr9940257

Laist, D. W., Taylor, C., and Reynolds, J. E. (2013). Winter habitat preferences for florida manatees and vulnerability to cold. PLoS ONE 8:e58978. doi: 10.1371/ journal.pone. 0058978

Lavigne, D. M., Innes, S., Worthy, G. A. J., and Edwards, E. F. (1990). Lower critical temperatures of blue whales, Balaenoptera musculus. J. Theor. Biol. 144, 249-257. doi: 10.1016/S0022-5193(05)80323-6

Lavigne, D. M., Innes, S., Worthy, G. A. J., Kovacs, K. M., Schmitz, O. J., and Hickie, J. P. (1986). Metabolic rates of seals and whales. Can. J. Zool. 64, 279-284. doi: 10.1139/z86-047

Lewden, A. S., Enstipp, M. R., Bonnet, B., Bost, C., Georges, J.-Y., and Handrich, Y. (2017a). Thermal strategies of king penguins during prolonged fasting in water. J. Exp. Biol. 220, 4600-4611. doi: 10.1242/jeb.168807

Lewden, A. S., Enstipp, M. R., Picard, B., Van Walsum, T., and Handrich, Y. (2017b). High peripheral temperatures in king penguins while resting at sea: thermoregulation versus fat deposition. J. Exp. Biol. 3084-3094. doi: 10.1242/ jeb. 158980

Lewis, S., Phillips, R. A., Burthe, S. J., Wanless, S., and Daunt, F. (2015). Contrasting responses of male and female foraging effort to year-round wind conditions. J. Anim. Ecol. 84, 1490-1496. doi: 10.1111/1365-2656.12419

Liwanag, H. E. M. (2008). Fur Versus Blubber: A Comparative Look at Marine Mammal Insulation and Its Metabolic and Behavioral Consequences. PhD dissertation., Santa Cruz, CA: University of California, Santa Cruz.

Liwanag, H. E. M., Berta, A., Costa, D. P., Abney, M., and Williams, T. M. (2012a). Morphological and thermal properties of mammalian insulation: the evolution of fur for aquatic living. Biol. J. Linn. Soc. 106, 926-939. doi: 10.1111/j.10958312.2012.01900.x

Liwanag, H. E. M., Berta, A., Costa, D. P., Abney, M., and Williams, T. M. (2012b). Morphological and thermal properties of mammalian insulation: the evolutionary transition to blubber in pinnipeds. Biol. J. Linn. Soc. 107, 774-787. doi: 10.1111/j.1095-8312.2012.01992.x

Liwanag, H. E. M., Williams, T. M., Costa, D. P., Kanatous, S. B., Davis, R. W., and Boyd, I. L. (2009). The effects of water temperature on the energetic costs of juvenile and adult California sea lions (Zalophus californianus): the importance of skeletal muscle thermogenesis for thermal balance. J. Exp. Biol. 212, 3977-3984. doi: 10.1242/jeb.033282

Liwanag, H. E. M. M. (2010). Energetic costs and thermoregulation in northern fur seal (Callorhinus ursinus) Pups: the importance of behavioral strategies for thermal balance in furred marine mammals. Physiol. Biochem. Zool. 83, 898-910. doi: $10.1086 / 656426$

Loughlin, T. R. (1977). Activity Patterns, Habitat Partitioning, and Grooming Behavior of the Sea Otter, Enhydra lutris, in California. PhD dissertation., University of California, Los Angeles, Los Angeles, CA.

Lovvorn, J. R. (2001). Upstroke thrust, drag effects, and stroke-glide cycles in wing-propelled swimming by birds. Am. Zool. 41, 154-165. doi: 10.1093/icb/41. 2.154

Lovvorn, J. R. (2007). Thermal substitution and aerobic efficiency: measuring and predicting effects of heat balance on endotherm diving energetics. Philos. Trans. R. Soc. B 362, 2079-2093. doi: 10.1098/rstb.2007.2110

Lovvorn, J. R., and Jones, D. R. (1991). Body mass, volume, and buoyancy of some aquatic birds, and their relation to locomotor strategies. Can. J. Fish. Aquat. Sci. 69, 2888-2892. doi: 10.1139/z91-407

Lovvorn, J. R., and Jones, D. R. (1994). Biomechanical conflicts between adaptations for diving and aerial flight in estuarine. Estuaries 17, 62-75. doi: $10.2307 / 1352335$

Lustick, S. (1984). "Thermoregulation in Adult Seabirds," in Seabird Energetics, eds G. C. Whittow and H. Rahn (Boston, MA: Springer), 183-201. doi: 10.1007/ 978-1-4684-4859-7 9

Lutcavage, M. E., Bushnell, P. G., and Jones, D. R. (1992). Oxygen stores and aerobic metabolism in the leatherback sea turtle. Can. J. Zool. 70, 348-351. doi: $10.1139 / 292-051$

Lutcavage, M. E., and Lutz, P. L. (1991). Voluntary diving metabolism and ventilation in the loggerhead sea turtle. Mar. Biol. Ecol. 147, 287-296. doi: 10.1016/0022-0981(91)90187-2

Lutz, P. L., and Bentley, T. B. (1985). Respiratory physiology of diving in the sea turtle. Copeia 1985, 671-679. doi: 10.2307/1444761

Markussen, N. H., Ryg, M., and Øritsland, N. A. (1994). The effect of feeding on the metabolic rate in harbour seals (Phoca vitulina). J. Comp. Physiol. B 164, 89-93. doi: 10.1007/BF00301648
Mauck, B., Bilgmann, K., Jones, D. D., Eysel, U., and Dehnhardt, G. (2003). Thermal windows on the trunk of hauled-out seals: hot spots for thermoregulatory evaporation? J. Exp. Biol. 206, 1727-1738. doi: 10.1242/jeb. 00348

McCafferty, D. J. (2007). The value of infrared thermography for research on mammals: previous applications and future directions. Mamm. Rev. 37, 207223. doi: 10.1111/j.1365-2907.2007.00111.x

McCafferty, D. J., Gallon, S., and Nord, A. (2015). Challenges of measuring body temperatures of free-ranging birds and mammals. Anim. Biotelem. 3, 1-10. doi: 10.1186/s40317-015-0075-2

McCafferty, D. J., Gilbert, C., Paterson, W., Pomeroy, P., Thompson, D., Currie, J. I., et al. (2011). Estimating metabolic heat loss in birds and mammals by combining infrared thermography with biophysical modelling. Comp. Biochem. Physiol. - A Mol. Integr. Physiol. 158, 337-345. doi: 10.1016/j.cbpa.2010.09.012

McCafferty, D. J., Gilbert, C., Thierry, A. M., Currie, J., Le Maho, Y., and Ancel, A. (2013). Emperor penguin body surfaces cool below air temperature. Biol. Lett. 9:20121192. doi: 10.1098/rsbl.2012.1192

McDonald, B. I., Johnson, M., and Madsen, P. T. (2018). Dive heart rate in harbour porpoises is influenced by exercise and expectations. J. Exp. Biol. 221:jeb168740. doi: $10.1242 /$ jeb. 168740

McDonald, B. I., and Ponganis, P. J. (2012). Lung collapse in the diving sea lion: hold the nitrogen and save the oxygen. Biol. Lett. 8, 1047-1049. doi: 10.1098/ rsbl.2012.0743

McGinnis, S. M. (1975). Peripheral heat exchange in phocids. Rapp. P.-V. Reun. Cons. int. Explor. Mer. 169, 481-486.

McGinnis, S. M., Whittow, G. C., Ohata, C. A., and Huber, H. (1972). Body heat dissipation and conservation in two species of dolphins. Comp. Biochem. Physiol. 43, 417-423. doi: 10.1016/0300-9629(72)90200-9

McKnight, J. C., Bennett, K. A., Bronkhorst, M., Russell, D. J. F., Balfour, S., Milne, R., et al. (2019). Shining new light on mammalian diving physiology using wearable near-infrared spectroscopy. PLoS Biol. 17:e3000306. doi: 10. 1371/journal.pbio.3000306

McMahon, C. R., and Hays, G. C. (2006). Thermal niche, large-scale movements and implications of climate change for a critically endangered marine vertebrate. Glob. Chang. Biol. 12, 1330-1338. doi: 10.1111/j.1365-2486.2006. 01174.x

Meagher, E. M., Mclellan, W. A., Westgate, A. J., Wells, R. S., Blum, J. E., and Pabst, A. D. (2008). Seasonal patterns of heat loss in wild bottlenose dolphins (Tursiops truncatus). J. Comp. Physiol. B 178, 529-543. doi: 10.1007/s00360-007-0245-5

Meagher, E. M., McLellan, W. A., Westgate, A. J., Wells, R. S., Frierson, D. J., and Pabst, D. A. (2002). The relationship between heat flow and vasculature in the dorsal fin of wild bottlenose dolphins Tursiops truncatus. J. Exp. Biol. 205, 3475-3486.

Meek, R., and Avery, R. A. (1988). Mini-review: thermoregulation in Chelonians. Herpetol. J. 1, 253-259.

Meir, J. U., and Ponganis, P. J. (2010). Blood temperature profiles of diving elephant seals. Physiol. Biochem. Zool. 83, 531-540. doi: 10.1086/651070

Mellish, J.-A., Hindle, A., Skinner, J., and Horning, M. (2015). Heat loss in air of an Antarctic marine mammal, the Weddell seal. J. Comp. Physiol. B 185, 143-152. doi: 10.1007/s00360-014-0868-2

Mellish, J.-A. E., Tuomi, P., and Horning, M. (2004). Assessment of ultrasound imaging as a noninvasive measure of blubber thickness in pinnipeds. J. Zoo Wildl. Med. 35, 116-118. doi: 10.1638/03-028

Midtgård, U. (1981). The rete tibiotarsale and arteriovenous association in the hind limb of birds: a compartive morphological study on counter-current heat exchange systems. Acta Zool. 62, 67-87. doi: 10.1111/j.1463-6395.1981. tb00617.x

Miller, P. J. O., Johnson, M. P., Tyack, P. L., and Terray, E. A. (2004), Swimming gaits, passive drag and buoyancy of diving sperm whales Physeter macrocephalus. J. Exp. Biol. 207, 1953-1967. doi: 10.1242/jeb.00993

Minamikawa, S., Naito, Y., Sato, K., Matsuzawa, Y., Bando, T., and Sakamoto, W. (2000). Maintenance of neutral buoyancy by depth selection in the loggerhead turtle Caretta caretta. J. Exp. Biol. 203, 2967-2975.

Mitani, Y., Andrews, R. D., Sato, K., Kato, A., Naito, Y., and Costa, D. P. (2010). Three-dimensional resting behaviour of northern elephant seals: drifting like a falling leaf. Biol. Lett. 6, 163-166. doi: 10.1098/rsbl.2009.0719

Molyneux, G. S., and Bryden, M. M. (1978). Arteriovenous anastomoses in the skin of seals: I. The weddell seal leptonychotes weddelli and the elephant seal Mirounga leonina (Pinnipedia: Phocidae). Anat. Rec. 191, 239-251. doi: 10. 1002/ar.1091910209 
Mrosovsky, N. (1980). Thermal biology of sea turtles. Am. Zool. 20, 531-547. doi: $10.1093 / \mathrm{icb} / 20.3 .531$

Mrosovsky, N., and Pritchard, P. C. H. (1971). Body temperatures of dermochelys coriacea and other sea turtles. Source: Copeia 1971, 624-631. doi: 10.2307/ 1442630

Murdaugh, H. V., Seabury, J. C., and Mitchell, W. L. (1961). Electrocardiogram of the diving seal. Circ. Res. 9, 358-361. doi: 10.1161/01.RES.9.2.358

Murphy, J. C. (2012). Marine invasions by non-sea snakes, with thoughts on terrestrial-aquatic-marine transitions. Integr. Comp. Biol. 52, 217-226. doi: $10.1093 / \mathrm{icb} / \mathrm{ics} 060$

Murphy, M. E. (1996). "Energetics and nutrition of molt," in Avian Energetics and Nutritional Ecology, ed. C. Carey (Boston, MA: Springer), 158-198. doi: 10.1007/978-1-4613-0425-8_6

Nienaber, J., Thomton, J., Horning, M., Polasek, L., and Mellish, J.-A. (2010). Surface temperature patterns in seals and sea lions: a validation of temporal and spatial consistency. J. Therm. Biol. 35, 435-440. doi: 10.1016/j.jtherbio.2010. 09.005

Niizuma, Y., Gabrielsen, G. W., Sato, K., Watanuki, Y., and Naito, Y. (2007). Brünnich's guillemots (Uria lomvia) maintain high temperature in the body core during dives. Comp. Biochem. Physiol. Part A 147, 438-444. doi: 10.1016/j. cbpa.2007.01.014

Noren, D. P., Williams, T. M., Berry, P., and Butler, E. (1999). Thermoregulation during swimming and divng in bottlenose dolphins (Tursiops truncatus). J. Comp. Physiol. B 169, 93-99.

Noren, S. R., Kendall, T., Cuccurullo, V., and Williams, T. M. (2012). The dive response redefined: underwater behavior influences cardiac variability in freely diving dolphins. J. Exp. Biol. 215, 2735-2741. doi: 10.1242/jeb.069583

Norris, A. L., Houser, D. S., and Crocker, D. E. (2010). Environment and activity affect skin temperature in breeding adult male elephant seals (Mirounga angustirostris). J. Exp. Biol. 213, 4205-4212. doi: 10.1242/jeb.042135

Odden, Å, Folkow, L. P., Caputa, M., Hotvedt, R., and Blix, A. S. (1999). Brain cooling in diving seals. Acta Physiol. Scand. 166, 77-78. doi: 10.1046/j.1365201x.1999.00536.x

Ohata, C. A., Miller, L. K., and Kajimura, H. (1977). Northern fur seal thermoregulation: thermal responses to pelagic conditions. J. Therm. Biol. 2, 135-140. doi: 10.1016/0306-4565(77)90019-5

Pabst, D. A., McLellan, W. A., Meagher, E. M., and Westgate, A. J. (2002). Measuring Temperatures and Heat Flux from Dolphins in the Eastern Tropical Pacific: Is Thermal Stress Associated with Chase and Capture in the ETPtuna Purse Seine Fishery? Report. La Jolla: National Marine Fishereis Service, NOAA.

Pabst, D. A., Rommel, S. A., and McLellan, W. A. (1999). "Functional anatomy of marine mammals," in Biology of Marine Mammals, eds R. J. III and R. SA (Washington, DC: Smithsonian Institution Press), 15-72.

Pabst, D. A., Rommel, S. A., McLellan, W. A., Williams, T. M., and Rowles, T. K. (1995). Thermoregulation of the intra-abdominal testes of the bottlenose dolphin (Tursiops truncatus) during exercise. J. Exp. Biol. 198, 221-226.

Paladino, F. V., O'Connor, M. P., and Spotila, J. R. (1990). Metabolism of leatherback turtles, gigantothermy, and thermoregulation of dinosaurs. Nature 344, 855-860. doi: 10.1038/344858a0

Parry, D. A. (1949). The structure of whale blubber, and a discussion of its thermal properties. Q. J. Microsc. Sci. 90, 13-25.

Pearson, L. E. (2015). Blubber and Beyond: The Role of Lipids in Thermoregulation and Energy Reserves of Phocid Seals. PhD dissertation., University of Alaska Fairbanks, Fairbanks, AK.

Perryman, W. L., Donahue, M. A., Laake, J. L., and Martin, T. E. (1999). Diel variation in migration rates of eastern Pacific gray whales measured with thermal imaging sensors. Mar. Mammal Sci. 15, 426-445. doi: 10.1111/j.17487692.1999.tb00811.x

Pettit, T. N., Whittow, G. C., and Grant, G. S. (1981). Rete mirabile ophthalmicum in hawaiian seabirds. Auk 98, 844-846. doi: 10.1093/auk/98.4.844

Pitman, R. L., Fearnbach, H., Panigada, S., and Joyce, T. (2019). Skin in the game: epidermal molt as a driver of long-distance migration in whales. Mar. Mammal Sci. 1-30. doi: 10.1111/mms.12661

Ponganis, P. J. (2015). Diving Physiology of Marine Mammals and Seabirds. Cambridge: Cambridge University Press.

Ponganis, P. J., Kooyman, G. L., Baranov, E. A., Thorson, P. H., and Stewart, B. S. (1997a). The aerobic submersion limit of Baikal seals. Phoca sibirica. Can. J. Zool. 75, 1323-1327. doi: 10.1139/z97-756
Ponganis, P. J., Kooyman, G. L., Starke, L. N., Kooyman, C. A., and Kooyman, T. G. (1997b). Post-dive blood lactate concentrations in emperor penguins, Aptenodytes forsteri. J. Exp. Biol. 200, 1623-1626.

Ponganis, P. J., Kooyman, G. L., Castellini, M. A., Ponganis, E. P., and Ponganis, K. V. (1993). Muscle temperature and swim velocity profiles during diving in a Weddell seal, Leptonychotes Weddellii. J. Exp. Biol. 183, 341-348.

Ponganis, P. J., Meir, J. U., and Williams, C. L. (2011). In pursuit of Irving and Scholander: a review of oxygen store management in seals and penguins. J. Exp. Biol. 214, 3325-3339. doi: 10.1242/jeb.031252

Ponganis, P. J., Van Dam, R. P., Knower, T., and Levenson, D. H. (2001). Temperature regulation in emperor penguins foraging under sea ice. Comp. Biochem. Physiol. Part A 129, 811-820. doi: 10.1016/s1095-6433(01)00349-x

Ponganis, P. J., Van Dam, R. P., Levenson, D. H., Knower, T., Ponganis, K. V., and Marshall, G. (2003). Regional heterothermy and conservation of core temperature in emperor penguins diving under sea ice. Comp. Biochem. Physiol. Part A 135, 477-487. doi: 10.1016/S1095-6433(03)00133-8

Porter, W. R., and Witmer, L. M. (2016). Avian cephalic vascular anatomy, sites of thermal exchange, and the rete ophthalmicum. Anat. Rec. 299, 1461-1486. doi: $10.1002 /$ ar. 23375

Prince, P. A., Huin, N., and Weimerskirch, H. (1994). Diving depths of albatrosses. Antarct. Sci. 6, 355-358. doi: 10.1017/S0954102094000544

Pyenson, N. D., Kelley, N. P., and Parham, J. F. (2014). Marine tetrapod macroevolution: physical and biological drivers on 250Ma of invasions and evolution in ocean ecosystems. Palaeogeogr. Palaeoclimatol. Palaeoecol. 400, 1-8. doi: 10.1016/j.palaeo.2014.02.018

Reidenberg, J. S. (2007). Anatomical adaptations of aquatic mammals. Anat. Rec. 290, 507-513. doi: 10.1002/ar.20541

Richman, S. E., and Lovvorn, J. R. (2011). Effects of air and water temperatures on resting metabolism of auklets and other diving birds. Physiol. Biochem. Zool. Ecol. Evol. Approaches 84, 316-332. doi: 10.1086/660008

Rode, K., and Stirling, I. (2018). "Polar bear," in Encyclopedia of Marine Mammals, eds B. Würsig, J. G. M. Thewissen, and K. M. Kovacs (San Diego, CA: Academic Press), 743-746. doi: 10.1016/b978-0-12-804327-1.00201-6

Rommel, S. A., and Caplan, H. (2003). Vascular adaptations for heat conservation in the tail of Florida manatees (Trichechus manatus latirostris). J. Anat. 202, 343-353. doi: 10.1046/j.1469-7580.2003.00170.x

Rommel, S. A., Early, G. A., Matassa, K. A., Pabst, D. A., and McLellan, W. A. (1995). Venous structures associated with thermoregulation of phocid seal reproductive organs. Anat. Rec. 243, 390-402. doi: 10.1002/ar.1092430314

Rommel, S. A., Pabst, D. A., McLellan, W. A., Williams, T. M., and Friedl, W. A. (1994). Temperature regulation of the testes of the bottlenose dolphin (Tursiops truncatus): evidence from colonic temperatures. J. Comp. Physiol. B 164, 130-134. doi: 10.1007/BF00301654

Rosen, D. A., Winship, A. J., and Hoopes, L. A. (2007). Thermal and digestive constraints to foraging behaviour in marine mammals. Philos. Trans. R. Soc. B Biol. Sci. 362, 2151-2168. doi: 10.1098/rstb.2007.2108

Rosen, D. A. S., Gerlinsky, C. D., and Trites, A. W. (2015). Evidence of partial deferment of digestion during diving in Steller sea lions (Eumetopias jubatus). J. Exp. Mar. Bio. Ecol. 469, 93-97. doi: 10.1016/j.jembe.2015.04.017

Rosen, D. A. S., Hindle, A. G., Gerlinsky, C. D., Goundie, E., Hastie, G. D., Volpov, B. L., et al. (2017). Physiological constraints and energetic costs of diving behaviour in marine mammals: a review of studies using trained Steller sea lions diving in the open ocean. J. Comp. Physiol. B 187, 29-50. doi: 10.1007/s00360016-1035-8

Rosen, D. A. S., and Renouf, D. (1997). Seasonal changes in blubber distribution in atlantic harbor seals: indications of thermodynamic considerations. Mar. Mammal Sci. 13, 229-240. doi: 10.1111/j.1748-7692.1997.tb00630.x

Rosen, D. A. S., and Trites, A. W. (1997). Heat increment of feeding in steller sea lions, Eumetopias jubatus. Comp. Biochem. Physiol. Part A Physiol. 118, 877-881. doi: 10.1016/S0300-9629(97)00039-X

Rosen, D. A. S., and Trites, A. W. (2003). No evidence for bioenergetic interaction between digestion and thermoregulation in steller sea lions Eumetopias jubatus. Physiol. Biochem. Zool. 76, 899-906. doi: 10.1086/378140

Rotherham, L. S., van der Merwe, M., Bester, M. N., and Oosthuizen, W. H. (2005). Morphology and distribution of sweat glands in the Cape fur seal, Arctocephalus pusillus pusillus (Carnivora:Otariidae). Aust. J. Zool. 53, 295-300. doi: 10.1071/zo04075

Ryg, M., Smith, T. G., and Øritsland, N. A. (1988). Thermal significance of the topographical distribution of blubber in ringed seals (Phoca hispida). Can. J. Fish. Aquat. Sci. 45, 985-992. doi: 10.1139/f88-121 
Sakamoto, W., Uchida, I., Naito, Y., Kureha, K., Tujimura, M., and Sato, K. (1990). Deep diving behavior of the loggerhead turtle near the frontal zone. Nippon Suisan Gakkaishi 56, 1435-1443. doi: 10.2331/suisan.56.1435

Sato, K. (2014). Body temperature stability achieved by the large body mass of sea turtles. J. Exp. Biol. 217, 3607-3614. doi: 10.1242/jeb.109470

Sato, K., Matsuzawa, Y., Tanaka, H., Bando, T., Minamikawa, S., Sakamoto, W., et al. (1998). Internesting intervals for loggerhead turtles, Caretta caretta, and green turtles, Chelonia mydas, are affected by temperature. Can. J. Zool. 76, 1651-1662. doi: 10.1139/z98-107

Sato, K., Naito, Y., Kato, A., Niizuma, Y., Watanuki, Y., Charrassin, J. B., et al. (2002). Buoyancy and maximal diving depth in penguins: do they control inhaling air volume? J. Exp. Biol. 205, 1189-1197.

Sato, K., Sakamoto, W., Matsuzawa, Y., Tanaka, H., and Naito, Y. (1994). Correlation between stomach temperatures and ambient water temperatures in free-ranging loggerhead turtles. Caretta caretta. Mar. Biol. 118, 343-351. doi: $10.1007 / b f 00349802$

Sato, K., Sakamoto, W., Matsuzawa, Y., Tanaka, H., Minamikawa, S., Naito, Y., et al. (1995). Body temperature independence of solar radiation in free-ranging loggerhead turtles, Caretta caretta, during internesting periods. Mar. Biol. 123, 197-205. doi: 10.1007/bf00353611

Scheffer, V. B. (1961). Pelage and Surface Topography of the Northern fur Seal. Seattle, WA: U.S. Fish and Wildlife Service, Bureau of Commercial Fisheries.

Schmidt, A., Alard, F., and Handrich, I. (2006). Changes in body temperatures in king penguins at sea: the result of fine adjustments in peripheral heat loss? Am. J. Physiol. Regul. Integr. Comp. Physiol. 291, 608-618. doi: 10.1152/ajpregu.00826. 2005.-To

Schmidt-Nielsen, K. (1984). "Scaling, why is animal size so important?," in Scaling, Why Is Animal Size so Important?, (Cambridge: Cambridge University Press), 143-150.

Scholander, P. F. (1955). Evolution of climatic adaptation in homeotherms. Evolution (N. Y). 9, 15-26. doi: 10.2307/2405354

Scholander, P. F., Irving, L., and Grinnell, S. W. (1942). On the temperature and metabolism of the seal during diving. J. Cell. Comp. Physiol. 19, 67-78. doi: $10.1002 /$ jcp. 1030190107

Scholander, P. F., Walters, V., Hock, R., and Irving, L. (1950). Body insulation of some arctic and tropical mammals and birds. Biol. Bull. 99, 225-236. doi: $10.2307 / 1538740$

Schreiber, E. A., and Burger, J. (2002). "Seabirds in the marine evironment," in Biology of Marine Birds, eds E. A. Schreiber and J. Burger (Boca Raton: CRC Press), 1-16.

Schwartz, F. J. (1978). Behavioral and tolerance responses to cold water temperatures by three species of sea turtles (Reptilia, Chelondiidae) in North Carolina. Florida Mar. Res. Publ. 33, 16-18.

Shaffer, S. A., Costa, D. P., Williams, T. M., and Ridgway, S. H. (1997). Diving and swimming performance of white whales, Delphinapterus leucas: an assessment of plasma lactate and blood gas levels and respiratory rates. J. Exp. Biol. 200, 3091-3099.

Sharma, N., and Liwanag, H. E. M. (2017). The effects of submergence on the thermal function of pinniped fur. Mar. Mammal Sci. 33, 611-620. doi: 10.1111/ mms. 12372

Simmons, S. E., Crocker, D. E., Hassrick, J. L., Kuhn, C. E., Robinson, P. W., Tremblay, Y., et al. (2010). Climate-scale hydrographic features related to foraging success in a capital breeder, the northern elephant seal Mirounga angustirostris. Endanger. Species Res. 10, 233-243. doi: 10.3354/esr00254

Slip, D. J., Gales, N. J., and Burton, H. R. (1992). Body mass loss, utilization of blubber and fat, and energetic requirements of male southern elephant seals, Mirounga leonina, during the molting fast. Aust. J. Zool. 40, 235-243. doi: 10.1071/zo9920235

Smith, E. N., Long, N. C., and Wood, J. (1986). Thermoregulation and evaporative water loss of green sea turtles. J. Herpetol. 20, 325-332. doi: 10.2307/1564499

Southwood, A. L., Andrews, R. D., Paladino, F. V., and Jones, D. R. (2005). Effects of diving and swimming behavior on body temperatures of pacific leatherback turtles in tropical seas. Physiol. Biochem. Zool. 78, 285-297. doi: 10.1086/427048

Southwood, A. L., Reina, R. D., Jones, V. S., and Jones, D. R. (2003). Seasonal diving patterns and body temperatures of juvenile green turtles at Heron Island, Australia. Can. J. Zool. 81, 1014-1024. doi: 10.1139/Z03-081

Sparling, C. E., Fedak, M. A., and Thompson, D. (2007). Eat now, pay later? Evidence of deferred food-processing costs in diving seals. Biol. Lett. 3, 94-98. doi: $10.1098 / \mathrm{rsbl} .2006 .0566$
Sparling, C. E., Thompson, D., Fedak, M. A., Gallon, S. L., and Speakman, J. R. (2008). Estimating field metabolic rates of pinnipeds: doubly labelled water gets the seal of approval. Funct. Ecol. 22, 245-254. doi: 10.1111/j.1365-2435.2007. 01368.x

Speakman, J. R., and Hambly, C. (2016). Using doubly-labelled water to measure free-living energy expenditure: some old things to remember and some new things to consider. Comp. Biochem. Physiol. - Part A Mol. Integr. Physiol. 202, 3-9. doi: 10.1016/j.cbpa.2016.03.017

Speakman, J. R., and Ward, S. (1998). Infrared thermography: principles and applications. Zoology 101, 224-232.

Spotila, J. R., and Standora, E. A. (1985). Environmental constraints on the thermal energetics of sea turtles. Source: Copeia 1985, 694-702. doi: 10.2307/1444763

Stahel, C. D., and Nicol, S. C. (1982). Temperature regulation in the little penguin, Eudyptula minor, in air and water. J. Comp. Physiol. 148, 93-100. doi: 10.1007/ bf00688892

Standora, E. A., Spotila, J. R., and Foley, R. E. (1982). Regional endothermy in the sea turtle, Chelonia mydas. J. Therm. Biol. 7, 159-165. doi: 10.1016/03064565(82) $90006-7$

Stewart, R. E. A., and Lavigne, D. M. (1980). Neonatal growth of northwest Atlantic harp seals, Pagophilus groenlandicus. J. Mammal. 61, 670-680. doi: 10.2307/ 1380312

Storch, S., Grémillet, D., and Culik, B. M. (1999). The telltale heart: a non-invasive method to determine the energy expenditure of incubating great cormorants Phalacrocorax carbo carbo. Ardea 87, 207-215.

Storch, S., Wilson, R. P., Hillis-Starr, Z. M., and Adelung, D. (2005). Cold-blooded divers: temperature-dependent dive performance in the wild hawksbill turtle Eretmochelys imbricata. Mar. Ecol. Prog. Ser. 293, 263-271. doi: 10.3354/ meps 293263

Szesciorka, A. R., Calambokidis, J., and Harvey, J. T. (2016). Testing tag attachments to increase the attachment duration of archival tags on baleen whales. Anim. Biotelemetry 4, 1-12. doi: 10.1186/s40317-016-0110-y

Tattersall, G. J. (2016). Infrared thermography: a non-invasive window into thermal physiology. Comp. Biochem. Physiol. -Part A Mol. Integr. Physiol. 202, 78-98. doi: 10.1016/j.cbpa.2016.02.022

Taylor, C. R., Karas, R. H., Weibel, E. R., and Hoppeler, H. (1987). Adaptive variation in the mammalian respiratory system in relation to energetic demand: II, Reaching the limits to oxygen flow. Respir. Physiol. 69, 7-26. doi: 10.1016/ 0034-5687(87)90101-0

Taylor, E. N., DeNardo, D. F., and Malawy, M. A. (2004). A comparison between point- and semi-continuous sampling for assessing body temperature in a free-ranging ectotherm. J. Therm. Biol. 29, 91-96. doi: 10.1016/j.jtherbio.2003. 11.003

Thomas, D. B., and Fordyce, R. E. (2012). Biological plasticity in penguin heatretention structures. Anat. Rec. 295, 249-256. doi: 10.1002/ar.21538

Thompson, D., and Fedak, M. A. (1993). Cardiac responses of grey seals during diving at sea. J. Exp. Biol. 174, 139-154.

Thompson, D., and Fedak, M. A. (2001). How long should a dive last? A simple model of foraging decisions by breath-hold divers in a patchy environment. Anim. Behav. 61, 287-296. doi: 10.1006/anbe.2000.1539

Trassinelli, M. (2016). Energy cost and optimisation in breath-hold diving. J. Theor. Biol. 396, 42-52. doi: 10.1016/j.jtbi.2016.02.009

Trillmich, F., and Kooyman, G. L. (2001). Field metabolic rate of lactating female Galápagos fur seals (Arctocephalus galapagoensis): the influence of offspring age and environment. Comp. Biochem. Physiol. - A Mol. Integr. Physiol. 129, 741-749. doi: 10.1016/S1095-6433(01)00343-9

Udevitz, M. S., Burn, D. M., and Webber, M. A. (2008). Estimation of walrus populations on sea ice with infrared imagery and aerial photography. Mar. Mammal Sci. 24, 57-70. doi: 10.1111/j.1748-7692.2007.00169.x

Udyawer, V., Simpfendorfer, C. A., Heupel, M. R., and Clark, T. D. (2016). Coming up for air: thermal dependence of dive behaviours and metabolism in sea snakes. J. Exp. Biol. 219, 3447-3454. doi: 10.1242/jeb.146571

Uhen, M. D. (2007). Evolution of marine mammals: back to the sea after 300 million years. Anat. Rec. 290, 514-522. doi: 10.1002/ar.20545

Vacquié-Garcia, J., Guinet, C., Dragon, A.-C., Viviant, M., El Ksabi, N., and Bailleul, F. (2015). Predicting prey capture rates of southern elephant seals from track and dive parameters. Mar. Ecol. Prog. Ser. 541, 265-277. doi: 10.3354/ meps 11511

Villegas-Amtmann, S., Atkinson, S., Paras-Garcia, A., and Costa, D. P. (2012). Seasonal variation in blood and muscle oxygen stores attributed to diving 
behavior, environmental temperature and pregnancy in a marine predator, the California sea lion. Comp. Biochem. Physiol. Part A 162, 413-420. doi: 10.1016/ j.cbpa.2012.04.019

Villegas-Amtmann, S., McDonald, B. I., Páez-Rosas, D., Aurioles-Gamboa, D., Costa, D. P., Paez-Rosas, D., et al. (2017). Adapted to change: low energy requirements in a low and unpredictable productivity environment, the case of the Galapagos sea lion. Deep. Res. Part II Top. Stud. Oceanogr. 140, 94-104. doi: 10.1016/j.dsr2.2016.05.015

Walcott, S. M., Kirkham, A. L., and Burns, J. M. (2020). Thermoregulatory costs in molting Antarctic Weddell seals: impacts of physiological and environmental conditions. Conserv. Physiol. 8, 1-14. doi: 10.1093/conphys/coaa022

Wallace, B. P., Williams, C. L., Paladino, F. V., Morreale, S. J., Lindstrom, R. T., and Spotila, J. R. (2005). Bioenergetics and diving activity of internesting leatherback turtles Dermochelys coriacea at Parque Nacional Marino Las Baulas, Costa Rica. J. Exp. Biol. 208, 3873-3884. doi: 10.1242/jeb.01860

Watanuki, Y., and Burger, A. E. (1999). Body mass and dive duration in alcids and penguins. Can. J. Zool. 77, 1838-1842. doi: 10.1139/z99-157

Watanuki, Y., Niizuma, Y., Gabrielsen, G. W., Sato, K., and Naito, Y. (2003). Stroke and glide of wing-propelled divers: deep diving seabirds adjust surge frequency to buoyancy change with depth. Proc. R. Soc. B 270, 483-488. doi: 10.1098/rspb.2002.2252

Webb, P. M., Andrews, R. D., Costa, D. P., and Le Boeuf, B. J. (1998). Heart rate and oxygen consumption of northern elephant seals during diving in the laboratory. Physiol. Zool. 71, 116-125. doi: 10.1086/515894

Weise, M. J. (2009). Effects of Stress on Marine Mammlas Exposed to Sound. Arlington, TX: ONR Workshop, 1-59.

West, N. H., Butler, P. J., and Bevan, R. M. (1992). Pulmonary blood flow at rest and during swimming in the green turtle, Chelonia mydas. Physiol. Zool. 65, 287-310. doi: 10.1086/physzool.65.2.30158254

Westgate, A. J., Mclellan, W. A., Wells, R. S., Scott, M. D., Meagher, E. M., and Pabst, D. A. (2007). A new device to remotely measure heat flux and skin temperature from free-swimming dolphins. J. Exp. Mar. Bio. Ecol. 346, 45-59. doi: 10.1016/j.jembe.2007.02.014

Whittow, G. C. (1987). Thermoregulatory adaptations in marine mammals: interacting effects of exercise and body mass, A review. Mar. Mammal Sci. 3, 220-241. doi: 10.1111/j.1748-7692.1987.tb00165.x

Whittow, G. C., Matsuura, D. T., and Lin, Y. C. (1972). Temperature regulation in the california sea lion (Zalophus californianus). Physiol. Zool. 45, 68-77. doi: 10.1086/physzool.45.1.30155928

Williams, C. L., Meir, J. U., and Ponganis, P. J. (2011). What triggers the aerobic dive limit? Patterns of muscle oxygen depletion during dives of emperor penguins. J. Exp. Biol. 214, 1802-1812. doi: 10.1242/jeb.052233

Williams, T. M. (1998). "Physiological challenges in semi-aquatic mammals: swimming against the energetic tide," in Behaviour and Ecology of Riparian Mammals, eds N. Dunstone and M. L. Gorman (Cambridge: Cambridge University Press), 17-30. doi: 10.1017/CBO9780511721830.003

Williams, T. M., Blackwell, S. B., Richter, B., Sinding, M. H. S., and HeideJørgensen, M. P. (2017). Paradoxical escape responses by narwhals (Monodon monoceros). Science 358, 1328-1331. doi: 10.1126/science.aao2740

Williams, T. M., Davis, R. W., Fuiman, L. A., Francis, J., Le Boeuf, B. J., Horning, M., et al. (2000). Sink or swim: strategies for cost-efficient diving by marine mammals. Science 288, 133-136. doi: 10.1126/science.288.5463.133

Williams, T. M., Fuiman, L. A., Horning, M., and Davis, R. W. (2004). The cost of foraging by a marine predator, the Weddell seal Leptonychotes weddellii: pricing by the stroke. J. Exp. Biol. 207, 973-982. doi: 10.1242/jeb. 00822

Williams, T. M., Fuiman, L. A., Kendall, T., Berry, P., Richter, B., Noren, S. R., et al. (2015). Exercise at depth alters bradycardia and incidence of cardiac anomalies in deep-diving marine mammals. Nat. Commun. 6:6055. doi: 10 . 1038/ncomms7055

Williams, T. M., Haun, J., Davis, R. W., Fuiman, L. A., and Kohin, S. (2001). A killer appetite: metabolic consequences of carnivory in marine mammals. Comp. Biochem. Physiol. Part A 129, 785-796. doi: 10.1016/S1095-6433(01) 00347-6

Williams, T. M., Haun, J. E., and Friedl, W. A. (1999a). The diving physiology of bottlenose dolphins (Tursiops truncatus): I. Balancing the demands of exercise for energy conservation at depth. J. Exp. Biol. 202, 2739-2748.
Williams, T. M., Noren, D., Berry, P., Estes, J. A., Allison, C., and Kirtland, J. (1999b). The diving physiology of bottlenose dolphins (Tursiops Truncatus): III. Thermoregulation at depth. J. Exp. Biol. 202, 2763-2769.

Williams, T. M., Kooyman, G. L., and Croll, D. A. (1991). The effect of submergence on heart rate and oxygen consumption of swimming seals and sea lions. J. Compar. Physiol. B 160, 637-644. doi: 10.1007/bf00571261

Williams, T. M., Zavanelli, M., Miller, M. A., Goldbeck, R. A., Morledge, M., Casper, D., et al. (2008). Running, swimming and diving modifies neuroprotecting globins in the mammalian brain. Proc. R. Soc. B Biol. Sci. 275, 751-758. doi: 10.1098/rspb.2007.1484

Willis, K., and Horning, M. (2005). A novel approach to measuring heat flux in swimming animals. J. Exp. Mar. Bio. Ecol. 315, 147-162. doi: 10.1016/j.jembe. 2004.09.019

Willis, K., Horning, M., Rosen, D. A. S., and Trites, A. W. (2005). Spatial variation of heat flux in Steller sea lions: evidence for consistent avenues of heat exchange along the body trunk. J. Exp. Mar. Bio. Ecol. 315, 163-175. doi: 10.1016/j.jembe. 2004.09.018

Willmer, P., Stone, G., and Johnston, I. (2005). Environmental Physiology of Animals, 2nd Edn. Hoboken, NJ: Blackwell Science Ltd.

Wilson, R., Putz, K., Peters, G., Weimerskirch, H., Regel, J., Gremillet, D., et al. (1998). Short retention times of stomach temperature loggers in free-living seabirds: is there hope in the spring? Mar. Biol. 130, 559-566. doi: 10.1007/ s002270050277

Wilson, R. P. (2003). Penguins predict their performance. Mar. Ecol. Prog. Ser. 249, 305-310. doi: 10.3354/meps249305

Wilson, R. P., Cooper, J., and Plotz, J. (1992a). Can we determine when marine endotherms feed? A case study with seabirds. J. Exp. Biol. 167, 267-275.

Wilson, R. P., Hustler, K., Ryan, P. G., Burger, A. E., and Christian, E. (1992b). Diving birds in cold water: do archimedes and boyle determine energetic costs? Am. Nat. 140, 179-200. doi: 10.1086/285409

Wilson, R. P., and Culik, B. M. (1991). The cost of a hot meal: facultative specific dynamic action may insure temperature homeostasis in post-ingestive endotherms. Comp. Biochem. Physiol. 100, 151-154. doi: 10.1016/03009629(91)90198-1

Wilson, R. P., and Grémillet, D. (1996). Body temperatures of free-living African penguins (Spheniscus demersus) and bank cormorants (Phalacrocorax neglectus). J. Exp. Biol. 199, 2215-2223.

Wilson, R. P., Putz, K., Gremillet, D., Culik, B. M., Kierspel, M., Regel, J., et al. (1995). Reliability of stomach temperature changes in determining feeding characteristics of seabirds. J. Exp. Biol. 198, 1115-1135.

Wilson, R. P., Ropert-Coudert, Y., and Kato, A. (2002). Rush and grab strategies in foraging marine endotherms: the case for haste in penguins. Anim. Behav. 63, 85-95. doi: 10.1006/anbe.2001.1883

Worthy, G. A. J., and Edwards, E. F. (1990). Morphometric and biochemical factors affecting heat loss in a small temperate cetacean (Phocoena phocoena) and a small tropical cetacean (Stenella attenuata). Physiol. Zool. 63, 432-442. doi: 10.1086/physzool.63.2.30158506

Worthy, G. A. J., and Lavigne, D. M. (1987). Mass loss, metabolic rate, and energy utilization by harp and gray seal pups during the postweaning fast. Physiol. Zool. 60, 352-364. doi: 10.1086/physzool.60.3.30162289

Worthy, G. A. J., Morris, P. A., Costa, D. P., and Le Boeuf, B. J. (1992). Moult energetics of the northern elephant seal (Mirounga angustirostris). J. Zool. 227, 257-265. doi: 10.1111/j.1469-7998.1992.tb04821.x

Zapol, W. M., Liggins, G. C., Schneider, R. C., Qvist, J., Snider, M. T., Creasy, R. K., et al. (1979). Regional blood flow during simulated diving in the conscious Weddell seal. Am. Physiol. Soc. 968-973. doi: 10.1152/jappl.1979.47.5.968

Conflict of Interest: The authors declare that the research was conducted in the absence of any commercial or financial relationships that could be construed as a potential conflict of interest.

Copyright (c) 2020 Favilla and Costa. This is an open-access article distributed under the terms of the Creative Commons Attribution License (CC BY). The use, distribution or reproduction in other forums is permitted, provided the original author(s) and the copyright owner(s) are credited and that the original publication in this journal is cited, in accordance with accepted academic practice. No use, distribution or reproduction is permitted which does not comply with these terms. 